\title{
Strengthening the food safety control scheme in Indonesia through WTO law and food safety science
}

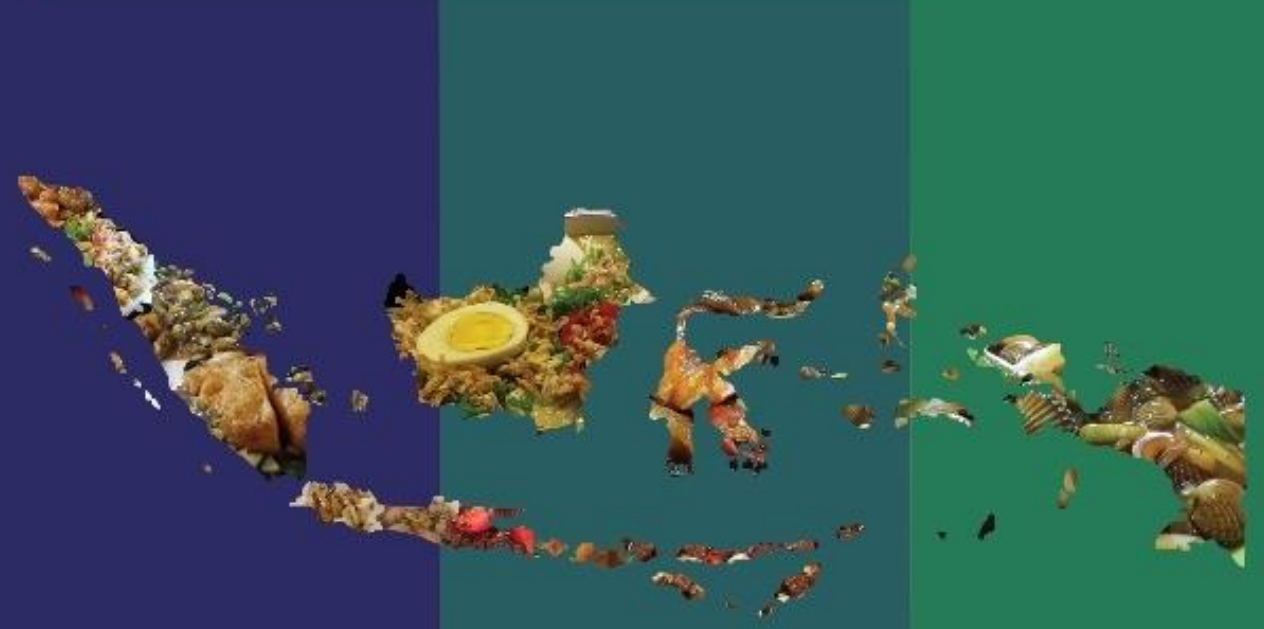

Dasep Wahidin 


\section{Propositions}

1. Legal reform is the most reasonable way to strengthen the national food control system in Indonesia.

(this thesis)

2. The determination of the appropriate level of protection (ALOP) in Indonesia will be more effective and accurate if it is based on scientific evidence.

(this thesis)

3. The solution to all economics problems is "it depends".

4. The Indonesian government must develop appropriate policies to gain real economic profits from the "demographic dividend" in Indonesia.

5. To become a nice person you can agree to everything, but to become a good person you must not be afraid to say "No".

6. Doing a PhD is like looking for a needle in a pile of hay.

Propositions belonging to the thesis, entitled

'Strengthening the food safety control scheme in Indonesia through WTO law and food safety science'

Dasep Wahidin

Wageningen, 08 May 2018. 


\section{STRENGTHENING THE FOOD SAFETY CONTROL SCHEME IN INDONESIA THROUGH WTO LAW AND FOOD SAFETY SCIENCE}

DASEP WAHIDIN 


\section{Thesis committee}

\section{Promotor}

Prof. Dr C.J.A.M. Termeer

Professor of Public Administration and Policy

Wageningen University \& Research

\section{Co-promotor}

Dr K.P. Purnhagen

Associate Professor, Law and Governance Group

Wageningen University \& Research

\section{Other members}

Prof. Dr M.G. Faure, Maastricht University

Prof. Dr D. Fardiaz, Bogor Agricultural University (IPB), Bogor, Indonesia

Dr R. Hartemink, Wageningen University \& Research

Prof. Dr M.P.M. Meuwissen, Wageningen University \& Research

This research was conducted under the auspices of the Graduate School of Social Science (WASS) 


\title{
STRENGTHENING THE FOOD SAFETY CONTROL SCHEME IN INDONESIA THROUGH WTO LAW AND FOOD SAFETY SCIENCE
}

\author{
DASEP WAHIDIN
}

Thesis

submitted in fulfillment of the requirements for the degree of doctor at Wageningen University

by the authority of the Rector Magnificus

Prof. Dr A.P.J. Mol,

in the presence of the

Thesis Committee appointed by the Academic Board

to be defended in public

on Tuesday $8^{\text {th }}$ of May 2018

at 4. p.m. in the Aula. 
Dasep Wahidin

Strengthening the Food Safety Control Scheme in Indonesia through WTO Law and Food Safety Science

144 pages.

ISBN: 978-94-6343-892-6

DOI: https://doi.org/10.18174/439932 


\section{ACKNOWLEDGEMENT}

This thesis was made through hardship and enjoyment. The fact that I am not a lawyer, but a pharmacist has made my PhD journey to be quite challenging, especially in the first year of my PhD journey. Although, during that hardship, there are people that always support me and in this part of the thesis, I would like to acknowledge them.

To my supervisor/co-promotor, Kai Purnhagen, I thank you for your guidance, patience, and kindness. You were always there for me from the start until the end of my PhD journey. During this PhD journey, you have become a great mentor and a very good friend. We discussed everything, from topic of work, family, etc. at various places, in the Netherlands and Indonesia. My "favorite" joint activity was the "Ping Pong" session, where we had a "battle" with our own expertise to write a good paper.

To my first and former promoter, Bernd van der Meulen, I thank you for giving me the chance to become a PhD candidate at Law and Governance Group and for your support during my early phase of my PhD journey.

To my current promoter, Katrien Termeer, I thank you for all your supports and motivations during my most difficult time as a $\mathrm{PhD}$ candidate. You have given your precious experience, expertise, and time for guiding me, especially at the final stage of my PhD journey.

To my colleagues at the Law and Governance group, Germaine, Gisella, Hanna, Nadia, and Harry, I thank you for your help and supports during my PhD journey. Best of luck for your carrier and family.

To all my PhD colleagues and friends, especially Teh Pini, Kang Dadan, Teh Nia, Dominique, Belinda, Teh Novi, Kang Indra, Nuning, Pak Misbah, Pak Iman, Pak Dikky, Pak Ery, Pak Waldi, Pak Taufik, Yuda, Mbak Arita, Mbak Atin, Mbak Shinta, Pak Thomas, Linda, Nani, Mbak Ovi, Indra, Pak Sakti, Pak Panca, Bang Reo, Teh Eva, Windi, Pak Eko, Nila, Titis, Tika, Mbak Hikmah, Mbak Vivi, Gumi, Emil, Mas Fajar, Fanny, Pak Ahmad, Uni Eli, Pak Yohanes, and Silvi. I am truly happy with the time that we have spent together in Wageningen and may we have another awesome gathering in Indonesia, best of luck and success for all of you.

To former and current high officials of BPOM/NADFC, Mr. Roy Sparringa, Mr. Bagong Suratmono, and Mrs. Hayati Amal, I thank you for your support, blessing, and motivation especially at the beginning of my $\mathrm{PhD}$ journey. To all my office mates in the Food Inspection and Certification Directorate, especially to Teh Yuyu, Ibu Nisa, Fitrianna, Mas Didik, Fitri, Endah, Asrina, Yoggy, Andi, Spica, Retno, Tyas, and Dita and also to former and current officials of Human and Resources Department of NADFC, especially to Mrs. Atiek, Mrs. Ayu, and Mr. Perdana Ari, I thank you for all your help and supports.

To my beloved mother and father, I thank you for giving me life, blessing, love and for taking care my children when I was in the Netherlands. Both of you are my biggest inspiration and motivation to prove that even a child from a poor family can 
get the highest academic degree. To my wife, Nofa, I thank you for all your patience, support, love and understanding during my master and $\mathrm{PhD}$ journey and especially for giving me two handsome sons, Dafa and Firza. In the time I finished this PhD journey, finally we can live again as a normal family. 


\section{CONTENTS}

1. General Introduction 11

2. Determining an FSO/ALOP for the Application in Developing Countries 25

3. Political Versus Science in the Establishment of Appropriate Level of 38 Protection (ALOP): The Case of Fukushima Nuclear Accident

4. How to Design a Genetically Modified Food Labeling Regulation in Indonesia by Using WTO Law and Food Safety Science

5. Spicing up the Export Market Access of Indonesia to the EU: the Case of Shrimp and Nutmeg

6. General Conclusions and Reflection 105

$\begin{array}{ll}\text { Bibliography } & 120\end{array}$

$\begin{array}{ll}\text { Summary } & 135\end{array}$ 


\section{LIST OF TABLES}

Table 1 Overview of research design per each research question

Table 2 Guideline levels (in Bq/ kg) of radioactive contaminants in foods according to the Codex General Standard for Contaminants and Toxins in Food and Feed (Codex Stan 1931995).

Table 3 Regulatory limits (in Bq/ kg) of radioactive contaminants in foods according to the Japanese provisional regulation.

Table 4 Regulatory limits (in $\mathrm{Bq} / \mathrm{kg}$ ) of radioactive contaminants in foods according to the new standard (MHLW, 2012).

Table 5 Pre-established regulatory limits (in $\mathrm{Bq} / \mathrm{kg}$ ) of radioactive contaminants in foods according to the Commission Implementing Regulation No 297/2011

Table 6 Regulatory limits (in $\mathrm{Bq} / \mathrm{kg}$ ) of radioactive contaminants in foods according to the Commission Implementing Regulation No 351/2011

Table 7 Regulatory limits (in $\mathrm{Bq} / \mathrm{kg}$ ) of radioactive contaminants in foods according to the Commission Implementing Regulation No 284/2012

Table 8 Regulatory limits (in $\mathrm{Bq} / \mathrm{kg}$ ) of radioactive contaminants in foods according to the Ministry of Health Decree No 00474/B/II/87

Table 9 Regulatory limits (in $\mathrm{Bq} / \mathrm{kg}$ ) of radioactive contaminants in foods according to the Ministry of Health Decree No 1031/PER/V/2011

Table 10 Regulatory limits (in $\mathrm{Bq} / \mathrm{kg}$ ) of radioactive contaminants in fresh products of animal and vegetable origin according to the Ministry of Agricultural Decree No 20/Permentan/OT.140/3/2011

Table 11 Comparison matrix of GM food Labeling Regulation in the EU, the US, Japan, Malaysia, China, and Indonesia 


\section{LIST OF FIGURES}

Figure 1. The National Food Control System in Indonesia in Accordance with the Government Regulation No 28/2004 on Food Safety, Quality, and Nutrition.

Figure 2. Model of the FSO/ALOP system in the food supply chain.

Figure 3. Management model for developing the FSO/ALOP for the application in developing countries.

Figure 4. Authorization procedure of GM food in Indonesia.

Figure 5. Frequency of notifications by the EU concerning banned antimicrobials in shrimp imports from Indonesia.

Figure 6. Frequency of notifications by the EU concerning aflatoxins (AFs) in nutmeg imports from Indonesia.

Figure 7. Food safety objective (FSO) and its relationship to performance objectives (PO) at different stages of the supply chain.

Figure 8. Model of the FSO/ALOP in the international food supply chain.

Figure 9. FSO/ALOP-based national food control system, adapted from FAO/WHO. 



\section{CHAPTER 1}

\section{GENERAL INTRODUCTION}




\subsection{BACKGROUND AND PROBLEM OUTLINE}

\subsubsection{National Food Control System and WTO Law}

Food control is a mandatory regulatory activity of enforcement by national or local authorities to provide consumer protection and ensure that all foods during production, handling, storage, processing, packaging, transportation, distribution, and sale are safe, wholesome and fit for human consumption; conform to safety and quality requirements; and are honestly and accurately labelled as prescribed by law (ASEAN 2017). The national food control system encompasses applicable food laws and regulations, food control management, inspection service, laboratory service, and information, education, communication, and training (FAO/WHO, 2005).

Food control is one of the most regulated areas in Indonesia. It is governed primarily by the Food Law No 18/2012, Government Regulation No 28/2004 on Food Safety, Quality, and Nutrition, and Government Regulation No 69/1999 on Food Labelling and Advertising. ${ }^{1}$ Institutionally, the national food control system is centralized at the national level, with several agencies overlooking the market for foods. Each agency is a competent authority for a different type of food product (Figure 1). Fresh foods, such as vegetables, meat, and eggs, are under the control of the Minister of Agriculture (MoA). Fresh seafood and aquacultures are under the control of the Minister of Marine Affairs and Fisheries (MoMAF). Certain processed foods are under the control of the National Agency of Drug and Food Control (NADFC). Finally, fast foods are under the control of the Minister of Health $(\mathrm{MoH})$. To a large extent, the Indonesian food control system distinguishes between regulations concerning premarket control and post-market control.

1 See UU. No. 18 Tahun 2012 tentang Pangan, Peraturan Pemerintah No. 28 Tahun 2004 tentang Keamanan, Mutu, dan Gizi Pangan, dan Peraturan Pemerintah No 69 Tahun 1999 tentang Label dan Iklan Pangan. Translated by D. Wahidin. 


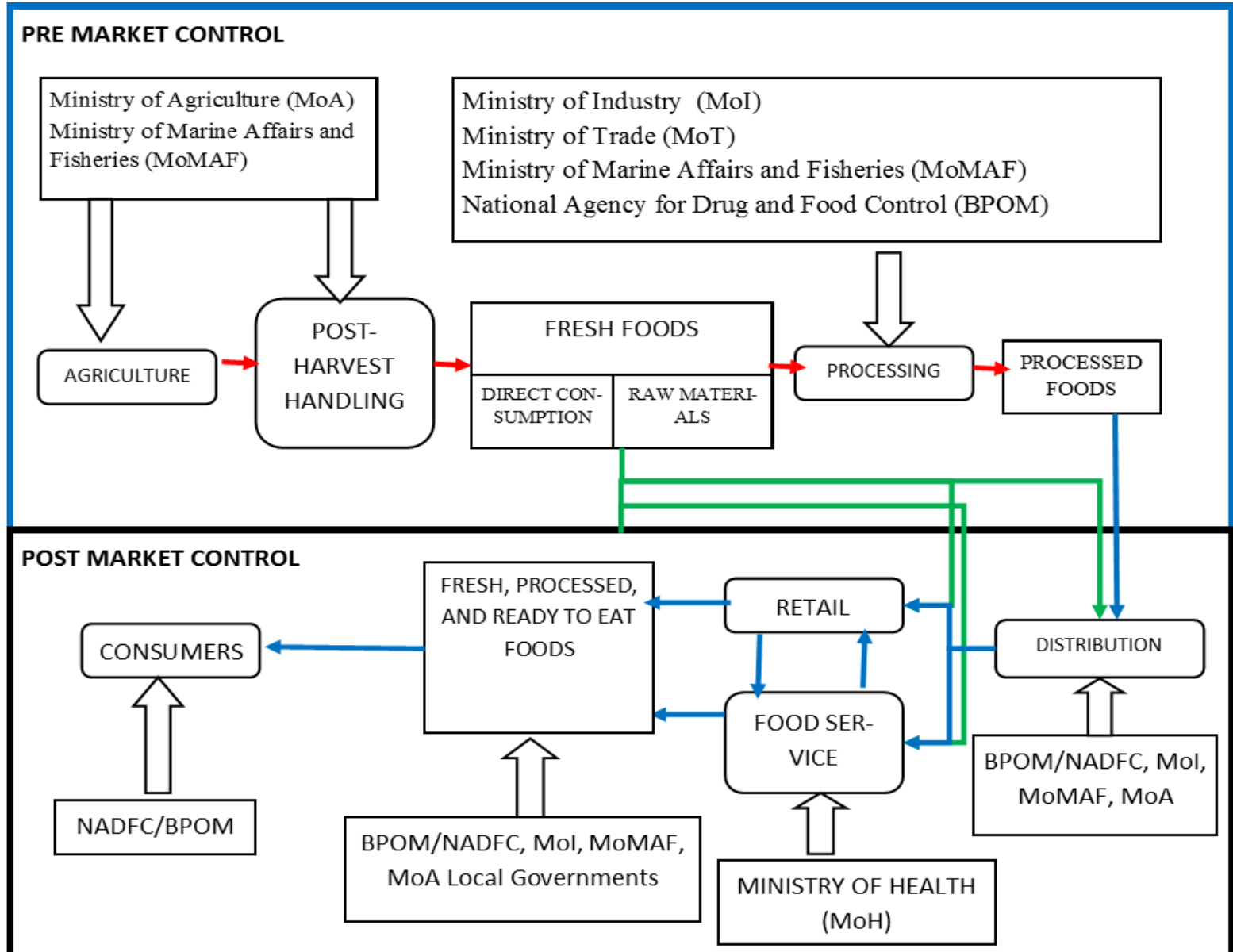

Figure 1. The National Food Control System in Indonesia in Accordance with the Government Regulation No 28/2004 on Food Safety, Quality, and Nutrition.

At the same time, the Indonesian food regulatory system becomes more internationally connected, increasing the importance of a well-functioning local Indonesian food control system. There is increasing worldwide consumer demand for a wide variety of foods, which entails a longer and more complex food supply chain (Fukuda 2015). In parallel with that demand, contamination at the one end of the food supply chain can affect public health on the other side of the world (Fukuda 2015). If the Indonesian food control system does not work well, the health of consumers in other countries might be adversely affected. Hence, the increasing international food trade has largely resulted in transnational food safety problems that can transform into health risks. At the same time, developing countries benefit economically from the rise of trade (WTO 2010). Thus, in addition to solving local problems, a stronger national food control system in Indonesia needs to find answers to the increasing transnational food safety problems without jeopardizing the country's economic improvements realized through international food trade. While a strong embedding in the socioeconomic context of Indonesia is warranted, an effective Indonesian food control system should be based on the rules of international trade law (Sinopoli and 
Purnhagen 2016). In this respect, the rules of the World Trade Organization (WTO) can provide a level playing field for developing the Indonesian framework, as the WTO system provides a conflict resolution mechanism for these issues. The WTO Agreement on the Application of Sanitary and Phytosanitary Measures (SPS Agreement) ${ }^{2}$ encourages countries to base the development of their food laws and regulations on the relevant international standards and scientific evidence while providing room to take into account local socioeconomic setting differences (Ming Du 2010).

In a situation where the relevant international standard is not available, developed countries may have some advantages over developing countries in developing an effective food safety control system since they usually have a better food safety infrastructure and more resources available to scientifically justify more stringent measures through the risk assessment mechanism and to assess each country's tolerance level of risk acceptance. Hence, food control systems in developed countries can be tailor-made to the needs and requirements of the respective population. In contrast, due to the lack of food safety infrastructure and resources, developing countries are often unable to execute a sound risk assessment or identify the population's level of acceptable risk, resulting in difficulties in realizing their right granted by WTO law to determine their own Appropriate Level of Protection (ALOP) or effective SPS measures according to the needs of the population. This domino effect formulates the major challenge for developing countries, on the one hand, to effectively protect the health of their citizens and, on the other hand, to gain access to export markets in developed countries in data-poor environments.

This thesis will provide a policy tool for the effective assessment and design of laws and regulations to govern an effective Indonesian food control system. This tool, termed FSO/ALOP framework for developing countries, will be based on the unique socioeconomic prerequisites of developing countries, the rules governing the internationalization of food trade, and the obligation to base food laws and regulations on scientific evidence. The tool will be designed to overcome the shortcomings of the national food control system in Indonesia and can serve as an element in the reform of food laws and regulations in Indonesia, drawing on the requirements of WTO law, findings from food safety science, and local socioeconomic prerequisites.

\subsubsection{Shortcomings of the food regulatory system in Indonesia}

There are shortcomings in the food regulatory system in Indonesia, such as poor regulatory practices, lack of engagement between regulation and the actual socioeconomic factors, the lack of quantitative and empirical analysis of available academic papers in the decision-making of regulation, the absence of public

\footnotetext{
2 Agreement on the Application of Sanitary and Phytosanitary Measures, opened for signature 15 April 1994, in force 1 January 1995, 1867 UNTS 493, SPS Agreement.
} 
consultation in the regulatory formulation, and the absence of legal basis and strategy for regulatory review and simplification. These shortcomings are indicated by the fact that the rate of non-compliant foods observed in Indonesia keeps rising each year (FAO 2017). This fact raises questions about the effectiveness and the fitness for purpose of the Indonesian food control system.

As explained in the previous section, the centralized food regulatory system in Indonesia can be categorized as a center-state regulation. Thus, the shortcomings could largely be attributed to the generally perceived failures developed in regulatory theory of state-centered regulation (Black 2001). For example, the Indonesian regulations could be inappropriate and unsophisticated (instrument failure); the Indonesian government could have insufficient knowledge to identify non-compliance and the cause of the problem in order to design appropriate solutions (information and knowledge failure); the Indonesian regulations could be only partially implemented (implementation failure); the objects of the Indonesian regulation could be declined compliance and the authorities may have a lack of motivation to regulate in the public interest (motivation failure and capture theory). Apart from the state-centered regulation failures, most national food laws and regulations, like in Indonesia, operate largely in reaction to food safety incidents and employ a rather pragmatic and ad hoc basis in the implementation of the laws and regulations, precluding an anticipatory and systematic approach (Neeliah and Goburdhun 2007). These types of food laws and regulations provide little predictability for food businesses, which also results in a lack of compliance in their implementation. Substantively, Indonesian food laws and regulations adopt solutions from developed countries (Western countries). This adoption induces high compliance costs and are, in the worst case, inconsistent with Indonesia's national requirements and market demands (Juwana 2004). Furthermore, decisions with regard to food laws and regulations are based primarily on political needs and often failed to take into account the latest science as a basis for the decisions (Cantrell 2015). The situation becomes even more complicated as multiple agencies are involved in the national food control system in Indonesia (Figure 1). These problems even increase due to coordination deficits resulting from a multitude of agencies that are involved in the national food control system (Fardiaz et al. 2011). With regard to the control capacity, food safety authorities often do not have a clearly defined scope of authority and operating procedures (Fardiaz et al. 2011). Furthermore, the overall quality of foodstuffs varies to a large extent (Fardiaz et al. 2011). The allocation of available resources has been often not optimized due to misaligned incentives and mismanagement. For example, Indonesia continuously ranks high in the corruption index of Transparency International (Transparency International 2016). Food safety systems and standards for food manufacturing and export food are different from those for domestic consumption with a variable level of enforcement (Fardiaz et al. 2011). Small-scale food industries outnumber medium- to large-scale food industries 
by far: about $99 \%$ of food industries are considered small scale. Yet, only $24 \%$ of them comply with the GMP standard (BPS-Statistics Indonesia 2016; Media Indonesia 2016).

Each of those general observations about the shortcomings of regulatory systems is not new to developed countries. In developed countries, the solution for the shortcomings is mainly attributed to forms of decentered regulation that take into consideration seven aspects: the complexity, fragmentation, and construction of knowledge, the fragmentation of the exercise of power and control, the recognition of autonomy of social actors, the existence and complexity of interactions and interdependencies between social actors and the government in the process of regulation, the collapse of the public/private distinction, and the set of normative propositions as to the regulatory strategies that should be adopted (Black 2002).

To extrapolate those solutions to the Indonesian context might, however, be too simplistic since the socioeconomic setting and the magnitude of food safety problems might substantially differ. Food safety infrastructure, resources, and data are very limited in Indonesia (Hariyadi 2011). The data, such as epidemiological data, to conduct a risk assessment are very limited in developing countries and are most likely to remain limited (FAO/WHO 2007, 2003). Hence, focusing on information flow as a regulatory means, for example, misses the point that most information is regularly, simply not available in data-poor environments such as the Indonesian food sector. This circumstance can be illustrated by the fact that a full risk assessment in the development of food safety law and regulations, particularly the exposure assessment, is often not implemented in developing countries (Akhtar et al. 2014; Dey et al. 2005).

\subsection{KEY CONCEPTS}

\subsubsection{ALOP Concept in WTO Law}

As a starting point, this thesis resorts to the concept of ALOP as spelled out in the SPS Agreement: "Appropriate level of sanitary and phytosanitary protection - the level of protection deemed appropriate by the Member establishing a sanitary and phytosanitary measure to protect human, animal or plant health within its territory."3 Countries have a prerogative right to determine their own ALOP (desirable level of protection or acceptable level of risk). Despite the prerogative right in determining the ALOP, they are obliged to recognize different measures from other countries as long as those measures result in an equivalent ALOP (Henson and Loader 2001).

In terms of the justification of SPS measures in achieving the ALOP, countries have two options: They may first apply international standards, or else they shall provide a scientific justification if they apply measures that result in a higher ALOP than if they apply the relevant international standard. ${ }^{4}$ SPS measures encompass all relevant laws, decrees, regulations, requirements, and procedures, including, inter alia,

Annex A (5) SPS Agreement.

4 Article 3.2 and Article 3.3 of the SPS Agreement. 
end product criteria; processes and production methods; testing, inspection, certification, and approval procedures; quarantine treatments, including relevant requirements associated with the transport of animals or plants or with the materials necessary for their survival during transport; provisions on relevant statistical methods, sampling procedures, and methods of risk assessment; and packaging and labelling requirements directly related to food safety. ${ }^{5}$

\subsubsection{FSO Concept of ICMSF}

In order to determine an ALOP and to ensure that the ALOP is applied in an effective way, this thesis will resort to concepts developed in the practice of the Food Safety Management System (FSMS). This concept is applied to the food supply chain in both developed and developing countries. This approach has been developed by the ICMSF (International Commission on Microbiological Specifications for Foods) in the form of the Food Safety Objective (FSO) concept and has been adopted by the Codex Alimentarius Commission (CAC) in its principles and guidelines for the conduct of microbiological risk management (MRM) (CAC 2016a). In the context of food laws and regulations, the FSO acts as the regulatory limit that determines the level of safety of a hazard/food combination that informs the ALOP. Since the FSO is mandatory, all actors in the food supply chain shall apply the appropriate FSMS to meet the FSO in order to ensure the safety of the food starting from the primary production stage until the moment of consumption (aligns with the principle of farm to fork).

\subsubsection{FSO/ALOP-based Food Safety Policy}

To implement these concepts into policy-making, this thesis relies on a concept developed by de Swarte \& Donker (2005). They have developed a management model for developing the FSO/ALOP that provides a way to assess the implication and the implementation of the FSO/ALOP in the policy-making process (De Swarte and Donker 2005). The model explicitly introduces the relevant information from the life sciences, socioeconomic studies and agro-technology/agro-logistics into the decisionmaking of the ALOP and FSO (De Swarte and Donker 2005). The model consists of four stages: risk assessment, the determination of the ALOP, the translation of the ALOP into the FSO, and monitoring and evaluation.

\subsection{RESEARCH QUESTIONS}

The main research question that this thesis aims to assess is: How can Indonesia strengthen its national food control system by designing more effective food laws and regulations through the lens of the WTO law and food safety science? To address this main research question, I define four sub-research questions:

\footnotetext{
5 Annex A (1) of the SPS Agreement.
} 
1. How to design an effective management tool for developing more effective food laws and regulations in developing countries?

2. Science vs. politics: Which one is the preferred reasoning for determining an ALOP in food trade from a developing country's perspective?

3. In practice, how would the application of the FSO/ ALOP framework in developing countries improve food laws and regulations in Indonesia?

4. How would the application of the FSO/ALOP framework for developing countries facilitate export trade from Indonesia to the EU?

By answering these research questions, I want to contribute to the literature on international economic law, by introducing FSO/ALOP-based food laws and regulations. This thesis also seeks to contribute to food safety policy decision-making, via the design of a more appropriate framework for developing food laws and regulations that can be used by developing countries such as Indonesia to strengthen their national food control system.

\subsection{METHODOLOGY}

\subsubsection{Research Methods}

This project combines political and doctrinal methods as well as methods of interdisciplinary communication and food safety science. As this project includes many methods, the respective methodologies will be introduced as an integral part of each paper/chapter. The "law in action" approach (Pound 1910) forms the overall theoretical framework for this thesis. The "law in action" approach focuses on the mobilization of law, centered to the question of when and how social actors of different sorts - for example, people, families, formal organizations, social movements - turn to the law to solve the problem (Sandefur 2015).

\section{Doctrinal Approach}

When reviewing laws and regulations, this thesis employs a doctrinal approach. The doctrinal analysis describes "a critical conceptual analysis of all relevant legislation and case law to reveal a statement of the law relevant to the matter under investigation." (Hutchinson 2014). The doctrinal approach results in the presentation of relevant legal data, their policy options, and the gaps left in regulation, which can be used for further analysis. In this thesis, this method applies particularly to the mapping of the WTO-SPS Agreement as a context condition for the development of the FSO/ALOP framework for the application in developing countries.

\section{Interdisciplinary Approach}

The doctrinal analysis will be combined with an interdisciplinary approach, in which non-legal data are combined with legal data (Schrama 2011). In order to answer the first sub-research question, I will complement doctrinal analysis with methods 
from food safety science to fill in the gaps revealed by the doctrinal analysis. In particular, I will marry insights from food safety science with the need to determine an ALOP in WTO law. More precisely, I will use two concepts: The FSO concept of the ICMSF, reflecting a food supply chain approach, will be used and combined with a management view on FSO/ALOP, as developed by De Swarte \& Donker (2005). The application of the interdisciplinary approach in this thesis is necessary since I intend to use the management tool in "real life" or in "law in action" to strengthen the national food control system in developing countries. There are two methods to conduct the interdisciplinary approach: unilateral and multilateral. The unilateral method implies that a legal researcher aims at carrying out the research, starting from a legal research question, but making use of the data from another discipline (Schrama 2011). Whereas, the multilateral refers to legal research that is done by two or more researchers from different disciplines. This is where the multilateral method has more benefit that the unilateral method (Schrama 2011). In this thesis, I use the multilateral method, where $\mathrm{I}$, the expert in food safety science, work together with an expert of the law to further develop the management tool for developing a well-functioning national food control system in developing countries.

\section{Comparative Law}

The core of comparative law is the act of comparing the law of one country to that of another (Eberle 2009). The aim of comparative law for the legislature or court is to inform itself and find a solution to a given problem (Smits 2006). The first step of comparative analysis is to address the similarities and differences between the different legal systems. The next step of the analysis depends on the comparative legal method that is to be used, see for a profound analysis of different methods the contributors to (Reimann and Zimmermann 2007). The functional comparative method (Michaels 2006) is used to analyze the similarities and differences between the different legal systems to illustrate the different interpretation of FSO/ALOP. Finally, the conclusions will be formulated and transplanted into the Indonesian legal system.

\section{Case Studies}

Generally, case studies are the preferred research method for answering "why" and "how" questions, when the researcher has little control over situations and when the focus of research is on an up-to-date phenomenon within some real-life context (Yin 1994). The aim of case studies is to conduct an in-depth analysis of an issue, within its context with a view to understanding the issue from the perspective of participants (Harrison et al. 2017). In this thesis, the developed FSO/ALOP framework for application in developing countries is tested with actual and contemporary food safety cases. Each case study represents an area of diverse hazard/food combination and a relevant, existing international standard. Through these case studies, I expect the FSO/ALOP framework developed for application in developing countries to be more 
systematic and a stronger management tool for the establishment of more effective food laws and regulations.

\subsubsection{Methods of Data Collection}

I use the text, syntax, and context of laws and regulations, and cases are used as the primary data. Besides that, I use articles from international peer-reviewed journals, internet databases, and government documents, and reports are used as the secondary data.

\subsubsection{Research Design}

Research question 1 corresponds to the need to address the FSO/ALOP framework needed for the development of food laws and regulations in developing countries. I will first explore the legal context conditions as a baseline. To this end, I will determine the limits of the ALOP concept as enshrined in the WTO-SPS Agreement, which stipulates the design of food laws and regulations. The value commitments determined in this way will form the basis for the design of the effective management tool. In addition, I determine how the FSO concept from the ICMSF and the management model for developing the FSO/ALOP (De Swarte and Donker 2005) can be implemented in these underlying value commitments, thereby already determining a first rough sketch of the management tool. Subsequently, I will discuss how this tool can be used as a policy tool to design more effective food laws and regulations as part of the food control system in developing countries, tailored to the socioeconomic prerequisites of developing countries.

Research question 2 corresponds to the preference of the developed and developing countries when determining an FSO/ALOP. It is the political right of each country to determine its level of acceptable risk. However, WTO institutions and food safety science prefer a more scientifically developed FSO/ALOP. Which one of these two approaches is preferable for developing countries? We will test the hypothesis voiced earlier, which stated that developing countries, due to lack of resources, have difficulties to formulate an FSO/ALOP that corresponds to their citizen's needs, by comparing the implementation of several political FSO/ALOP determinations in comparable situations (radioactive contaminants in foods following the Fukushima nuclear accident) in two developed entities (the EU and Japan) and compare them to Indonesia. While the EU and Japan share the same FSO/ALOP that are based on scientific insights, Indonesia imposes a more relaxed (political) FSO/ALOP, which do not take into account scientific insights. Subsequently, we apply the FSO/ALOP framework developed for application in developing countries from research question 1 , which is applied, in this case, in order to compare the findings between the politically determined FSO/ALOP and the scientifically determined FSO/ALOP.

Research question 3 corresponds to the potential of the FSO/ALOP framework developed for application in developing countries in designing robust food laws and 
regulations for the benefit of their citizens. I will illustrate its application in connection to the GM food labeling regulation in Indonesia. To this end, I will first map the current related GM food labeling laws and regulations in Indonesia. I will then apply the FSO/ALOP framework developed for application in developing countries from research question 1 in order to identify the loopholes in the current labeling regime. Subsequently, based on the identified loopholes, I propose recommendations for a more effective GM food labeling regulation in Indonesia.

Research question 4 corresponds to the practical implementation of the FSO/ALOP framework developed for application in developing countries. I illustrate how the framework can be utilized to facilitate export trade with the EU. From the perspective of developing countries, food laws and regulations of developed countries act as non-tariff barriers (NTBs) to trade with a market closure effect (Purnhagen and Feindt 2015). However, those laws and regulations can also act as catalysts for upgrading the national food control system in developing countries (Henson and Jaffee 2006; Jongwanich 2009). In that sense, I will illustrate how the application of the framework has the potential to facilitate more stringent food laws and regulations in Indonesia as stipulated, for example, by the EU, by taking into account the socioeconomic prerequisites of Indonesia. I will use chloramphenicol in shrimp and aflatoxins in nutmeg as case studies to illustrate the application of the framework. Finally, I propose recommendations for better strategies for Indonesia as well as other developing countries to handle more stringent food laws and regulations of the EU to eventually enhance access to export markets in the EU.

Table 1. Overview of research design per each research question

\begin{tabular}{|c|l|l|}
\hline $\begin{array}{c}\text { Research } \\
\text { question }\end{array}$ & \multicolumn{1}{|c|}{ Research design } & \multicolumn{1}{|c|}{$\begin{array}{c}\text { Methods of data collection and } \\
\text { analysis }\end{array}$} \\
\hline 1 & $\begin{array}{l}\text { I define the ALOP concept based on the } \\
\text { WTO law and combine it with the } \\
\text { concept of FSO from the ICMSF and the } \\
\text { management model from De Swarte \& } \\
\text { Donker (2005). }\end{array}$ & $\begin{array}{l}\text { I use doctrinal analysis and an } \\
\text { interdisciplinary approach. The } \\
\text { data consists of the text of the SPS } \\
\text { Agreement WTO dispute } \\
\text { settlement cases, articles from } \\
\text { international peer-reviewed } \\
\text { journals, internet databases, and } \\
\text { government documents and } \\
\text { reports. }\end{array}$ \\
\hline 2 & $\begin{array}{l}\text { I analyze the application of the current } \\
\text { FSO/ALOP concept of Japan, the EU, } \\
\text { and Indonesia in the establishment of } \\
\text { regulatory limits for radioactive } \\
\text { contaminants in foods following the } \\
\text { Fukushima nuclear accident. }\end{array}$ & $\begin{array}{l}\text { I use comparative law and the case } \\
\text { study method. The data consists of } \\
\text { the text of the relevant regulations } \\
\text { on regulatory limits in the EU, } \\
\text { Japan, and Indonesia as well as } \\
\text { articles from international peer- } \\
\text { reviewed journals, internet }\end{array}$ \\
\hline
\end{tabular}




\begin{tabular}{|l|l|l|}
\hline & & $\begin{array}{l}\text { databases, and government } \\
\text { documents and reports. }\end{array}$ \\
\hline 3 & $\begin{array}{l}\text { I analyze the application of the current } \\
\text { FSO/ALOP concept of the EU, the US, } \\
\text { Japan, Malaysia, China, and Indonesia } \\
\text { in the establishment of GM food labeling } \\
\text { regulation. I use the FSO/ALOP } \\
\text { framework developed for application in } \\
\text { developing countries to address } \\
\text { recommendations for a better GM food } \\
\text { study method. The data consists of } \\
\text { the text of the relevant regulations } \\
\text { on regulatory limits in the EU, the } \\
\text { labeling regulation in Indonesia. }\end{array}$ & $\begin{array}{l}\text { Indonesia as well as articles from } \\
\text { international peer-reviewed } \\
\text { journals, internet databases, and } \\
\text { government documents and } \\
\text { reports. }\end{array}$ \\
\hline $\begin{array}{l}\text { I compare the studied regulations in the } \\
\text { EU and Indonesia. I use the FSO/ALOP } \\
\text { framework developed for application in } \\
\text { developing countries to address } \\
\text { recommendations for better strategies } \\
\text { for Indonesia to deal with the more } \\
\text { stringent food laws and regulations in } \\
\text { the EU and to increase the export } \\
\text { markets in the EU, particularly in the } \\
\text { case of chloramphenicol in shrimp and } \\
\text { aflatoxins in nutmeg. }\end{array}$ & $\begin{array}{l}\text { I use comparative law and the case } \\
\text { study method. The data consists of } \\
\text { the text of the relevant regulations } \\
\text { on regulatory limits in the EU and } \\
\text { Indonesia. The data consist of } \\
\text { articles from international peer- } \\
\text { reviewed journals, internet } \\
\text { databes, and government } \\
\text { documents and reports. }\end{array}$ \\
\hline
\end{tabular}

\subsection{STRUCTURE OF THE THESIS}

This thesis consists of four scientific papers that have been published in or submitted to international peer-reviewed scientific journals. Chapter 2 is published as a scientific article in the European Journal of Risk Regulation (Wahidin and Purnhagen 2017). Chapter 3 was submitted on May 15, 2017, and it is currently under review by the Wageningen Journal of Life Science (NJAS). Chapter 4 was submitted to the Food and Drug Law Journal on April 30, 2018. Chapter 5 was submitted on October 21, 2017, and it is currently in the second round of review with minor revisions by the HeliyonElsevier Journal.

In chapter 2, I identify the holistic concept of the ALOP based on the WTO legal framework. Moreover, I analyze and then synthesize a FSO/ALOP framework developed for application in developing countries that is a combination of the ALOP concept from the WTO, the FSO concept from ICMSF, and the management model for developing the FSO/ALOP from De Swarte \& Donker (2005). In chapter 3, I describe to what extent science and politics are involved in the decision-making of the FSO/ALOP in Japan, the EU, and Indonesia in the case of the Fukushima nuclear accident. Next, in chapter 4, I describe how to design the FSO/ALOP-based laws and 
regulations in the case of the GM food labeling regulation in Indonesia. In chapter 5, I use the FSO/ALOP framework to propose better strategies for Indonesia as well as for other developing countries to spice up their level of national food control system and at the same time increase their access to export markets in the EU. Finally, in the chapter of general conclusions and reflection, I answer the research questions, further describe the reflection of the main contributions of this thesis to the literature of international economic law, and provide some policy recommendations for the policymakers in Indonesia. 



\section{CHAPTER 2}

\section{DETERMINING AN FSO/ALOP FOR THE APPLICATION IN DEVELOPING COUNTRIES}

\section{Dasep WAHIDINa, b, Kai PURNHAGENa}

aLaw and Governance Group, Wageningen University and Research, Hollandseweg

1, PO Box 8130, 6700 EW, Wageningen, The Netherlands; bNational Agency of Drug and Food Control of Indonesia (NADFC), Percetakan Negara, 23, 10560, Jakarta, Indonesia. 


\begin{abstract}
When determining an Appropriate Level of Protection (ALOP) for food laws and regulations, developed countries rely on the concept of Food Safety Objective (FSO) to meet the requirements of WTO law and to provide a high level of protection based on insights from food safety science. Implementing the FSO/ALOP concept is resourceintensive and costly. Developing countries have been often too constrained by limited food safety infrastructure and resources to provide an appropriate level of protection, and thus, they face difficulties in the implementation of the FSO/ALOP concept. As a consequence, developing countries may base their ALOP on other legally acceptable reasons, which are probably not science-based and less effective. We illustrate a less resource-intensive way to implement the FSO/ALOP concept, which enables developing countries to design food laws and regulations that are based on WTO law and sound science. Depending on the resources available in the respective country, we map different possibilities to design an FSO/ALOP framework for the application in developing countries to assist in the establishment and implementation of more effective food laws and regulations that are tailored to local socioeconomic prerequisites.
\end{abstract}

Keywords: FSO, ALOP, Law, Regulation, Developing Countries. 


\subsection{INTRODUCTION}

Food safety ensures that food will not cause harm to consumers when it is prepared and/or eaten according to its intended use (FAO 1999). The World Health Organization (WHO) regards food safety as a priority for public health, as every year, 1 in 10 people fall ill and 125,000 children under the age of 5 years die because of unsafe food consumption (WHO 2017b). Recent cases of foodborne diseases have called for a more effective national food control system (Gorris 2005; Purnhagen 2013). In addition, the constant increase in global food trade brings transboundary penetration of novel food safety hazards (Van de Venter 2000). The solution for those problems can not only be found at the national or regional level, but also at the global level (Van der Meulen 2010). To comply with WTO law, there are at least two options for countries with regard to the development and implementation of their national food control system: either comply with relevant international standards (e.g., Codex standards) or provide a risk assessment if it deviates from international standards (WTO 2015).

Life certainly will be much easier for countries if there is an international standard for each food safety issue on which they can base their SPS measures (Atik 2011). Unfortunately, not all food safety issues are covered by international standards. In such situations, which this paper focuses on, developed countries have more advantages over developing countries, especially when they develop and conduct a risk assessment in the establishment of food laws and regulations. Developed countries can implement more stringent food laws and regulations to reduce risk since they have more access to adequate food safety infrastructure and resources to do the risk assessment. In contrast, developing countries face difficulties to conduct a risk assessment, as data, e.g., epidemiological data, are rarely available (poor data environments) due to limited food safety infrastructure and resources. Despite that discrepancy, developing countries should not see these more stringent food laws and regulations of developed countries as non-tariff barriers (NTBs), but rather see this as an opportunity to increase their level of food safety and to design more effective food laws and regulations on the one hand and increase the access to the export market in developed countries on the other. In other words, this resolution will lead to the increase of not only the quality of life and health of their citizens, but also more chances for the countries to participate in the export food market and to have trade surpluses and benefits later on. Hence, developing countries can use the available international framework in the development of their food laws and regulations (Unnevehr 2015).

This study assesses how to develop a tool to establish and implement more effective food laws and regulations for the application in developing countries that is tailored to local socioeconomic prerequisites and based on WTO law and food safety science. This study combines the Appropriate Level of Protection (ALOP) concept embedded in WTO law (SPS Agreement), the Food Safety Objective (FSO) concept of the International Commission on Microbiological Specifications for Foods (ICMSF), 
and the management model for developing the FSO/ALOP from De Swarte \& Donker (2005). We propose an FSO/ALOP framework as the tool that is tailored to the socioeconomic prerequisites of developing countries:

1. To meet WTO legal requirements, developing countries base their ALOP on the concept of FSO.

2. Developing countries with an effective food inspection and laboratory system can develop an FSO/ALOP based on data on the frequency of a hazard at the retail level, as an alternative for robust epidemiological data.

3. In case an effective food inspection and laboratory system are lacking, developing countries may resort to data, e.g., the epidemiological data, available at the international level or other countries and extrapolate their data to the population of their own countries.

4. Regardless of which FSO/ALOP concept is implemented, due to a lack of food safety infrastructure and resources, it is more effective for developing countries to adopt a risk management plan (RMP) program, rather than rely only on costly on-site inspection and end-product testing. The RMP defines how risk related to the product is identified, analyzed, and managed by the food manufacturers, which are the most important actors in ensuring the safety of their product (CDC 2006).

This paper proceeds as follows: This study maps these obligations as determined by WTO law (II). Subsequently, we demonstrate the role of food safety science in the determination and implementation of the ALOP through the FSO concept of ICMSF (III). Next, we discuss how these concepts can be applied in the specific context of developing countries in the development of food laws and regulations by using the management model for developing the FSO/ALOP of De Swarte \& Donker (2005) (IV). Finally, we describe the main findings in the concluding chapter (V).

\subsection{A MEMBER'S RIGHT TO DETERMINE ITS ALOP AND THE NEED FOR QUANTITATIVE CRITERIA IN THE SPS AGREEMENT}

This section illustrates the concept of the ALOP under the WTO legal framework, particularly the Agreement on the Application of Sanitary and Phytosanitary Measures (SPS Agreement) (WTO 1995). The concept of the ALOP is specified in paragraph 5 of Annex A of the SPS Agreement. ${ }^{6}$ The general rule is that WTO Members are obliged to determine their ALOP ex-ante of its subsequent SPS measures. ${ }^{7}$

\footnotetext{
6 ALOP is "the level of protection deemed appropriate by the Member establishing a sanitary or phytosanitary measure to protect human, animal or plant health within its territory." See Annex A (5) of the SPS Agreement.

7 Implementing measures such as those mentioned in Article 5.5 of the SPS Agreement do not explicitly refer to "SPS measure". However, it is implicitly refers to SPS measures that are implemented to achieve a certain level of sanitary and phytosanitary protection (ALOP) (WTO 2006). See Annex A (1) of the SPS Agreement.
} 
Regarding the stringency of the ALOP, each WTO Member has the prerogative right to determine it according to national needs (socioeconomic prerequisites); it depends on the citizens' acceptance of risk (Ming Du 2011). ${ }^{8}$ In the end, this dependency leads to different ALOPs among WTO Members, even in similar or comparable situations (Atik 2011). ${ }^{9}$ The interpretation of the notion of "appropriate" in ALOP may indeed vary among WTO Members since the socioeconomic settings differ (Reid 2012). Despite that, the determination of an ALOP is necessary to ensure public health protection. Robert Howse has termed the ALOP as the "citizen's tolerance for risk" in opposition to the level of risk to the citizen's health (Howse 2007).

WTO Members have the sovereignty set the acceptable level of risk (ALOP) even to a "zero risk" level (WTO 1998a). Moreover, if it is proven that alternative SPS measures of exporting countries achieve the ALOP of importing countries, then the importing countries must acknowledge the alternative SPS measures as long as those meet the ALOP of the importing countries." As a general principle, according to Article 5.4 of the SPS Agreement, an ALOP should be designed with the objective of minimizing negative trade effects. The word "should" means that WTO Members are not obliged to meet the objective of minimizing negative trade effects when determining their ALOP. Although, WTO Members shall put the objective of minimizing negative trade effects in the interpretation of other provisions of the SPS Agreement (WTO 1998b). The notion "achieving consistency" in Article 5.5 of the SPS Agreement does not oblige a WTO Member to determine a consistent ALOP. Moreover, there is no obligation for a WTO Member to express its ALOP in a quantitative term (WTO 1998b). Arguably, it might not even have to be based on science. However, "a more explicit and in particular a quantitative expression of a Member's ALOP would greatly facilitate the consideration of compliance with other provisions of the SPS Agreement," especially to comply with Article 5.6 and also meet the basic obligation under Article 2.2 and 2.3 (WTO 1998a). A risk assessment will make the ALOP more effective and accurate, especially when comparing the related level of protection for different situations (WTO 2017).

In summary, WTO Members have the discretion to determine their own ALOP. This "right" is important, as socioeconomic prerequisites differ. Although WTO Members are allowed to determine their own ALOP and its subsequent SPS measures to meet their citizens' needs, developing countries often cannot fully use the right due to lack of food safety infrastructure and resources and poor management. Resources, such as one for the collection of epidemiological data at the population level, are often limited or even absent (Government of Malaysia 2004). Developing countries, hence, cannot realize the right granted by the WTO law to either develop their own ALOP or

8 Article 3.3 of the SPS Agreement; Appellate Body Report, EC-Hormones, para. 172.

9 Comparable situations are situations where the same substance or the same adverse health effect is involved (WTO 1998b). 
to present the ALOP in a more meaningful way. ${ }^{10}$ Consequently, there is a possibility that developing countries determine an ineffective ALOP, which later on results in ineffective food laws and regulations.

\subsection{QUANTIFYING AN ALOP THROUGH THE FSO CONCEPT}

Food safety science has responded to the WTO Panel's request for "a more explicit and in particular a quantitative expression of a Member's ALOP" by integrating insight from the food supply chain into the ALOP concept (ICMSF 2006). While there is no legal obligation under the WTO law to base the determination of the ALOP on scientific evidence, the SPS Agreement states that, "Whilst a country has the sovereign right to decide on the degree of protection it wishes of its citizens, it must provide, if required, the scientific evidence on which this level of protection rests (ICMSF 2006)." In that context, the ICMSF has developed the concept of FSO by linking the ALOP concept in WTO law to tangible and science-based criteria that can be applied by actors of the food supply chain. ICMSF defines the FSO as "the maximum frequency and/or concentration of a hazard in a food at the time of consumption that provides or contributes to the appropriate level of protection." In other words, the FSO is defined as the level of a hazard in a food at the time of consumption that contributes to the ALOP.

$H=H o+\sum I-\sum R \leq F S O$,

where $H$ is the level of the hazard, $H o$ is the initial level of the hazard, $\sum I$ is the total (cumulative) increase in the hazard and $\sum R$ is the total (cumulative) reduction in the hazard. FSO, Ho, $R$ and $I$ are expressed in $\mu g \mathrm{~kg}^{-1}$ for mycotoxins and log CFU $\mathrm{g}^{-1}$ for microbial contaminants. In this way, the ICMSF introduced a quantitative ALOP that is relevant for achieving the public health goal, which is then translated to an FSO to be more meaningful for actors in the food supply chain and food safety authorities.

In practice, this may work as follows: Regardless of whether the calculation is based on epidemiological data or food supply chain data, for example, if the current state of disease $x$ is 5 cases per 100.000 people per year and the country accepts this level of risk, then it becomes the ALOP. Later on, if the country wants to reduce the number of cases to 2.5 cases per 100000 people per year, then the latter number will serve as the future ALOP.

${ }^{10}$ See Atik J, supra note 7 who stipulates that in practice of dispute settlement Members "promulgate idiosyncratic measures and then ex-post seek to justify them by telling a story of careful legislative deliberation (which likely never happened)". 


\subsection{QUANTIFYING ALOP THROUGH THE FSO CONCEPT IN DEVELOPING COUNTRIES}

For developing countries, complying with the requirements of the SPS Agreement will take a longer time. ${ }^{11}$ Experience has shown that due to lack of available resources and data, developing countries often do not have the means to design an FSO/ ALOP and its subsequent food laws and regulations in the same way as developed countries, which rely on a risk assessment to determine it. Nevertheless, the FSO/ALOP concept remains a useful way for developing countries to design and implement food laws and regulations tailored to their actual food safety problems and to ensure that these comply with WTO legal requirements in a non-arbitrary manner. In order to benefit from determining and implementing an FSO/ALOP where resources are limited, developing countries should use a novel FSO/ALOP framework that fits with their socioeconomic setting.

To design that novel FSO/ALOP framework, we propose that governments of developing countries adhere to the following three steps. First, an FSO/ ALOP should be determined at the government level. An FSO/ALOP should be based on a risk assessment and also take into account local socioeconomic prerequisites. Second, in order to ensure the applicability, technical guidelines for food manufacturers should be created, which encompass detailed operating procedures of how to apply the FSO/ALOP framework. Finally, governments should establish more effective law enforcement systems, which are mainly based on the evaluation and monitoring of the application of the FSO/ALOP by food industries. These three steps are explained in detail in the next sections:

\subsubsection{An FSO/ALOP Should Be Based on a Risk Assessment and Also Take into Account Local Socioeconomic Prerequisites}

Countries are required to design an FSO/ALOP that is based on a risk assessment. This requires a ranking of possible risks, according to the needs of a country in order to achieve its public health goal (Lake et al. 2010; Hoffmann 2010; Angulo et al. 2009). Although, the establishment of a risk profile should be carried out before the ranking of risk, which precedes also the determination of the FSO/ALOP. ${ }^{12}$ This order is to ensure that countries obtain the most benefit from WTO law and design their FSO/ALOP effectively, for example, by expressing the ALOP in a quantitative term and translating it into an FSO (Gkogka et al. 2013).

Food safety science has developed two approaches to quantify the ALOP and its subsequent FSO: the "top-down" and "bottom-up" approach. The "top-down"

\footnotetext{
11 Article 10.2 of the SPS Agreement states that, "Where the appropriate level of sanitary or phytosanitary protection allows scope for the phased introduction of new sanitary or phytosanitary measures, longer time-frames for compliance should be accorded on products of interest to developing country Members so as to maintain opportunities for their exports."

12 "Risk profile provides contextual and background information about the potential risk when a food and hazard are combined" (Ministry of Primary Industry 2017).
} 
approach requires the availability of robust epidemiological data (Gkogka et al. 2013). This approach provides the most accurate formulation for a public health policy goal because it uses the actual level of the targeted disease in the relevant population. However, the feasibility of this approach relies on an intensive and effective surveillance and monitoring system, which often is a great challenge for developing countries (ICMSF 2006). The epidemiological data are often limited or even absent in developing countries. As a consequence, the bottom-up approach may be a better alternative to meet the requirement in the places where resources are limited. In the bottom-up approach, the determination of an ALOP is based on the available clinical information (e.g., the number of stool samples that contain a targeted microbial hazard) (Gkogka et al. 2013). This information is combined with microbiological surveys, which provide the concentration of certain microbiological hazards in food at the retail level (Gkogka et al. 2013). In the bottom-up approach, the data collection relies on food inspection and laboratory analysis; this is probably available in developing countries, as opposed to an all-encompassing and costly surveillance system to generate epidemiological data. Still, although some developing countries have a well-established inspection and laboratory system in place, some do not. For developing countries with that particular situation, the FSO/ALOP could be determined by extrapolating the risk assessment from available international data, particularly for the toxicological assessment. However, this approach should be applied with care and only in a temporary fashion since the exposure assessment should differ. Either way, such data can only form the basis for the political determination of an ALOP. Other factors such as economic prerequisites and production factors need to be considered as well (De Swarte and Donker 2005).

To be meaningful, the ALOP needs to be translated into a parameter that can be used by food manufacturers and assessed by government agencies. This is done by translating an ALOP into an FSO. The approach used for this purpose resembles the approach used to quantify the ALOP, however, this time in the context of food safety science. To ensure that the FSO is accessible to government officials and food manufacturers, it should have the form of a mandatory published standard or a publicly available regulation. In this way, operators have the flexibility to apply any available food safety management system (FSMS) and technology to their production or distribution facilities as long as the concentration of the hazard in their products does not exceed the FSO value.

\subsubsection{Guideline: Who Should Determine the FSO/ALOP? and How?}

The FSO/ALOP should only be established if there is proof of a significant impact of the hazard/food combination on public health. Thus, an effective establishment of the FSO/ALOP requires careful consideration of which hazard/food combination represents a significant public health risk (ICMSF 2006). In order to achieve this, an integrated approach in the food supply chain is indispensable. The first aspect is, 
extrapolating from the experience with the EU food law, that food manufacturers should have the prime responsibility to assess the risk in their food supply chain, from post-harvesting of the food through to production, storage, and distribution (farm to fork approach). ${ }^{13}$ Food manufacturers, therefore, carry the burden of gathering and assessing information about any possible risks related to their product and eliminating or reducing those risks to an acceptable level. This structure significantly reduces the information burden on the food safety authority and produces more accurate data since it is harvested by the actor with the best knowledge of risks related to the product. The authority's role in this step is to supervise and verify the implementation of the FSMS by the food manufacturers, whether they meet the FSO and contribute to the ALOP. The second aspect is that the FSO/ALOP should be determined by the authority responsible for food control in cooperation with an independent scientific advisory committee. This collaboration ensures that the determination of the FSO/ALOP is based on science and less influenced by political interests.

When the FSO is very low, for example, the FSO for genotoxic and carcinogenic hazard, food manufacturers can establish Performance Objectives (POs) as intermediate targets of their FSMS. POs are equivalent to a FSO and defined as "the maximum frequency and/or concentration of a hazard in a food at a specific step of the food production chain before the time of consumption that provides or contributes to an FSO or ALOP, as applicable" (Skovgaard 2003). From the point of view of Hazard Analysis and Critical Control Points (HACCP), POs can be regarded as the critical limit that contributes directly to or is equivalent to the FSO as the acceptable level of the maximum concentration of a hazard at a specific stage of the food supply chain (FAO/WHO 1997). If necessary, the food manufacturer can determine the POs on each Critical Control Point of the food supply chain (e.g., receiving raw materials from primary production, during the production process, and at the retail level). For instance, in order to meet these POs, the food manufacturer must ensure its suppliers and distributors to apply suitable FSMS, e.g., Good Agricultural Practice (GAP), Good Hygiene Practice (GHP), Good Manufacturing Practice (GMP) or Hazard Analysis, and Critical Control Points (HACCP), and Good Retail Practice (GRP) in their business processes. Moreover, the traceability system shall be applied in the FSO/ALOP framework. This integration grants the ability to follow the movement of food through specified stage(s) of production, processing, and distribution by using the PO values as the reference points for control measures (Figure 2) (FAO/WHO 2006).

\footnotetext{
13 Article 17(1) of Regulation (EC) No 178/2002 of January 28, 2002 lays down the general principles and requirements of food law, establishing the European Food Safety Authority and laying down procedures in matters of food safety, OJ L31, p1, 1/02/2002
} 


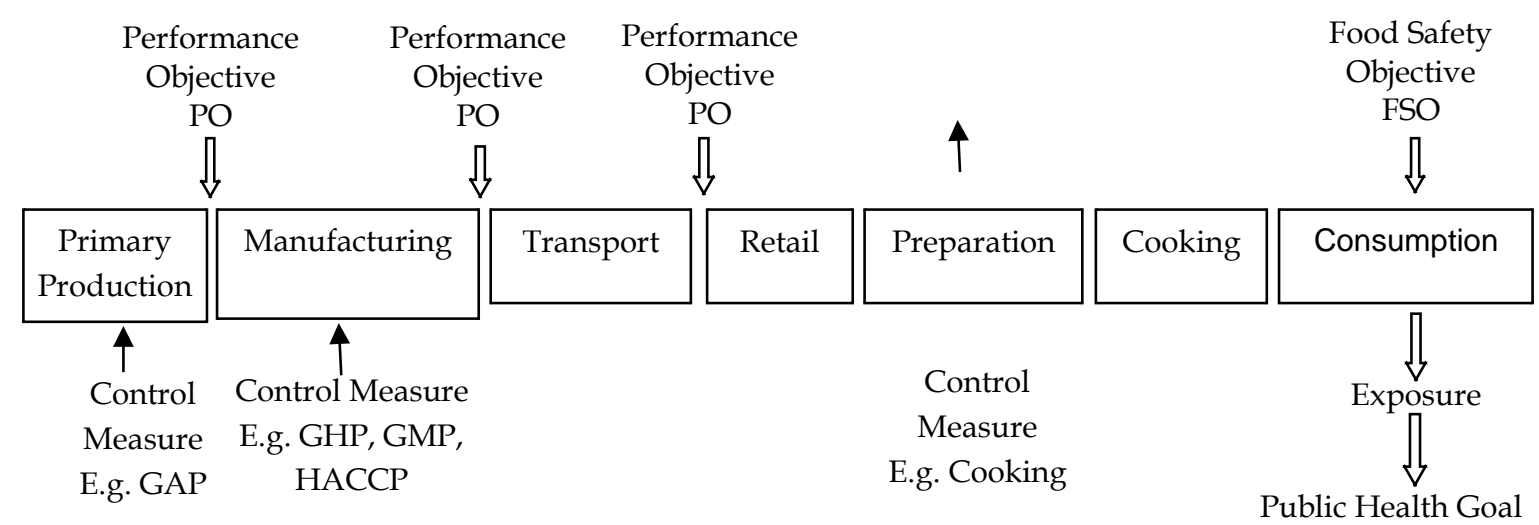

Figure 2. Model of the FSO/ALOP system in the food supply chain (ICMSF 2006).

\subsubsection{Effective Enforcement of FSO/ALOP-Based Regulation}

To be effective, the implementation of the proposed FSO/ALOP framework for the application in developing countries requires an effective law enforcement. This law enforcement has been a challenge in developing countries as food safety infrastructure and resources are often very limited. Despite this constraint, current food control systems in developing countries often rely heavily on the on-site inspection of food facilities and end-product testing. These conditions result in a high-cost law enforcement, which in turn often leads to low compliance with the food laws and regulations. We propose a novel approach to law enforcement to overcome this problem. In this novel approach, costly on-site inspection plays only a minor role. Instead, the law enforcement should be switched to a co-regulation framework. Food industries are obligated to draw up a Risk Management Plan (RMP) that integrates the FSO/ALOP framework within a self-inspection regime. ${ }^{14}$ The RMP encompasses the following steps:

1. A food manufacturer registers their participation in the RMP with the authority.

2. The authority then verifies the eligibility of the food manufacturer based on its history of food control system via the authority's on-site inspection database. If it is eligible, then the food manufacturer must prepare the following RMP documents: records of the current implementation of GMP, HACCP, and other practices of the FSMS in its facilities and the implementation of internal audits. However, if it is not eligible, the authority will inform the food manufacturer to do the Corrective and Preventive Action (CAPA) on the current implementation of the FSMS, and afterward the food industry should update its RMP documents.

\footnotetext{
14 The RMP is a program based on Information Communication Technology (ICT). The program uses web-based software. The participant (food manufacturer) can upload RMP documents and the documents are saved in a database. The authority can verify the documents and provide a real-time progress report of the process online. Indonesia has been implementing this system since 2015 (NADFC 2017b).
} 
3. The authority then makes an on-site inspection to verify the RMP documents of the food manufacturer. Based on this verification, the authority determines the current risk profile and classifies the food industry into a risk zone. The risk zone determines the level of food control, for example, the frequency of on-site inspections, which will be conducted by the authority.

The evaluation of the RMP by the authority can be assessed by two different methods: the benchmark method developed by ICMSF or the margin of safety (MOS) of the accounting tool. The benchmark method developed by the ICMSF is as follows (Cole 2004):

$F S O-H \geq 0$

where FSO, which is derived from the ALOP, denotes an explicit level of a hazard at the point of food consumption. The design and implementation of best practices, such as HACCP, GHP, and GMP, should be based on the Performance Objective (PO) and Performance Criteria (PC) set by the food manufacturer.

The MOS of the accounting tool is an alternative method to measure whether the manufacturer has sufficiently integrated the FSO/ALOP into its RMP (Weygandt et al. 2009). The government authority may use the MOS equation, which is derived from Equation 2, for the evaluation:

$M O S=F S O-H$

MOS Ratio $(\%)=\frac{M O S}{F S O} \times 100$

The MOS must be positive to ensure that the actual level of hazard $(H)$ as the result of the FSMS complies with the expected level of the hazard at the point of consumption (FSO). If the MOS is negative, then the food manufacturer must conduct a Corrective and Preventive Action (CAPA), for example, to put more stringent POs on the critical control points. Otherwise, a food manufacturer can use the MOS ratio to evaluate the performance of the current FSMS. A low MOS ratio is an alert for the food manufacturer to start finding a new combination of control measures to ensure the level of hazard is not exceeding the POs value.

We propose developing countries to change their costly on-site inspection and end-product testing to a more cost-effective RMP program. In this program, the authority checks whether a food industry meets the requirement of the FSO/ALOP framework through a document check of its internal audit records, which acts as the baseline of the actual implementation of the FSMS. Under the RMP program, the food industry must periodically carry out an internal audit to measure the actual performance of the FSMS. Furthermore, the authority should register the internal audit documents in the database that records all past performances of the FSMS. This 
database allows the authority to make a risk profile of the food industry, which then determines the food control level (frequency of on-site inspections) and can eventually be used to evaluate the implementation of the FSO/ALOP framework.

As previously mentioned, an ALOP should only be established for a hazard/food combination that has a significant impact on public health. The approach, therefore, should be prioritized for high-risk foods, such as infant food, canned food, and frozen food. This hierarchy will ensure that the resources of both the authority and food manufacturers are more effectively allocated. The decision on whether to set an ALOP for a hazard in a food should be based on a risk profile. Hence, the establishment of a risk profile is the foremost step in the management model for developing the FSO/ALOP for the application in developing countries (Figure 3).

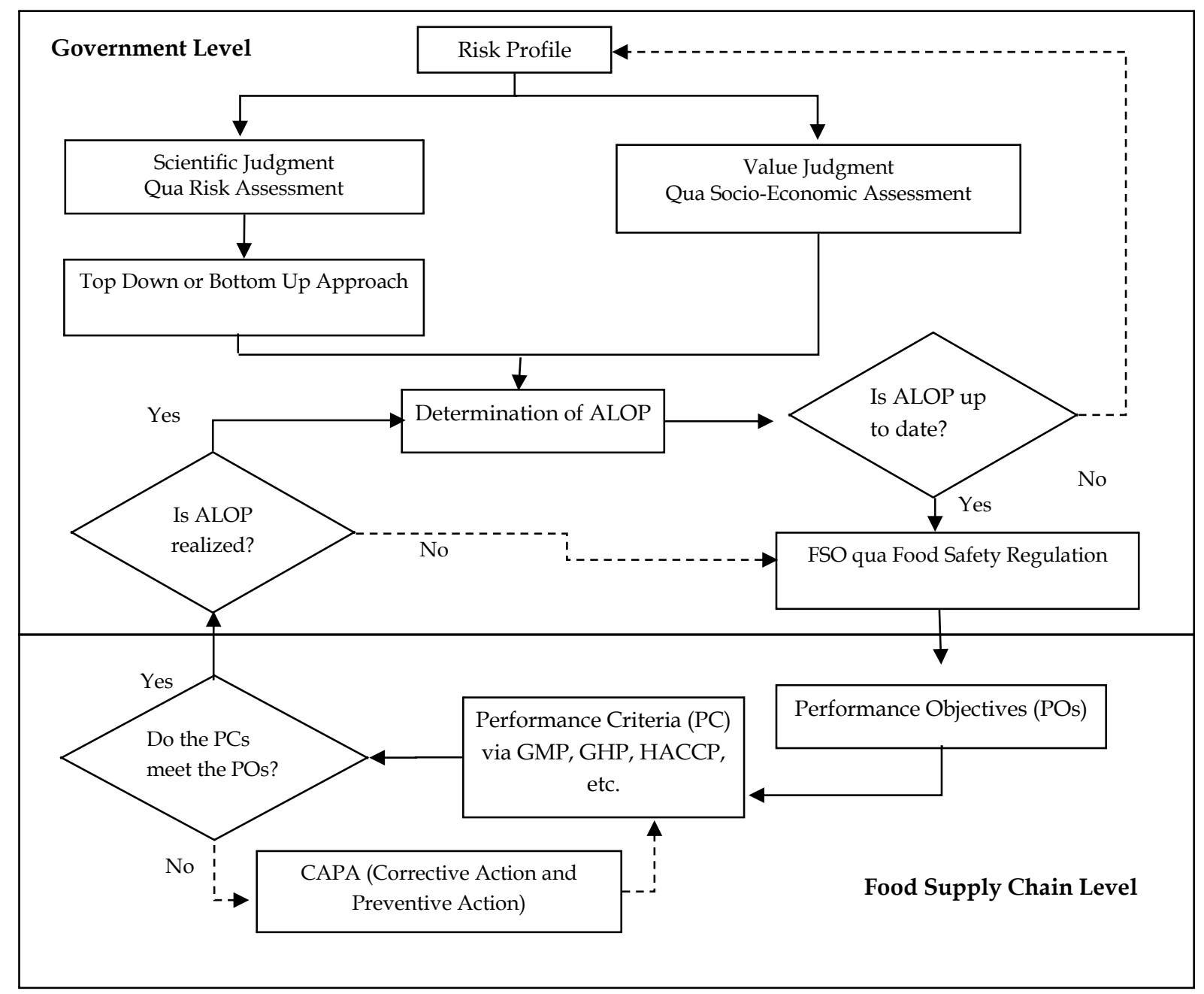

Figure 3. Management model for developing the FSO/ALOP for the application in developing countries.

\subsection{CONCLUSION}

The position of developing countries in the WTO is special. However, this special position does not lift the burden from developing countries of having to implement the obligations enshrined in the WTO legal framework that relate to food safety, which 
is the SPS Agreement. Within this agreement, there are two strongly related components in the establishment of food laws and regulations: ALOP and SPS measures. The ALOP acts as the objective, and implementing SPS measures is the tool to achieve it. We propose an FSO/ALOP framework for the application in developing countries to guide those countries with limited food safety infrastructure and resources (data-poor environments) to establish more effective food laws and regulations that meet the requirements of WTO law, food safety science, and the socioeconomic prerequisites of developing countries. This FSO/ALOP framework encompasses these aspects: a quantitative form of the FSO/ALOP, establishment of technical guidance and effective law enforcement. 



\section{CHAPTER 3}

\section{POLITICS VERSUS SCIENCE IN THE ESTABLISHMENT OF THE APPROPRIATE LEVEL OF PROTECTION (ALOP): THE CASE OF THE FUKUSHIMA NUCLEAR ACCIDENT}

\section{Dasep WAHIDINa, b, Kai PURNHAGENa}

aLaw and Governance Group, Wageningen University and Research, Hollandseweg

1, PO Box 8130, 6700 EW, Wageningen, The Netherlands; bNational Agency of Drug and Food Control of Indonesia (NADFC), Percetakan Negara, 23, 10560, Jakarta, Indonesia.

Based on the article submitted to the Wageningen Journal of Life Sciences (NJAS) (2017). 


\begin{abstract}
Despite the availability of the international standard, following the Fukushima nuclear accident in 2011, Japan, the EU, and Indonesia have taken a different approach towards the establishment of the appropriate level of protection (ALOP) and its subsequent food safety objective (FSO). This study assesses how Japan, the EU, and Indonesia establish their ALOP and FSO when in comparable situations through the lens of political and scientific factors and whether it creates a superfluous protection. This study shows that Japan and the EU establishes more stringent regulatory limits (FSOs) due to the political factor of maintaining their citizens' trust, which are enveloped by scientific insights and may create a superfluous protection scheme. Their measures are not against the WTO law, even though their FSOs are more stringent than the ones in the Codex Standard, since they can justify them with a risk assessment. Whereas, Indonesia cannot use the same reason since its measure is not based on a risk assessment. Ironically, the level of protection that is provided by the Indonesian FSOs seems to be logical, based on the risk assessment provided by Japan. However, conducting a risk assessment is obligatory since Indonesian FSOs are more stringent than the ones in the Codex Standard. Political factors are indeed an important part of the decision-making of the ALOP and FSO since the decision-making is a political decision. Although, science should come before politics in order to obtain more effective food laws and regulations.
\end{abstract}

Keywords: FSO/ALOP, Fukushima accident, food safety, regulatory limits. 


\subsection{INTRODUCTION}

Despite the availability of the international standard, following the Fukushima nuclear accident in 2011, Japan, the EU, and Indonesia have taken a different approach for the establishment of an appropriate level of protection (ALOP) and its subsequent food safety objective (FSO) (FAO/WHO 1995). The reasons can largely be attributed to the influence of political and scientific factors in the decision-making of an FSO/ALOP. This study assesses how Japan, the EU, and Indonesia establish their FSO/ALOP in comparable situations based on those two factors and whether it creates a superfluous protection. This study proceeds as follows: We describe the impact of the Fukushima nuclear accident on the environment, the paths of radioactive contaminant exposure, and the impact of the accident on food safety in chapter II. Next, we explore the international protection system of radiological protection and the relevant international standard of the regulatory limit of radioactive contaminants in foods in chapter III. Later on, we explore the legal framework of the regulatory limit of radioactive contaminants in food in Japan, the EU, and Indonesia and whether the relevant regulation is based on the Codex Standard in chapter IV. Then, we analyze the findings by using the FSO/ALOP framework for the application in developing countries from our previous work (Wahidin and Purnhagen 2017) in chapter V. Finally, we answer the research question in the concluding chapter.

\subsection{FUKUSHIMA NUCLEAR ACCIDENT AND FOOD SAFETY}

The Fukushima nuclear accident, which happened on March 11, 2011, has reminded us of the devastating impact of nuclear power plant accidents on public health and the environment. Although the radionuclides released from the Fukushima nuclear accident were much less than the Chernobyl nuclear accident, the Fukushima nuclear accident is still regarded as the greatest environmental disaster in the $21^{\text {st }}$ century (Merz et al. 2013; Harada et al. 2014; Povinec et al. 2013). Approximately 520 PBq of radionuclides were released into the environment (Steinhauser et al. 2014). ${ }^{15}$

There is a potential risk to human health from the possible public exposure to radionuclides following the Fukushima nuclear accident. There are two main pathways for the public to become exposed to the released radionuclides: external exposure from radionuclides deposited on the ground and internal exposure from the ingestion of radionuclides as contaminants in foods (Balonov et al. 2007). In the longer term, the internal exposure pathway through the consumption of radioactively contaminated foods can contribute more significantly to public exposure compared to the external exposure pathway (Balonov et al. 2007). Some examples of the main radioactive contaminants connected to the internal exposure pathway are iodine (131I, ${ }^{132} \mathrm{I}$, and $\left.{ }^{133} \mathrm{I}\right)$, cesium $\left({ }^{137} \mathrm{Cs}\right.$ and $\left.{ }^{134} \mathrm{Cs}\right)$, and strontium $\left({ }^{90} \mathrm{Sr}\right.$ and $\left.{ }^{89} \mathrm{Sr}\right)$. In the aftermath

15 Becquerel is used to measure the quantity of a radionuclide, 1 becquerel equals one nuclear transformation per second. Whereas 1 PBq (petabecquerel) equals to $10^{15} \mathrm{~Bq}$ (NEA-OECD 2008). 
of a nuclear accident, the most affected countries must do an intensive monitoring of the level of radioactive contaminants in foods, particularly for the potential risk of cancer in children and pregnant women. Besides that, there is strong evidence to suggest that the rate of secondary thyroid cancers among children can be increased due to the internal exposure of radioactive contaminants in foods (Christodouleas et al. 2011). However, the actual effective dose from the Fukushima nuclear accident was reported to be at a very low level, even compared to the natural background radiation before the accident (Shimura, Yamaguchi, Terada, Svendsen, et al. 2015). Thus, there was most probably only a few people that consumed radioactively contaminated foods to the level of endangering their health (Gibney 2015). Even in the areas most affected by the radiation, that is the Fukushima prefecture, there was no observable increased risk of cancer after the accident, compared to the level of risk due to the natural background radiation before the accident (WHO 2013). Despite those facts, there are potential risks to public health, particularly in relation to the low dose radiation exposure and its stochastic effect that can be regarded as the "radical uncertainties." 16

\subsection{INTERNATIONAL SYSTEM OF RADIOLOGICAL PROTECTION}

The International Commission on Radiological Protection (ICRP) developed an international system of radiological protection, which has become the most common framework used by relevant international organizations and countries for the development of legislation on radiological protection (ICRP 2007). The latest ICRP recommendation is the ICRP Publication 103, which stipulates two principles for the radiological protection control measure: justification and optimization (ICRP 2007). The latter principle denotes a likelihood of incurring exposure, a number of people exposed, and a magnitude of the individual dose that should always be kept as low as reasonably achievable (ALARA), taking into account economic and social factors (ICRP 2007). ${ }^{17}$ Thus, the ICRP recommends using the ALARA approach for the development of legislation on radiological protection.

By using the principle of ALARA, Codex has established guideline levels (GLs) for radioactive contaminants in foods in the Codex General Standard for Contaminants and Toxins in Food and Feed (Table 2) (CAC 2010). These GLs act as the international reference for the regulatory limits of radioactive contaminants in foods. Codex used data on annual food consumption rates for infants and adults, radionuclide- and age-

16 Radical uncertainties are food safety hazards that are not well-identified and whose potential adverse health effects are lack of scientific evidence. Stochastic radiation effects are the effects of ionizing radiation that are not based on their severity, but the probability of their occurrence. Hence, there is no threshold level for this kind of effect (ENS 2017). We classify the adverse health effects of radioactive contaminants in food as the "radical uncertainties" when the situation is linked to the commercialization of foods whose dangers are unknown to the producer when they put them on the market (Callon 2009; Kimura 2013).

17 ALARA means that even in a small dose, if receiving that dose has no direct benefit, you should avoid it (CDC 2015). 
dependent ingestion dose coefficients, and import-to-production factors to assess the mean public exposure level in a country that is sourced from imported foods from other countries with residual radioactivity. ${ }^{18}$ The GLs apply to the foods that have been contaminated in a nuclear or radiological emergency, are destined for human consumption, and are traded internationally (CAC 2010). The GLs are established using the following equation:

$\mathrm{GL}=\frac{\mathrm{IED}}{\operatorname{IPF} \times \mathrm{e}_{\mathrm{ing}}(\mathrm{A}) \times \mathrm{M}(\mathrm{A})}$,

where GL is the guideline level (Bq/ $\mathrm{kg})$; IED is the intervention exemption level of dose (mSv/year), which is the same as the effective dose; IPF is the import-toproduction factor (dimensionless), which can be seen as the ratio of contaminated foods to total foods; eing (A) is the age-dependent ingestion dose coefficient $(\mathrm{mSv} / \mathrm{Bq})$; and $\mathrm{M}(\mathrm{A})$ is the age-dependent mass of food consumed per year $(\mathrm{kg} /$ year $) .{ }^{19}$

Codex used an intervention exemption level of dose (IED) of $1 \mathrm{mSv} /$ year from the ICRP Publication 82 (ICRP 1999) and an import-to-production factor (IPF) of 10\%. Codex established different GLs for infants and adults by using the age-dependent ingestion dose coefficient [ $\mathrm{e}_{\text {ing }}(\mathrm{A})$ ] from the ICRP Publication 72 (ICRP 1995). Moreover, Codex regulated GLs for 20 different radionuclides $\left({ }^{238} \mathrm{Pu},{ }^{239} \mathrm{Pu},{ }^{240} \mathrm{Pu}\right.$, ${ }^{241} \mathrm{Am},{ }^{90} \mathrm{Sr},{ }^{106} \mathrm{Ru},{ }^{129} \mathrm{I},{ }^{131} \mathrm{I},{ }^{235} \mathrm{U},{ }^{35} \mathrm{~S},{ }^{60} \mathrm{Co},{ }^{89} \mathrm{Sr},{ }^{103} \mathrm{Ru},{ }^{134} \mathrm{Cs},{ }^{137} \mathrm{Cs},{ }^{144} \mathrm{Ce},{ }^{192} \mathrm{Ir},{ }^{3} \mathrm{H},{ }^{14} \mathrm{C}$, and ${ }^{99} \mathrm{Tc}$ ) for two types of food (infant food and other food).

Table 2 Guideline levels (in $\mathrm{Bq} / \mathrm{kg}$ ) of radioactive contaminants in foods according to the Codex General Standard for Contaminants and Toxins in Food and Feed (Codex Stan 1931995).

\begin{tabular}{|l|c|c|}
\hline \multirow{2}{*}{ Radionuclides } & \multicolumn{2}{|c|}{ Guideline level in foods (Bq/kg) } \\
\cline { 2 - 3 } & Infant foods & Other foods \\
\hline${ }^{238} \mathrm{Pu},{ }^{239} \mathrm{Pu},{ }^{240} \mathrm{Pu},{ }^{241} \mathrm{Am}$ & 1 & 10 \\
\hline${ }^{90} \mathrm{Sr},{ }^{106} \mathrm{Ru},{ }^{129} \mathrm{I},{ }^{131} \mathrm{I},{ }^{235} \mathrm{U}$ & 100 & 100 \\
\hline $\begin{array}{l}{ }^{35} \mathrm{~S},{ }^{60} \mathrm{Co},{ }^{89} \mathrm{Sr},{ }^{103} \mathrm{Ru},{ }^{134} \mathrm{Cs},{ }^{137} \mathrm{Cs}, \\
{ }^{144} \mathrm{Ce},{ }^{192} \mathrm{Ir}\end{array}$ & 1000 & \\
\hline
\end{tabular}

18 Residual activity is radioactivity in radioactive sources, excluding background radiation that persists for more than one minute.

19 Sievert (Sv) is used to measure an effective dose. $1 \mathrm{mSv}$ (millisievert) equals to $10^{-3} \mathrm{~Sv}$. An effective dose is defined as the "weighted sum of the "equivalent doses" to the various organs and tissues multiplied by weighting factors reflecting the differing sensitivities of organs and tissues to radiation." 


\begin{tabular}{|l|c|c|}
\hline${ }^{3} \mathrm{H},{ }^{14} \mathrm{C},{ }^{99} \mathrm{Tc}$ & 1000 & 1000 \\
\hline
\end{tabular}

\subsection{REGULATORY LIMIT OF THE RADIOACTIVE CONTAMINANTS IN FOOD IN JAPAN, THE EU, AND INDONESIA}

\subsubsection{Japan}

Food scandal in a country can often lead to a major change in other countries' food safety legal system, as seen in the case of Bovine Spongiform Encephalopathy (BSE) in the EU and the "melamine" scandal in China (Xiao 2011; Ji et al. 2014; Vos 2000). These food scandals, particularly the BSE case in 2001, have also triggered a major change in the food safety legal system in Japan (Takahashi 2009), specifically the establishment of the Food Safety Basic Law in 2003.20 This law is to some extent similar to the EU's General Food Law. Both laws emphasize the consumer's right, the distinction between a risk assessor and a risk manager, and the use of science to guarantee food safety (Takahashi 2009).

When the emergency situation happened following the Fukushima nuclear accident, Japan didn't have any specific regulation on the regulatory limit of radioactive contaminants in foods. The Ministry of Health, Labor, and Welfare (MHLW) as the risk manager, under the recommendation of the Nuclear Emergency Commission led by the Prime Minister, responded quickly by establishing a regulation that stipulates the provisional regulatory limits of radioactive contaminants in foods. These regulatory limits were adopted from the "index relating to limits on food and drink ingestion" of the Nuclear Safety Commission (NSC) of Japan (Shimura, Yamaguchi, Terada, Yunokawa, et al. 2015). This quick response was aimed at reducing the potential risk of internal exposure to radioactively contaminated foods and at the same time recovering public trust, which was at the time on a very low level (Reiher 2016). These provisional regulatory limits were calculated based on the same equation used by Codex in developing the GLs (Equation 4). However, different from the Codex Standard, which regulates only two food categories, the Japanese regulation covers three food categories by adding drinking water to the list. Nevertheless, these provisional regulatory limits (Table 3) were established without a full risk assessment by the Food Safety Commission (FSC) as the risk assessor (Japan 2003).

Table 3 Regulatory limits (in $\mathrm{Bq} / \mathrm{kg}$ ) of radioactive contaminants in foods according to the Japanese provisional regulation.

\begin{tabular}{|c|c|c|c|}
\hline Radionuclides & Milk $\left(^{*}\right)$ & $\begin{array}{c}\text { Vegetables, grains, Meat, } \\
\text { egg, fish, other foods. }\end{array}$ & $\begin{array}{c}\text { Drinking } \\
\text { water }\end{array}$ \\
\hline Radioactive iodine & 300 & 2000 & 300 \\
\hline Radioactive cesium & 200 & 500 & 200 \\
\hline
\end{tabular}

20 Law No 48/2003 or well known as The Food Safety Basic Law (FSA). https://www.fsc.go.jp/sonota/fsb_law160330.pdf, accessed 09.02.2017. 


\begin{tabular}{|c|c|c|c|}
\hline Radioactive uranium & 20 & 100 & 20 \\
\hline $\begin{array}{c}\text { Radioactive plutonium } \\
\text { and other transuranic } a \\
\text { emitters }\end{array}$ & 1 & 10 & 1 \\
\hline
\end{tabular}

(*) Provides guidance so that materials exceeding $100 \mathrm{~Bq} / \mathrm{kg}$ are not used in milk supplied for use in powdered baby formula or for direct drinking. Vegetables, grains, meat, egg, fish, and other foods as well as water were regulated, due to their significant and essential function in the diets of the general public, and milk was regulated because it is mostly consumed by infants and children.

To address the absence of a risk assessment in the establishment of the provisional regulatory limits and to comply with the international standard, a year after the accident, the MHLW replaced the limits with new regulatory limits that were based on a full quantitative risk assessment from the FSC (Table 4). ${ }^{21}$ The new regulatory limits incorporate three elements of the Food Safety Basic Law. First, the focus of the establishment is to protect consumer interest. Second, there is a distinction between a risk assessor and a risk manager. Finally, the development of regulatory limits was based on sound science through a risk assessment (FSC, 2011, MHLW, 2012).

Table 4 Regulatory limits (in $\mathrm{Bq} / \mathrm{kg}$ ) of radioactive contaminants in foods according to the new Japanese standard (MHLW, 2012).

\begin{tabular}{|c|c|c|c|c|}
\hline Radionuclides & $\begin{array}{c}\text { Infant } \\
\text { foods }\end{array}$ & Milk & General foods & Drinking water \\
\hline $\begin{array}{c}\text { Radioactive } \\
\text { cesium* }\end{array}$ & 50 & 50 & 100 & 10 \\
\hline
\end{tabular}

${ }^{(*)}$ These limits take into account the contribution from strontium, plutonium, etc.

\subsubsection{The EU}

Following the Fukushima nuclear accident, the European Commission implemented a series of protective measures. On March 12, 2011 just 24 hours after the accident, the Commission activated an emergency team and transmitted an emergency alert to all Member States through the ECURIE (European Community Urgent Radiological Information Exchange). Later on, the European Commission established the Commission Implementing Regulation (EU) 297/2011 on March 25, 2011 (Table 5), ${ }^{22}$ which imposed special conditions on the import of feed and food originating in or consigned from Japan following the accident. This regulation stipulated the

\footnotetext{
21 New standard limits for radionuclides in foods. http://www.mhlw.go.jp/english/topics/2011eq/dl/new_standard.pdf, accessed 09.02.2017. 22 Commission Implementing Regulation (EU) No 297/2011 of 2March 25, 2011 imposes special conditions that govern the import of feed and food originating in or consigned from Japan following the accident at the Fukushima nuclear power station. OJ L 80, 26.3.2011, p. 5-8.
} 
requirement for the sampling and analysis of certain foodstuffs from certain prefectures in Japan, to be taken by the Japanese food safety authorities before exporting the foodstuffs to the EU. The regulation adopted regulatory limits in the Annex of the Regulation 3954/87, Regulation 944/89, and Regulation 770/90 and did not adopt the regulatory limit in the Regulation 733/2008 since this regulation only covers the radioactive contaminants in foods following the Chernobyl nuclear accident (Table 4). ${ }^{23}$

Different from other food safety issues that are covered by the General Food Law (GFL) under the Treaty establishing the European Community, the establishment of the regulatory limits of radioactive contaminants in foods falls under the European Atomic Energy Community (EURATOM) Treaty. The risk assessment is not conducted by the European Food Safety Authority (EFSA), as is generally done for other food safety issues; it is done by the "Article 31 group of experts," a group of persons appointed by the Scientific and Technical Committee (EU 2012).

Table 5 Pre-established regulatory limits (in $\mathrm{Bq} / \mathrm{kg}$ ) of radioactive contaminants according to foods in the Commission Implementing Regulation No 297/ 2011.

\begin{tabular}{|c|c|c|c|c|}
\hline Radionuclides & $\begin{array}{c}\text { Infant } \\
\left.\text { foods }{ }^{(* *}\right)\end{array}$ & $\begin{array}{c}\text { Dairy } \\
\text { produces }\end{array}$ & $\begin{array}{c}\text { Other foodstuffs except } \\
\left.\text { for minor foodstuffs }{ }^{(* *}\right)\end{array}$ & $\begin{array}{c}\text { Liquid } \\
\text { foodstuffs }\end{array}$ \\
\hline $\begin{array}{c}\text { Sum of isotopes } \\
\text { of strontium, } \\
\text { notably 90Sr }\end{array}$ & 75 & 125 & 750 & 125 \\
\hline $\begin{array}{c}\text { Sum of isotopes } \\
\text { of iodine, } \\
\text { notably 131 }\end{array}$ & 150 & 500 & 2000 & 20 \\
\hline $\begin{array}{c}\text { Sum of Alpha- } \\
\text { emitting } \\
\text { isotopes of } \\
\text { plutonium and } \\
\text { transplutonium } \\
\text { elements, } \\
\text { notably }{ }^{239} \text { Pu, } \\
\text { 241Am }\end{array}$ & 1 & 20 & 80 & 1000 \\
\hline $\begin{array}{c}\text { Sum of all other } \\
\text { nuclides of half- } \\
\text { life greater than }\end{array}$ & 400 & 1000 & & \\
\hline
\end{tabular}

23 Commission Regulation (Euratom) No 3954/87 of Commission Regulation (Euratom) No 944/89 of April 12, 1989 details the maximum permitted levels of radioactive contamination in minor foodstuffs following a nuclear accident or any other case of radiological emergency. OJ L 101, 13.4.1989, p. 17-18; Commission Regulation (Euratom) No 944/89 of April 12, 1989 details the maximum permitted levels of radioactive contamination in minor foodstuffs following a nuclear accident or any other case of radiological emergency. OJ L 101, 13.4.1989, p. 17-18. 


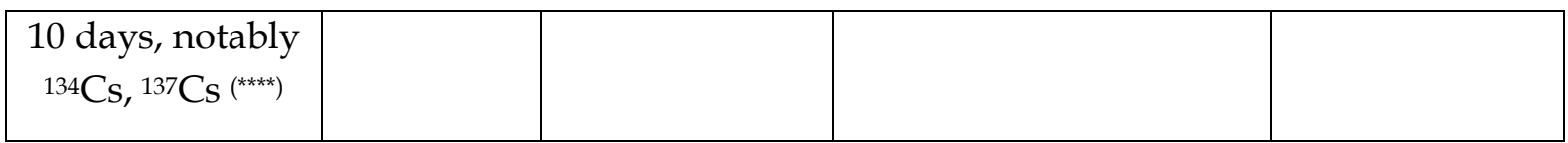

(*) The level applies to concentrated or dried products, and it is calculated on the basis of the reconstituted product as ready for consumption.

${ }^{* *}$ Infant food is defined as those foodstuffs intended for the feeding of infants during the first four to six months of life, which meet, in and among themselves, the nutritional requirements of this category of person and are put up for retail sale in packages which are clearly identified and labelled "food preparation for infants."

${ }^{(* *)}$ For the minor foodstuffs, listed in Regulation No 944/89, the maximum levels to be applied are 10 times those applicable to "other foodstuffs except minor foodstuffs."

${ }^{(* \star *)}$ Carbon 14, tritium, and potassium 40 are not included in this group.

Less than a month after the enactment of the Commission Implementing Regulation No 297/2011, the European Commission replaced it with the Commission Implementing Regulation No 351/2011 (Table 6). The Commission considered that regulatory limits in the Regulation No 297/2011 were not sufficient to protect public health since they were less stringent compared to the Japanese regulatory limits. The European Commission had decided to establish the same regulatory limits as the ones in Japan in the Commission Implementing Regulation No 351/2011. This measure is taken to ensure a consistency between the pre-export checks performed by the Japanese food safety authorities and the food control at the EU borders.

Table 6 Regulatory limits (in $\mathrm{Bq} / \mathrm{kg}$ ) of a radioactive contaminant in food (*) according to the Commission Implementing Regulation No 351/2011.

\begin{tabular}{|c|c|c|c|c|}
\hline Radionuclides & $\begin{array}{c}\text { Foods for } \\
\text { infants and } \\
\text { young children }\end{array}$ & $\begin{array}{c}\text { Milk and } \\
\text { dairy } \\
\text { products }\end{array}$ & $\begin{array}{c}\text { Other foodstuffs, } \\
\text { except liquid } \\
\text { foodstuffs }\end{array}$ & $\begin{array}{c}\text { Liquid } \\
\text { foodstuffs }\end{array}$ \\
\hline $\begin{array}{c}\text { Sum of Isotopes } \\
\text { of strontium, } \\
\text { notably 90Sr }\end{array}$ & 75 & 125 & 750 & 125 \\
\hline $\begin{array}{c}\text { Sum of Isotopes } \\
\text { of iodine, notably } \\
\text { 131I }\end{array}$ & 100 & 300 & 2000 & 300 \\
\hline $\begin{array}{c}\text { Sum of Alpha- } \\
\text { emitting isotopes } \\
\text { of plutonium and } \\
\text { trans-plutonium } \\
\text { elements, notably } \\
\text { 239Pu, 241Am }\end{array}$ & 1 & 1 & 10 & 200 \\
\hline $\begin{array}{c}\text { Sum of all other } \\
\text { nuclides of half- } \\
\text { life greater than }\end{array}$ & 200 & 200 & 500 & \\
\hline
\end{tabular}




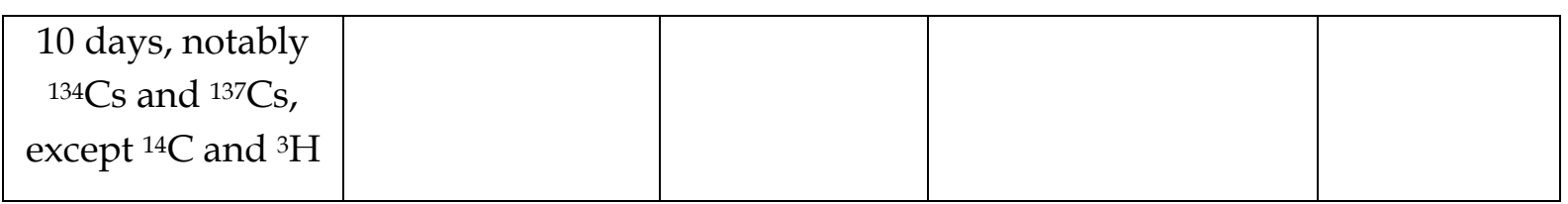

${ }^{(*)}$ The level applies to concentrated or dried products, and it is calculated on the basis of the reconstituted product as ready for consumption.

The regulatory limits were then updated periodically to be aligned with the ones applied in Japan by replacing the Implementing Commission Regulation No 351/2011 with the Implementing Commission Regulation No 284/2012 (Table 7), which is aligned with the regulatory limits in the new Japanese standard. ${ }^{24}$ These regulatory limits are still applied in the current Commission Implementing Regulation (EU) No $6 / 2016$.

Table 7 Regulatory limits (1) (in Bq/ $\mathrm{kg}$ ) of radioactive contaminants in foods ${ }^{*}$ ) according to the Commission Implementing Regulation No 284/2012.

\begin{tabular}{|c|c|c|c|c|}
\hline Radionuclides & $\begin{array}{c}\text { Foods } \\
\text { for } \\
\text { infants } \\
\text { and } \\
\text { young } \\
\text { childre } \\
\mathrm{n}\end{array}$ & $\begin{array}{c}\text { Milk and } \\
\text { dairy } \\
\text { products }\end{array}$ & $\begin{array}{c}\text { Other foods, with the } \\
\text { exception of } \\
\text { mineral water } \\
\text { and similar drinks }\end{array}$ & $\begin{array}{c}\text { Mineral } \\
\text { water and } \\
\text { similar } \\
\text { drinks and } \\
\text { tea brewed } \\
\text { from } \\
\text { tea brewed } \\
\text { from unfermented } \\
\text { leaves } \\
\text { soybean and } \\
\text { leaves }\end{array}$ \\
\hline $\begin{array}{c}\text { Sum of }{ }^{134} \mathrm{Cs} \\
\text { and }{ }^{137} \mathrm{Cs}\end{array}$ & $5^{(2)}$ & $50^{(2)}$ & $\begin{array}{c}100^{(2)}(3) \\
\text { soybean products }\end{array}$ & \\
\hline
\end{tabular}

(1) For dried products that are intended to be consumed in a reconstituted state, the maximum level applies to the reconstituted product as ready for consumption. For dried mushrooms, a reconstitution factor of 5 is applied.

(2) For tea, the maximum level applies to the infusion brewed from tea leaves. The processing factor for dried tea is 50 , and therefore a maximum level of $500 \mathrm{~Bq} / \mathrm{kg}$ in dried tea leaves ensures that the level in the brewed tea does not exceed the maximum level of $10 \mathrm{~Bq} / \mathrm{kg}$.

(2) In order to ensure consistency with the maximum levels currently being applied in Japan, these values replace on a provisional basis the values laid down in the Council Regulation (EURATOM) 3954/87.

(3) For rice and rice products, the maximum level applied is from October 1, 2012. Before this date, the maximum level of $500 \mathrm{~Bq} / \mathrm{kg}$ applies.

24 Commission Implementing Regulation (EU) No 322/2014 of March 28, 2014 imposes special conditions governing the import of feed and food originating in or consigned from Japan following the accident at the Fukushima nuclear power. OJ L 95, 29.3.2014, p. 1-11. 
(4) For soybean and soybean products, the maximum level of $500 \mathrm{~Bq} / \mathrm{kg}$ applies.

\subsubsection{Indonesia}

Indonesia has established regulatory limits of radioactive contaminants in foods since 1987, long before the Fukushima nuclear accident (Table 8). The Minister of Health Decree No 00474/B/II/87 was established following the Chernobyl nuclear accident. However, following the Fukushima nuclear accident Indonesia replaced that Regulation with the Minister of Health Decree 1031/PER/V/2011 on May 27, 2011, detailing the regulatory limits of radioactive contaminants in foods, which originate in countries or areas that are experiencing a nuclear emergency situation (Table 9). In addition, Indonesia, through the Minister of Agriculture, has also established The Minister of Agricultural Decree No 20/Permentan/OT.140/3/2011, detailing the regulatory limits of radioactive contaminants in fresh products of animal and vegetable origin that originate in Japan (Table 10).

Table 8. Regulatory limits (in $\mathrm{Bq} / \mathrm{kg}$ ) of radioactive contaminants in foods according to the Minister of Health Decree No 00474/B/II/87.

\begin{tabular}{|c|c|c|c|c|c|c|}
\hline Radionuclide & $\begin{array}{c}\text { Milk and } \\
\text { dairy } \\
\text { products }\end{array}$ & $\begin{array}{c}\text { Fruits and } \\
\text { vegetables (fresh } \\
\text { and processed } \\
\text { products) }\end{array}$ & $\begin{array}{c}\text { Fish (fresh and } \\
\text { processed } \\
\text { products) }\end{array}$ & $\begin{array}{c}\text { Meat and } \\
\text { meat } \\
\text { products }\end{array}$ & $\begin{array}{c}\text { Mineral } \\
\text { water }\end{array}$ & Cereals \\
\hline${ }^{137} \mathrm{Cs}$ & 150 & 300 & 100 & 100 & 150 & 300 \\
\hline
\end{tabular}

Table 9. Regulatory limits (in $\mathrm{Bq} / \mathrm{kg}$ ) of radioactive contaminants in foods according to the Minister of Health Decree No 1031/PER/V/2011.

\begin{tabular}{|c|c|c|c|c|c|c|c|c|}
\hline Radionuclides & $\begin{array}{c}\text { Infant } \\
\text { foods }\end{array}$ & $\begin{array}{c}\text { Milk } \\
\text { and } \\
\text { dairy } \\
\text { products }\end{array}$ & $\begin{array}{c}\text { Fruits and } \\
\text { vegetables }\end{array}$ & $\begin{array}{c}\text { Fish } \\
\text { (fresh } \\
\text { and } \\
\text { processed } \\
\text { products) }\end{array}$ & Meat & $\begin{array}{c}\text { Packaged } \\
\text { drinking } \\
\text { water }\end{array}$ & $\begin{array}{c}\text { Cereals, } \\
\text { including } \\
\text { maize } \\
\text { flour and } \\
\text { barley }\end{array}$ & $\begin{array}{c}\text { General } \\
\text { foods }\end{array}$ \\
\hline${ }^{131} \mathrm{I}$ & 50 & 100 & 1000 & - & - & - & - & - \\
\hline${ }^{137} \mathrm{Cs}$ & 100 & 150 & 500 & 500 & 500 & 150 & 500 & 500 \\
\hline
\end{tabular}

Table 10. Regulatory limits (in Bq/kg) of radioactive contaminants in fresh products of animal and vegetable origin according to the Ministry of Agricultural Decree No 20/Permentan/OT.140/3/2011.

\begin{tabular}{|c|c|c|}
\hline Radionuclides & Milk and dairy products & $\begin{array}{c}\text { Other foodstuffs (cereals, fresh fruits and } \\
\text { vegetables, meats, and meat products) }\end{array}$ \\
\hline${ }^{131} \mathrm{Cs}$ & 100 & 1000 \\
\hline
\end{tabular}




\begin{tabular}{|l|c|c|}
\hline $137 \mathrm{Cs}$ & 150 & 500 \\
\hline
\end{tabular}

\subsection{FSO/ALOP ANALYSIS}

This study uses the FSO/ALOP framework applicable to developing countries to analyze the food laws and regulations on the regulatory limits of radioactive contaminants in foods in Japan, the EU, and Indonesia and uses the conclusion to assess each country's preferences in the establishment of the regulatory limits. To be more conscientious of its application in the food control system, governments should translate the ALOP into an FSO. This FSO can be used as an incentive for food businesses in relation to the implementation of their FSMSs, such as GMP (Good Manufacturing Practices) and HACCP (Hazard Analysis and Critical Control Point), in order for them to meet the FSO and further contribute to the ALOP. At the same time, food safety authorities can use the FSO in the verification of the implementation of FSMSs by food businesses for whether their FSMSs can meet the FSO that provides the ALOP and in the evaluation of the FSO/ALOP.

Before moving further in the analysis, an alignment of the FSO/ALOP framework for application in developing countries with the international radiological protection concept of the ICRP needs to be done. Based on the international radiological protection concept, an ALOP can be expressed as the effective dose. ${ }^{25} \mathrm{~A}$ FSO can be expressed as the maximum permissible level of a radioactive contaminant in a food (regulatory limit). A FSO/ALOP should only be established if the actual level of a radioactive contaminant in food $(\mathrm{H})$ is above the natural background radiation level (Ho) (the level before the accident) or if the food and consumer group are deemed to require a special attention, such as food that is most likely to be exposed to radioactive contaminant or food that is consumed by vulnerable consumers (e.g., infants, young children, pregnant women). $\Sigma R$ is an accumulation of control measures from food safety authorities and food businesses to reduce the targeted risk. Whereas, $\sum \mathrm{I}$ is the potential additional risk of internal exposure (Equation 1).

Under the FSO/ALOP framework for the application in developing countries, governments (food safety authorities) should weigh both the risk assessment (scientific judgment) and socioeconomic factors (value judgment) in the establishment of the FSO/ALOP (Figure 3). In the context of the Fukushima nuclear accident, food safety authorities should conduct an intensive and continuous monitoring of the level

\footnotetext{
25 An effective dose represents a "...radiobiological detriment from a particular, often inhomogeneous, type of radiation exposure." Detriment encompasses a balance between cancer mortality, life shortening, and heredity effects (Dietze et al. 2009). It is expressed as a unit of Sievert. It is always used as a measure of risk. An effective dose applies to a reference person and is aimed to meet a measure of risk to individuals. We value more the notion of "effective risk", which will be applied under the FSO/ALOP framework since it is a risk-based framework. Despite that, the current international radiological protection still acknowledges the effective dose as a measure of risk. Hence, we use it and provide it as the ALOP.
} 
of radioactive contaminants in foods during the emergency exposure and during the existing exposure situations ${ }^{26}$ to determine the actual level of radioactive contaminants in foods $(\mathrm{H})$. These monitoring results can be used as the exposure assessment as a part of the quantitative risk assessment. Food safety authorities can thereby use the risk estimate as the product of the risk assessment and combine it with socioeconomic factors, such as the factor of food availability in the market, risk perception, and consumer trust, when determining the FSO/ALOP. They can also use the monitoring results in the evaluation of the FSO/ALOP. For example, if the level of radioactive contaminants in foods is decreasing, especially in a prolonged situation, then food safety authorities may consider to lower the stringency of the FSO/ALOP.

\subsubsection{Japan}

Before the Fukushima nuclear accident, there was no regulation on the regulatory limits (FSOs) of radioactive contaminants in food. After the Fukushima nuclear accident, Japan established the provisional regulation by using an ALOP of 5 mSv/year (Table 2). This ALOP encompassed two radionuclides ( $3 \mathrm{mSv} /$ year for cesium and $2 \mathrm{mSv} /$ year for other radionuclides: iodine, uranium, plutonium, and other a emitters). These FSOs in the provisional regulation were considered sufficient for the protection of the Japanese public, despite the fact that the available knowledge on the best practice of food control and enforcement of the FSOs were limited (Gilmour et al. 2016).

On April 1, 2012, Japan established a new standard that replaced the provisional regulation (Table 4). Instead of using the ALOP of $5 \mathrm{mSv} /$ year, the new standard uses the ALOP of $1 \mathrm{mSv} /$ year, like the one applied in the Codex General Standard for Contaminants and Toxins in Food and Feed (MHLW, 2012), and combines it with other factors in Equation 5, which resulted in more stringent FSOs. Furthermore, there are three major differences between the new standard and the provisional regulation. First, there are four food categories in the new standard. Infant foods are added to the list, based on the FSC recommendation that infants are more vulnerable to radioactive contaminants in food than adults (MHLW 2012b). Second, only cesium radionuclides $\left({ }^{134} \mathrm{Cs}\right.$ and $\left.{ }^{137} \mathrm{Cs}\right)$ are regulated in the new standard. A number of reasons underlined this choice: ${ }^{137} \mathrm{Cs}$ is a typical fission product; ${ }^{134} \mathrm{Cs}$ is expected to be Fukushima's radiocesium signature, and the half-life of cesium is also long, two and 30 years for ${ }^{134} \mathrm{Cs}$ and ${ }^{137} \mathrm{Cs}$, respectively (Merz et al. 2013). Other radionuclides (90Sr, 106Ru, Pu) are not included in the new standard because it takes a long time to measure these radionuclides (MHLW 2012b). In the long-term, radioactive iodine is not considered a

\footnotetext{
26 An emergency exposure situation is defined as 'situations that may occur during the operation of a planned situation, or from a malicious act, or from any other unexpected situation and require urgent action in order to avoid or reduce undesirable consequences' (Clarke and Valentin 2009). Whereas, an existing exposure situation is defined as the exposure situations following emergency exposure situations based on a decision by the government (authorities) (Clarke and Valentin 2009).
} 
concern due to its short half-life. Third, the FSO for radioactive cesium in the new standard is more stringent than in the provisional regulation. Based on Equation 5, in addition to EID, the ratio of contaminated foods (IPF) is also one of the most important determinants in establishing the FSO. Japan uses an IPF of 50\% in the new standard, whereas in the provisional regulation, the IPF is $10 \%$. Consequently, the FSO of cesium in milk and general foods according to the new standard is five times more stringent than the one according to the provisional regulation. Furthermore, the FSO of cesium in drinking water is 20 times more stringent than the one declared in the provisional regulation.

To meet these more stringent FSOs of the new standard, Japan has been monitoring foods and materials for agricultural production, restricting distribution of non-compliance foods, and decontaminating farmland (MHLW 2017a). Food samplings have also doubled from around 130.000 samples to 300.000 samples. These measures were done, even though the monitoring reported that after April 2012, the non-compliance rates of agricultural products, including cereals, vegetables and fruits, meat and milk, fish and fishery products, and edible fungi that were grown on media, were extremely low, i.e., less than 1\%, (MHLW 2017a). The exposure estimation (effective dose) to radioactive cesium in foods $(\mathrm{H})$ is constantly decreasing and is now lower than 1\% of $1 \mathrm{mSv}$ /year (ALOP) (MHLW 2017a). This shows that Japan has been managing to control the risk of internal exposure to be as low as reasonably achievable. In other words, Japan has consistently applied the ALARA (As Low as Reasonably Achievable) principle. Another measure that reflects the application of the ALARA principle is the immediate ban on non-compliant foods. A more extreme measure is that the Japanese government does not immediately withdraw it from the banned list of food whose level of contamination has been discovered to be below the FSO (Matsuzaki et al. 2016). The reason is largely attributed to the public pressuring the Japanese government to ensure that the level of a radioactive contaminant in any food is below half of the FSO, i.e. half of the FSO for cesium (50 Bq/ kg).

The application of the ALARA principle is used due to the low trust Japanese consumers have in the Japanese food safety governance system in the aftermath of the Fukushima nuclear accident and the potential loss of trust from international consumers (Reiher 2017). The principle is also applied in response to potential additional risks, particularly those from the emerging concerns related to the safety of fishery products in the water off the Fukushima prefecture (MAFF 2017). In that respect, the government of Japan has taken a more rigorous monitoring system and enhanced transparency by providing monthly monitoring reports (MHLW 2017b). The risk perception of the people associated with the radioactive contamination is extremely high; thus, even a low level of a radioactive contaminant in food may result in rejection from consumers, even when the level of contamination is the same as the natural background levels of radiation (Kaptan et al. 2017). For that reason, these more 
stringent FSOs in the new standard are still applied, and there is no sign to lower it in the near future.

\subsubsection{The EU}

Following the Fukushima nuclear accident, the European Commission established the Commission Implementing Regulation No 297/2011 (Table 4) that used preestablished FSOs from the Regulation No 3954/87, Regulation No 770/90, and Regulation No 944/89. However, these FSOs are less stringent compared to the FSOs in the Japanese provisional regulation. To comply with the ALARA principle, the European Commission has replaced the Regulation No 297/2011 with the Regulation No 351/2011 (Table 5). The EU adapted the FSOs declared in the Japanese provisional regulation in the Regulation No 351/2011.

The application of the same FSOs as the ones used in Japan has received significant attention from, among others, citizens, non-governmental organizations, and the media for whether the new FSOs provide the same level of protection compared to the previous established FSOs. In response to this concern, the EU Ombudsman has taken action and has requested a further explanation for this change from the European Commission, specifically for them to provide comparative information on the FSOs that specifically relate to the Fukushima nuclear accident in Regulation No 351/2011 (European Ombudsman 2011) and the FSOs in Regulation No 297/2011. After hearing from the EU Commission, the EU Ombudsman closed the inquiries with a conclusion that the FSOs of Regulation No 351/2011 provide a higher level of protection than the FSOs in Regulation No 297/2011. For example, the FSO of radioactive cesium in infant foods in Regulation No 351/2011 is two times more stringent than the one in Regulation No 297/2011. The FSOs in Regulation No $351 / 2011$ are adopted in order to ensure the compliance of imported foods from Japan at the same level of protection (European Ombudsman 2011).

Following the enactment of the new standard in Japan involving more stringent FSOs, the EU again replaced the Regulation No 351/2011 with the Regulation No 284/2012, which adopted the FSOs of the new Japanese standard (Table 7). This measure was not based on science, but mainly on maintaining the trust of the EU consumers. In addition to that factor, there are four additional factors that supported this shift. First, the likelihood of non-compliant foods from Japan in the EU market is reported low since the volume of imported foods originating in Japan to the EU is very low. Second, food controls from Japanese and the EU's food safety authorities $\left(\sum R\right)$ function well, e.g., the ban of any non-compliant foods to be exported to the EU, the attachment of a health certificate and a certificate of analysis (CA) on each consignment, and the additional random controls at the EU border to check for compliance. Third, the potential additional risk $\left(\sum \mathrm{I}\right)$ is negligible. Four, the number of radioactive contaminants in foods in the most affected prefectures in Japan is also a 
very low. Therefore, the actual levels of radioactive contamination in food $(\mathrm{H})$ are much lower than the regulatory limits (FSOs).

\subsubsection{Indonesia}

The government of Indonesia had already established FSOs of radioactive contaminants in foods long before the Fukushima nuclear accident. Those were taken following the Chernobyl nuclear accident in 1986 through the establishment of the Minister of Health Decree No 00474/B/II/87. In reaction to the Fukushima nuclear accident, the government of Indonesia replaced that Decree with the Minister of Health Decree No 031/MENKES/PER/V/2011. Compared to the previous decree, the new decree differs in these following aspects: there are two additional new food categories (foods for infant and general foods), there is a FSO of iodine added along with a FSO of cesium, and some FSOs are much less stringent than the ones in the old decree. For example, the FSOs of cesium in meat and fish are five times less stringent than the ones in the old decree.

This measure was not based on science due to the same factors as those explained in the section on the EU. However, different from the EU and Japan, the implementation of the decree is impaired since the inspection control is currently absent. The decision-making concerning the establishment of an FSO/ALOP in the Minister of Health Decree 031/MENKES/PER/V/2011 was neither based on risk assessment nor the ALARA principle. There is no reference that informs the current ALOP used in the new decree. Despite that, we know that the ALOP used in the old decree is $5 \mathrm{mSv}$ per year (Wahidin 2013). Since there are FSOs in the new decree that have the same value as those in the old decree (milk and drinking water) and less stringent values for the rest of FSOs (Cereals as well as fruits and vegetables), the ALOP in the new decree should be the same as the one in the old decree. Hence, the ALOP is much lower than the one that is applied by Japan, the EU, and the Codex (1 mSv per year). We might assume that the less stringent FSOs are due to the use of a lower IPF in the equation.

The replacement of the Minister of Health Decree No 00474/B/II/87 with the Minister of Health Decree 031/MENKES/PER/V/2011 did not attract a lot of attention from the citizens, compared to when in the EU replaced Regulation No 297/2011 with Regulation No 351/2011. Additionally, according to the recent survey from the Indonesian National Nuclear Agency (BATAN), 77.53\% of Indonesian people accept the existence of nuclear power plants (BATAN 2017). Hence, politically, there is less public pressure in the establishment of an FSO/ALOP in Indonesia compared to the EU and Japan. In other words, the consumer trust is not an important factor that was the basis for the establishment of the new decree. 


\subsection{DISCUSSION}

There is currently no major cause for concern regarding radioactive contaminants in foods in Japan. The level of contamination is very low both at the production and distribution stage, while the actual dose received by the general public from radiation contamination in foods is $0.019 \mathrm{mSV}$ per year, which is much lower than the ALOP of the EU and Japan (1 mSV per year) (Gilmour et al. 2016). In the EU, the ALARA principle aligns with the precautionary principle, which was formulated as a legal definition in Regulation 178/2002 and regarded as a part of the risk analysis methodology (Szajkowska 2010); therefore, it is very natural for the European Commission to use the ALARA principle in the legislation related to radiological protection. In the case of the Fukushima nuclear accident, the EU has decided to use the top-down approach by applying the FSO/ALOP of Japan. The EU justified this measure based on the following two factors: The government of Japan has applied the ALARA principle in addition to conducting a risk assessment in the establishment of the FSO/ALOP.

Based on Equation 5, one of the factors that require attention when establishing FSOs is the ratio of the amount of contaminated, imported foods to the local food factor (IPF). By applying the Japanese FSOs, the EU has implicitly used an IPF of $50 \%$. Hence, the risk has been overestimated. The actual IPF should be much lower than $50 \%$ since the volume of imported foods originating from Japan is very low. An IPF of $10 \%$, as is applied in the Codex Standard and in Regulation No 3954/87 and 297/2011, would be sufficient to provide an appropriate level of protection. Learning from the Chernobyl accident, overestimating risk can be more detrimental than underestimating risk (Tubiana et al. 2009). The EU should, in any case, consider that more stringent FSOs can potentially endanger the availability of certain foodstuffs, particularly in a situation where the actual IPF is high. However, it is unclear how the EU will formulate the FSOs in response to future nuclear incidents, namely whether the EU will use the ones that apply to such emergency situations that is declared in Regulation No 3954/87 or set a new one, which was the strategy applied in response to the Fukushima nuclear accident. Therefore, current more stringent FSOs both in the EU's and Japan's regulation following the Fukushima nuclear accident has resulted in a superfluous level of protection. Despite the determination of an ALOP and FSO is a political decision, The EU and Japan have taken more political factors than scientific assessments into account in the case of the Fukushima nuclear accident. However, this is not against WTO law since, in this case, Japan has determined its FSOs based on a quantitative risk assessment.

The political factor of maintaining consumer trust has been a predominant factor in the decision-making of the FSO/ ALOP in the EU and Japan. In contrast, it is unclear whether Indonesia base the establishment of the FSO/ALOP on political or scientific factors. Nevertheless, the FSOs of Japan, the EU, and Indonesia are more stringent than 
the ones in the Codex Standard. Due to the facts that the risk of a radioactive contaminant in food originating from Japan is negligible and Indonesian consumers are in general quite neutral about the nuclear issue, Indonesia applies a less stringent FSO/ALOP compared to the one in Japan and the EU in the case of the Fukushima nuclear accident. In a situation, where food safety infrastructure and data are limited, the policymakers in Indonesia should rather adopt the international standard (Codex Standard) or risk assessment from other countries as a last resort in establishing the FSO/ALOP based on WTO law and food safety science.

\subsection{CONCLUSION}

Before the Fukushima nuclear accident, Japan did not have any specific regulation on regulatory limits of radioactive contaminants in foods. In the emergency situation following the accident, Japan used provisional regulatory limits and later on replaced them with the new regulatory limits based on a full risk assessment. Contrastingly, the EU, which had existing regulatory limits that apply to such an emergency situation in Regulation No 3954/87, chose to establish a new regulation that applies only to the Fukushima nuclear accident. At first, they used the same regulatory limits, as was detailed in Regulation No 3854/87. However, later on, the EU replaced those with the Japanese provisional regulatory limits. The same measure was also taken by the EU when Japan replaced the provisional regulation with the new standard. Indonesia, however, chose to apply its own regulatory limits, which are less stringent compared to the EU's and Japanese regulatory limits.

Nevertheless, Japan, the EU, and Indonesia apply regulatory limits that are more stringent than the ones in the Codex Standard. The establishment of more stringent regulatory limits by Japan and the adoption of those limits by the EU are both based on the political factor to maintain their citizens' trust. However, their measures are not against the WTO law since they can justify them with a risk assessment. Whereas, Indonesia cannot use the same reason since its measure is not based on a risk assessment. All of those measures potentially provide a superfluous level of protection.

We considered the Fukushima nuclear accident as the best case to test the application of the FSO/ALOP framework for the application in developing countries in a quantitative manner. This becomes possible due to the application of the concept of international radiological protection from ICRP and the concept of Guideline Levels (GLs) from Codex. Besides that, by using the FSO/ALOP framework for the application in developing countries, we can also assess the establishment of the FSO/ALOP by Japan, the EU, and Indonesia for whether they prefer to base their decision-making on politics or science and whether their measures provide a superfluous level of protection. This evaluation is possible due to the fact that these three countries are facing comparable situations, which is to deal with radioactively contaminated foods in the aftermath of the Fukushima nuclear accident, and in a 
situation where the relevant international standard is actually available. Political factors are indeed an important part of determining the ALOP and FSO since the decision is a political one. However, the FSO/ ALOP framework for the application in developing countries urges to consistently establish the FSO/ALOP based on sound science in this political process in order to obtain more effective food safety laws and regulations. 



\section{CHAPTER 4}

\section{HOW TO DESIGN A GENETICALLY MODIFIED FOOD LABELING REGULATION IN INDONESIA BY USING WTO LAW AND FOOD SAFETY SCIENCE}

\section{Dasep WAHIDINa, b, Kai PURNHAGENa}

aLaw and Governance Group, Wageningen University and Research, Hollandseweg 1, PO Box 8130, 6700 EW, Wageningen, The Netherlands; bNational Agency of Drug and Food Control of Indonesia (NADFC), Percetakan Negara, 23, 10560, Jakarta, Indonesia. 


\begin{abstract}
There are shortcomings in the implementation of genetically modified (GM) food labeling regulation in Indonesia. This study assesses how to design a more effective GM food labeling regulation in Indonesia with a focus on the threshold level, scope, and label content. This study proposes a more effective GM food labeling regulation for Indonesia drawing from WTO law and food safety science and in a situation where the international regulation of GM food labeling is absent. The recommendations are to add the voluntary GM $(\mathrm{O})$ free labeling scheme along with the existing mandatory labeling scheme, to maintain the $5 \%$ threshold level with the addition of an appropriate traceability system, to limit the scope by adding sophisticated labeling exemptions, and to include only three major GM ingredients on the label.
\end{abstract}

Keywords: food safety, regulation, GM food, FSO/ALOP, Indonesia 


\subsection{INTRODUCTION}

Similar to other countries that ratified the Cartagena Protocol on Biosafety, Indonesia applies the precautionary approach in regulating genetically modified (GM) food. ${ }^{27}$ As one of the biggest importers of GM foods in the world, Indonesia put in place a GM food labeling regulation in its national legal system (USDA 2015b). The current regulation is inspired by the corresponding regulation in Japan (Gruère et al. 2009). The GM food labeling regulation in Indonesia is partially implemented (Gruère and Rao 2007). This thesis assesses how to improve the GM food labeling regulation in Indonesia, drawing WTO law and food safety science and in a situation where the international regulation of GM food labeling is absent (CAC 2016b).

This study proposes a more effective GM food labeling regulation in Indonesia by using the FSO/ALOP framework for the application in developing countries (Wahidin and Purnhagen 2017). To achieve this aim, we first illustrate the current regime of GM food control in Indonesia. Subsequently, based on the FSO/ALOP framework, we conduct a comparative law study of the GM food labeling regulations in Indonesia, The EU, The US, Japan, Malaysia, and China and evaluate the GM food labeling regulation in Indonesia to determine its loopholes. Finally, to remedy these identified loopholes, we propose recommendations for the design of a more effective GM food labeling regulation to be applied in Indonesia.

\subsection{TERMINOLOGICAL CLARIFICATION}

As with any interdisciplinary study, terminological clarification is essential to avoid confusion with overlapping or alternative terminology. Therefore, we use primarily the default jargon and terminology of Indonesian law as the main authority where available. Indonesian relevant law is meant to comply with WTO law; thus, we will revert to WTO law where the Indonesian law is incomplete. Wherever suitable, we will also refer to the terminology as used in other official documents such as the Codex Alimentarius Procedural Manual and the Cartagena Protocol on Biosafety (CAC 2016a). If this terminology deviates from the one used in WTO law, we will explicitly highlight this deviation. Subsequently, we will illustrate the key concepts used in our paper. We use the term of the ALOP as defined in the WTO Agreement on the Application of Sanitary and Phytosanitary Measures (SPS Agreement), Annex A, paragraph 5 as "the level of protection deemed appropriate by the Member establishing a sanitary or phytosanitary measure to protect human, animal or plant life or health within its territory." If we refer to the Food Safety Objective (FSO), we adopt the meaning introduced in the Definition of Risk Analysis Terms Related to Food Safety in Section 4 of the Codex Alimentarius Procedural Manual: an FSO is "the maximum frequency and/or concentration of a hazard in a food at the time of

27 UU No 21 Tahun 2004 tentang Ratifikasi Cartagena Protocol on Biosafety to the Convention of Biological Diversity. Translated by D. Wahidin. 
consumption that provides or contributes to the appropriate level of protection (ALOP)." According to De Swarte \& Donker, the FSO/ALOP-based food safety policy consists of four major phases (De Swarte and Donker 2005): 1. Risk assessment, 2. Setting ALOPs and FSOs, 3. Translating risk management to process management, and 4. Feedback on risk assessment and risk management when starting a new cycle or consolidation. When we use the term "risk", we refer to Art. 5 (1) of the SPS Agreement, which requires using the definition as determined by Codex. The definition of risk analysis terms related to food safety in Section 4, stipulates that "risk" is to be understood as a "function of the probability of an adverse health effect and the severity of that effect, consequential to a hazard(s) in a food".

\subsection{GM FOOD CONTROL IN INDONESIA}

\subsubsection{The Indonesian ALOP for GM Food}

The determination of an ALOP should not be illustrated in isolation from the measures achieving it, as the degree of risk also influences the degree of protection to be taken (De Swarte and Donker 2005). For that reason, we will illustrate the combination of the ALOP and the corresponding law and regulations in Indonesia. When foods are produced in Indonesia, food manufacturers must comply with all requirements embedded in Food Law No 18/2012 (hereafter Food Law). According to this law, they must adhere to good manufacturing practices (GMP) and on a voluntary basis adhere to principles of Hazard Analysis Critical Control Points (HACCP). The ALOP that these food safety management systems (FSMS) is expected to deliver, however, has not been defined in quantitative terms (van Schothorst et al. 2009).

Food Safety is a condition and effort that is required to eliminate biological, chemical and other hazards in food that can interfere, harm or endanger the human health and also do not conflict with the religions, beliefs and culture of the society so that it is safe for consumption. ${ }^{28}$

The Food Law has been established as a horizontal legislation, which is comparable to the EU's General Food Law (GFL). ${ }^{29}$ Article 67 (1) of the Food Law states, "food safety is implemented to maintain food to be safe, hygienic, excellent, nutritious, and not in conflict with religion, belief, and culture." 30 Article 68 (1) of the Food Law stipulates the role of government in the food safety area in the sense that "the central government and the local government have to ensure the implementation of food safety along the supply chain." 31 Moreover, the Food Law stipulates that the "implementing regulation

\footnotetext{
28 UU No. 18 Tahun 2012 tentang Pangan, Pasal 1 Ayat 5. Translated by D. Wahidin.

29 Regulation (EC) No 178/2002 of the European Parliament and of the Council of 28 January 2002 laying down the general principles and requirements of food law, establishing the European Food Safety Authority And laying down procedures in matters of food safety. OJ L 31/1, 1 February 2002.

30 Translation by D. Wahidin.

31 Translation by D. Wahidin.
} 
of this Law must be stipulated at the latest 3 (three) years since the promulgation of this Law." There is a violation of this provision since the establishment of implementing rules has been pending since 2012, which consequently means that the outdated implementing rules are still in use. ${ }^{32}$ Furthermore, with respect to GM food, chapter 4 of the Food Law is specifically dedicated to regulating the safety aspect of GM foods. Article 1 (33) of the Food Law defines GM food as "food that is produced from, or that uses raw materials, additives, and/or other materials that are produced from a genetically engineered process." 33 GM food is, according to Article 77 (1) and (2) of the Food Law, subject to pre-market approval: "anyone who has not obtained food safety approval prior to a product's distribution is prohibited from producing food obtained from a genetically engineered process" 34 and "anyone who carries out a food production process or food production activity is prohibited from using raw materials, food additives, and/or other materials produced from a genetic modification process, who has not obtained food safety approval before the product is distributed." 35 In addition, according to Art. 14 (1) of the Government Regulation No 28/2004 on Food Safety, Quality, and Nutrition, food producers have the responsibility to ensure the safety of GM food: "Everybody producing food or using raw materials, food additives and/or other auxiliary materials in the production activities or processes of food resulting from genetic engineering shall examine first safety of the food before the distribution." Article 79 (1) of Food Law then defines the shared responsibility for the enforcement of these regulations stands between the businesses and the government: "If food businesses do not comply with the implementing rules related to GM food, the government has every right to apply sanctions." 36

Apart from the food law, there is the Government Regulation No 21/2005 to implement the Cartagena protocol. This protocol binds Indonesia by international law to follow a precautionary approach in the area of Biosafety. Hence, the application of the precautionary approach in the regulation of genetically modified organisms (GMO) is expressed in Article 3 of the Government Regulation No 21/2005 on Biosafety of Genetically Modified Products. ${ }^{37}$ Furthermore, the Regulation also assigns and frames the responsibilities of the relevant authorities (Figure 4): the Ministry of Agriculture is responsible for the authorization of feed safety approval and commercialization of GM feed, whereas the National Agency of Drug and Food Control (NADFC) is responsible for the authorization of food safety approval and

32 Peraturan Pemerintah No 28 Tahun 2004 tentang Keamanan, Mutu, dan Gizi Pangan. Tranlated by

D. Wahidin.

33 Translation by D. Wahidin.

34 Translation by D. Wahidin.

35 Translation by D. Wahidin.

36 Translation by D. Wahidin.

37 Peraturan Pemerintah No. 21 Tahun 2005 tentang. Translated by D. Wahidin. 
commercialization of GM food. The NADFC to date has released 21 Food Safety Approvals for GM food (GM food distribution decree) (NADFC 2017a).

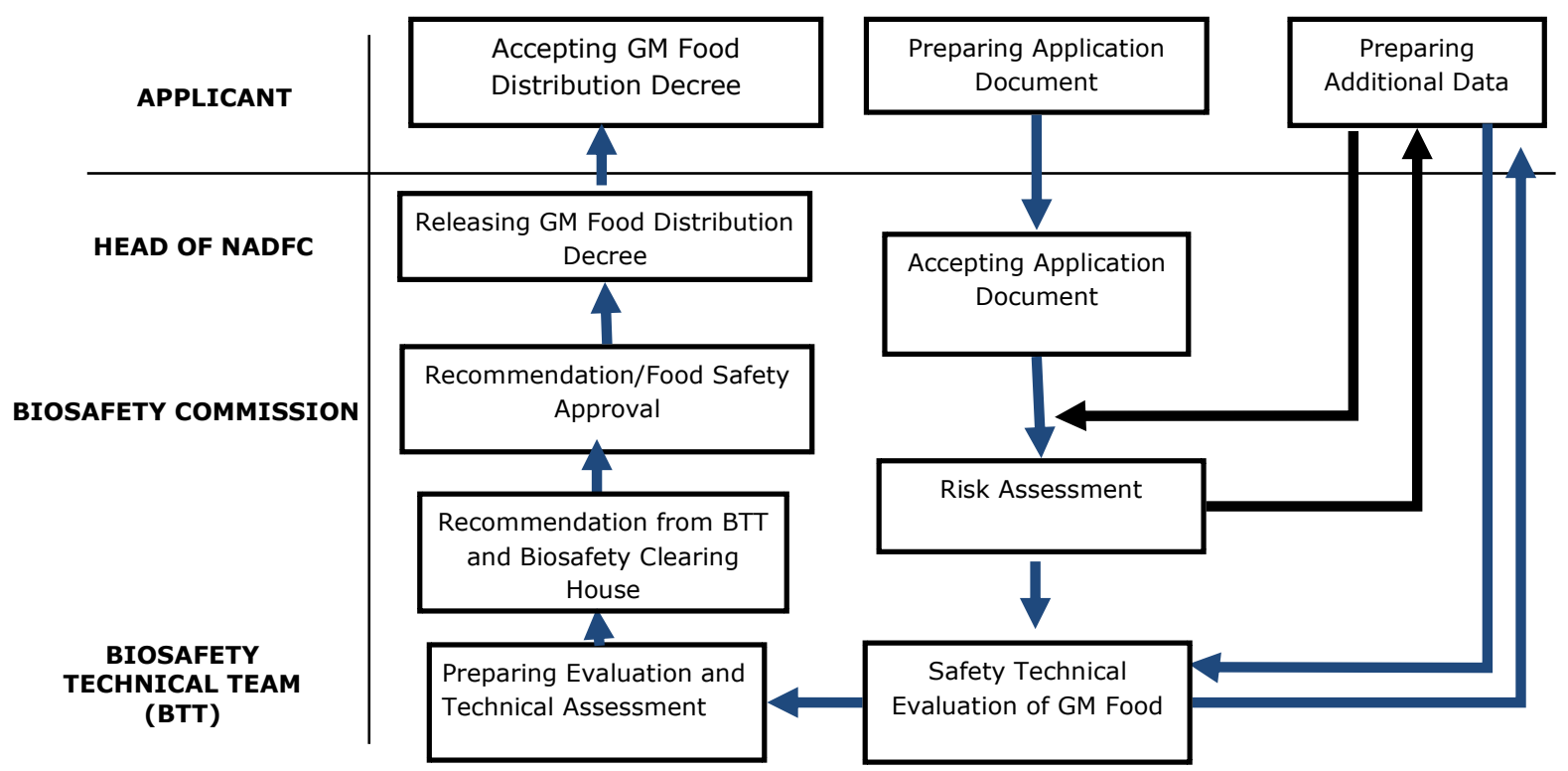

Figure 4. Authorization procedure of GM food in Indonesia.

After the authorization, the labeling requirement for conventional food is also applied to GM food. However, Article 35 of Government Regulation No 69/1999 on Food Labeling and Advertisement (hereafter the Food Labeling Regulation) ${ }^{38}$ stipulates that GM food must be additionally labeled as "Pangan Rekayasa Genetika" ("Genetically Modified Food"). ${ }^{39}$ According to Article 2 of Food Labeling Regulation, this labeling requirement only applies to packaged foods.

Indonesia has set a public health goal of GM food in Article 2 of the Government Regulation No 21/2005 "to improve [the] efficiency and effectiveness of Genetically Modified product use for people's welfare based on the principle of health and biological resource management, consumer protection and certainty the operating business." 40 However, the regulation does not specify how to assess these welfare applications, whether by qualitative or quantitative analysis or simply by political decision. A more detailed description that refers to the public health goal of GM food labeling is stated in the Head of NADFC Decree No. HK.03.1.23.03.12.1564 of 201241 (hereinafter Decree): "people are in need of protection from any substandard GM food and they are also in need to be protected from any misleading information concerning GM food via the labeling." Hence, one may resort to the general legal principle Lex specialis derogat legi generali, by which the special law or regulations shall be applied with priority before the more general ones. In this respect, the Decree shall be applied

\footnotetext{
38 Peraturan Pemerintah No. 69 Tahun 1999 tentang Label dan Iklan Pangan. Translated by D. Wahidin.

39 Translation by D. Wahidin.

40 Translated by D. Wahidin.

41 Peraturan Kepala Badan POM No. HK.03.1.23.03.12.1564 of 2012 tentang Pengawasan Pelabelan Pangan Produk Rekayasa Genetik. Translated by D. Wahidin.
} 
first in the case of GM food labeling. The Decree defines GM food as food that is produced from or contains food, a raw material, or a food additive that is produced from GM techniques. The Decree covers processed foods, raw materials, and food additives that are produced from or uses GM ingredients. The labeling requirements cover both domestic and imported products in addition to pre-packaged and non-prepackaged products. However, the mandatory labeling applies only to food that contains more than 5\% of GM ingredients based on the percentage of GM deoxyribonucleic acid (DNA) to non-GM DNA. Where there is more than one GM ingredient, the percentage is calculated to each individual GM ingredient. The labeling requirement applies to all GM foods, except for GM foods that have undergone an extensive refining process such that no GMO protein can be identified in the end product, such as but not limited to oil, fat, sugar, and starch. Next, all GM ingredients must be listed on the label. Finally, there are administrative sanctions ranging from a warning to a retraction of a distribution decree for any violation of the GM food labeling requirements.

\subsection{FSO/ALOP ANALYSIS}

Based on the FSO/ALOP framework as previously developed by the authors. ${ }^{42}$ The framework can be used to design more effective food laws and regulations under the following ideal conditions:

1. The regulation falls under the regime of the WTO law (SPS Agreement), or

2. The regulation is not yet regulated by a recognized international standard or goes beyond this, or

3. There is insufficient epidemiological data for the conduct of an FSO/ALOP analysis (data-poor environment).

It is not clear, however, whether GM food labeling is subject to the SPS regime or the General Agreement on Tariffs and Trade 1994 (TBT Agreement). ${ }^{43}$ When viewed in isolation, GM food labeling regulation is more technical- than product-related. One could, therefore, argue that it is subject to the TBT Agreement. Nonetheless, countries regularly challenge each other's GM food labeling regulation on more stringent requirements by applying the SPS Agreement rather than the more flexible provisions in the TBT Agreement (Stilwell 1999). This view is also supported in Annex A.1 of the SPS Agreement concerning "approval procedures (...) and packaging and labeling requirements directly related to food safety." Moreover, the mechanism of the precautionary approach in the SPS Agreement can also be applied under this criterion to further justify the acceptable level of risk related to full disclosure of GMOs in a food label. ${ }^{44}$ To this end, there are no internationally-agreed recommendations on the food labeling of GM food. The "draft Recommendations for the Labeling of Foods and Food

42 Ibid., at 7.

43 Agreement on Technical Barriers to Trade, Jan. 1, 1995, 1868 U.N.T.S. 120.

44 Art. 5.7 of the SPS Agreement. 
Ingredients Obtained through Certain Techniques of Genetic Modification/Genetic Engineering" is currently in step 3 of re-drafting by the Working Group of Codex Committee on Food Labeling (CCFL) (MacKenzie 2000). Data of long-term adverse health effects of GM food are not available yet.

The management model for developing the FSO/ALOP for the application in developing countries (Figure 3) was used in this study to analyze the coverage, threshold, and label content in the GM food labeling regulation of Indonesia, the EU, the US, Japan, Malaysia, and China. These three elements represent the stringency of the ALOP. They were assessed by using a management model for developing the FSO/ALOP for the application in developing countries. At the governmental level, the first step is to make a risk profile by implementing a qualitative risk assessment. Next, the risk estimate from the risk profile is assessed together with socioeconomic factors. If the government is willing to accept the risk estimate (risk level), then it becomes the ALOP. Afterward, the government should translate the ALOP to an FSO, which is then referenced in laws or regulations to be legally mandatory. At the level of the food chain, food businesses can use the FSO directly or set a performance objective (PO) that is equivalent to the FSO as the target of a food safety management system (FSMS) through a performance criterion (PC). The operators are required to evaluate internally whether the PC has achieved the PO or FSO and to execute corrective and preventive actions for any failure. Finally, periodically the food safety authority can verify whether the PC meets the PO or FSO, do an evaluation for any failure, and make any necessary revisions to its ALOP or FSO.

\subsubsection{Risk Profile}

In the context of the FSO/ALOP framework, a risk profile should be based on a qualitative risk assessment informed by data resulting from a hazard analysis, the assessment of all relevant information, and the description of the food safety problem on the ground and concluded as a risk estimate, which is the combination of the hazard's adverse health effect and exposure level (concentration or percentage of GM ingredients in a food product and the mass of consumption of the GM food). Based on that risk estimate, the government can take further actions either to accept this risk estimate as the level of risk or to take no action, by also weighing socioeconomic factors. If the government decides to take further action, then a quantitative risk assessment has to be done to establish a quantitative risk estimate. If the government accepts this risk estimate as the acceptable level of risk, then it becomes the ALOP. Moreover, the government can also decide to reduce the level of acceptable level of risk in a certain time frame. This level becomes the future ALOP.

However, to do a full risk assessment and later on determine an FSO/ALOP for GM food is unattainable due to the lack of scientific evidence on the adverse health effect of GM food in the long term. When in this situation, governments can take the precautionary approach until there is sufficient scientific evidence for the conduct of a 
full risk assessment. This strategy is also applied to the issue of GM food disclosure that is focused on labeling. In the case of GMO health risk, GM foods may cause an allergic reaction (allergenicity), gene transfer and/or outcrossing (WHO 2014). Thus, it has the potential to be a food safety hazard. However, there is still a lack of evidence for the adverse health effect of GM food in the long term (Bawa and Anilakumar 2013). Besides that, there are two parameters that need to be assessed from the exposure aspect: the amount of GM food present in the food chain and the amount of GM food that is consumed.

\subsubsection{The Determination of an ALOP}

In general, the government can choose between a top-down or bottom-up approach when determining an ALOP (Figure 3). A bottom-up approach describes a process where policymakers harvest their own data, carry out their own risk assessment, and eventually design their own risk management options. Whereas, in the top-down approach, decision-makers rely on foreign data, such as risk assessments or other measures of relevant issues from international organizations or other countries. Both approaches carry specific strengths and weakness (Wahidin and Purnhagen 2017). Even though to date there is no available international standard on the issue of GM food labeling, there are abundant references via the GM food labeling regulations of many countries across the world.

In a situation where epidemiological data is lacking or even absent, resources are also limited, and the relevant international standard is also absent, a top-down approach is more appropriate with regard to the determination of a ALOP. This is the case for the GM food labeling issue in Indonesia. Therefore, we used a comprehensive comparative analysis of the regulations of several countries in order to provide recommendations for an FSO/ALOP-based GM food labeling regulation in Indonesia. The following countries are included in the comparative analysis: EU, USA, Malaysia, Japan, and China. The EU and the US, being the major trading partners in the world, represent the barometer for policies on the labeling of GM food worldwide. Malaysia is one of the closest neighboring countries in the ASEAN region and one of Indonesia's most important trade partners (World Bank 2014). Japan represents a developed country with a valuable market and is also an important trade partner for Indonesia. The last country included in the analysis is China, which represents one of the biggest consumers of GM foods. We interpreted the ALOP of these countries qualitatively, based on the existing relevant GM food labeling regulations.

1. The European Union

The EU's ALOP concerning GMOs is to "provide the basis for ensuring a high level of protection of human life and health, animal health and welfare, environment and consumer interests in relation to genetically modified food and feed, whilst 
ensuring the effective functioning of the internal market." 45 To achieve this, the EU has implemented inter alia a co-existence policy of GM and non-GM products, which is governed by an information paradigm (Purnhagen and Wesseler 2016b). The labeling of GMOs is currently regulated by Directive 2001/18/EC. ${ }^{46}$ In addition, specific labeling requirements for food containing, consisting of, or produced from GMOs are stipulated in Regulation (EC) No 1829/2003. The labeling of GM food is mandatory in the EU. This mandatory labeling scheme relies on a dedicated system of traceability established by Regulation (EC) No 1830/2003. ${ }^{47}$ However, Articles 12 states that these labeling requirements shall not apply to food containing material that contains, consists of, or is produced from GMOs in a proportion no higher than $0.9 \%$ of the food ingredients considered individually or food consisting of a single ingredient, provided that this presence is adventitious or technically unavoidable. Though, the regulation does not have an impact on the sale of food labeled as genetically modified. The sale is mainly driven by consumer demand and a food producer's and retailer's policy (EU Commission 2006). The frequency of non-compliance with the food labeling requirements of the regulation across the EU may be estimated below 2\% (113 out of 7129 analyzed samples) (EU Commission 2006). This is a very small percentage of violations. From the enforcement perspective, the regulation has been applied appropriately by authorities across the EU.

The EU's regulation uses a more process-based approach for all GM products. In other words, every food and feed containing, consisting of, or produced from GMO shall be labeled as GM food. The notion of "produced from" means that even if the end product no longer contains or consists of GMOs, the food is still required to be labeled as GM food. However, the labeling requirement is exempted for a product that is produced with GMOs. Thus, processing aids and food products deriving from animals being fed GM feed are exempted from the labeling requirement. Moreover, the regulation stipulates a traceability system that is managed by transmitting information in writing among operators along the supply chain of food and feed if their product contains or consists of GMOs and puts an embedded unique identifier.

There is a coexistence principle in the EU's GM labeling regime, which refers to the choice of consumers and farmers between conventional, organic and GM crop production. In other words, the coexistence is carried out to segregate GM and non-

45 Art. 1 (a) Regulation (EC) No 1829/2003 of the European Parliament and of the Council of 22 September 2003 on genetically modified food and feed (Text with EEA relevance). Official Journal L 268, 18/10/2003 P. 0001 - 0023.

46 Directive 2001/18/EC of the European Parliament and of the Council of March 12, 2001 on the deliberate release of genetically modified organisms into the environment and repealing Council Directive 90/220/EEC -Commission Declaration. OJ L 106, 17.4.2001, p. 1-39

47 Regulation (EC) No 1830/2003 of the European Parliament and of the Council of September 22, 2003 concerns the traceability and labeling of genetically modified organisms and the traceability of food and feed products produced from genetically modified organisms and amends Directive 2001/18/EC. OJ L 268, 18.10.2003, p. 24-28. 
GM crops. Though, there is always a possibility of the adventitious presence of GM events in conventional foods. ${ }^{48}$ In this situation, the EU has established a threshold level of $0.9 \%$ for authorized GM foods, $0 \%$ for non-authorized GM foods, and $0.1 \%$ for GM feeds. These thresholds also act as an exemption if the food contains or consists of a GM event below the threshold level. If an operator can prove that the presence of a GM event is adventitious, then it is exempted from the labeling requirement.

These strict threshold levels and additional provisions on the adventitious presence of a GM event have affected GM food industries in the EU (Purnhagen and Wesseler 2016a). The food businesses in the EU produce only a small amount of GM crops and use less or even no GM ingredients in their food products. The food businesses in the EU have been avoiding GM food in their production. Hence, there are only a small number of GM foods circulating in the EU market. Despite that, the EU remains one of the biggest importers of GM foods in the world, particularly for soybean commodity. In 2013, The EU imported 18.5 million tons of soymeal and 13.5 million tons of soybean; most of these imports come from countries where GM crops are widely cultivated (EU Parliament 2015).

Those strict requirements within the GM food mandatory labeling regulation in the EU, such as a process-based approach, a comprehensive traceability system, a wide coverage of products, and a strict $0.9 \%$ threshold level, certainly provide the consumer with information, but it is still not clear whether this information meets the objective of preserving consumer informed choice (DG SANCO 2010). Besides the mandatory labeling for GM food, there is no voluntary $\mathrm{GM}(\mathrm{O})$-free labeling scheme at the EU level. Nevertheless, there are several Member States that facilitate a voluntary GM(O)free labeling scheme in their national legislation, such as Germany, France, and the Netherlands. The Commission has observed that in most of those Member States such national rules stipulate that the threshold level of the adventitious, technically unavoidable presence of GM material in $\mathrm{GM}(\mathrm{O})$-free products should be below the level of detection of the current analytical methods (DG SANCO 2010).

2. The United States of America

The US is one of the biggest producers and exporters of GM food in the world. For example, according to the USDA report, the acreage of GM soybeans in the USA was going up significantly from 17\% in 1997 to 68\% in 2001 and 94\% in 2014, 2015, and 2016; in 2015, the US exported soybeans to the top five destination countries: China, Mexico, Indonesia, Japan, and Taiwan (Fernandez-Cornejo and Wechsler 2014; USDA 2015d). The Food and Drug Administration (FDA) considers GM food as, to a large extent, equivalent to its conventional counterpart. Hence, there is no specific regulation for GM food labeling at the federal level. The FDA requires that GM foods, in principle, meet the same requirements as their conventional counterparts, including

48 GM event is a unique DNA recombination event that took place in one plant cell, which was then used to generate entire transgenic plants. 
the ones for labeling requirements. Despite that, the FDA has issued a non-binding policy in the form of guidance for industries regarding voluntary non-GM food labeling in November 2015. ${ }^{49}$ However, the guidance has yet to put in detail the threshold or scope. It simply provides guidance for industries in determining whether a food may containing GM ingredients is misbranded. The guidance also reaffirms the application of a product-based approach towards a GM food labeling policy under the FDA, with a focus on how to use the products rather than on the genetic engineering techniques used to produce them (Lau 2015).

There are two sections within the Federal Food, Drug, and Cosmetic Act (FFDCA) that might affect the FDA's policy on GM food labeling: Sections 403 and 201. In Section 403 (a) of the FFDCA states that food shall be deemed misbranded if its labeling is false and misleading in any particular way. In addition, Section 403 (i) of the FFDCA requires each ingredient to be stated on the label by its common name. Thus, if a GM food significantly differs from its conventional counterpart, then it is no longer appropriate to be called by its common name. Hence, the name of the GM food should be stated differently on the label. Section 201 of the FFDCA states that food shall be alleged to be misbranded if the labeling is misleading and fails to reveal material facts. Although there is no definition in the FFDCA for "material", in the guideline the FDA defines "material" as something that (1) poses special health risks, (2) misleads the consumer in light of other statements made on the labeling, and (3) lets consumers assume it has the same nutritional, organoleptic, and functional characteristic as other foods similar it, when in fact it is not true. Hence, GM food is not regarded as "material" that needs to be labeled differently from its conventional counterpart.

Some states, such as Vermont and Maine, have tried to apply mandatory labeling for GM foods. However, in July 2016 the US Congress enacted and later on President Obama approved the National Bioengineered Food Disclosure Standard or Genetically Engineered (GE) Disclosure Law that pre-empts the implementation of the aforementioned state and/or local laws. The law stipulates the mandatory labeling of GM foods and foods containing GM ingredients. ${ }^{50}$ However, there are several issues concerning this law that needs to be highlighted. First, the law orders the USDA to establish a national mandatory bioengineered food disclosure standard ${ }^{51}$ that may overlap with the regulation of the FDA. The law applies to bioengineered food and food that may be bioengineered, whereas the FDA does not consider bioengineered food as "material"; therefore, it does not require disclosure. Besides that, there is an

\footnotetext{
49 US-FDA. 2015. Guidance for Industry: Voluntary labeling indicating whether foods have or have not been derived from Genetically Engineered Plants. Docket No. FDA-2000-D-0075 for commenting starting 24 November 2015.

50 Public Law 114-216, 130 Stat. 834-839 (2016), amending the Agricultural Marketing Act of 1946 by adding Subtitles E and F, codified at 7 United States Code [USC] §§ 1639-1639c, §§ 1639i-1639j, § 6524. 517 USC $\S 1639 b$ (a) (1).
} 
option of disclosure via electronic digital links within the law that has a potential to overlap with the FDA's labeling regulation, which requires a disclosure to appear on food labels (Grossman 2016). The second issue is related to the definition of bioengineered food. The definition only covers the word "contain", meaning that the law does not cover food that is produced from a bioengineering process where the genetic material does not exist anymore, like for highly refined foods (oils, fats, sugars, etc.). ${ }^{52}$ Despite those issues, the GE disclosure law may not only bring significant change to the US's GM food labeling regime but also affect other countries. As further technical arrangements for GM food labeling, a national standard and procedures necessary for implementation shall be formulated by the Agricultural Marketing Service (AMS-USDA) no later than two years after the enactment of the GE disclosure law. Therefore, there is currently no available national standard and procedure that stipulates threshold level, scope, exemption, product or process-based, among other things.

\section{Japan}

GM crops are not commercially planted in Japan (Library of Congress 2015). Despite that, Japan is the third largest soybean importer in the world (Yamaura and Xia 2010). Soybeans for human consumption accounts for only $22 \%$ of the total imported soybean amount in Japan, and only non-GM soybeans are used for human consumption (Yamaura and Xia 2010). Japan started to label GM food in 2001 according to the quality labeling standard (hereafter referred to as the Japanese Food Labeling Standard) under the Food Sanitation Act and the Act for Standardization and Proper Labeling of Agricultural and Forestry Products (hereinafter referred to as the "JAS Law") (CAA 2011). The standard uses the identity preserve handling as the key measure to determine the type of labeling, i.e., whether "not genetically modified" or "genetically modified", etc. The labeling requirement is not applied to the nongenetically modified food that undergoes identity preserve handling; furthermore, operators have the right to put "not genetically modified" labeling voluntarily (CAA 2011). The difference lies in the segregation between GMOs and non-GMOs at each stage of production (CAA 2011).

Japan uses a more product-based approach, which places more emphasis on GM foods and the way they are used rather than on the genetic engineering process used to produce them. In other words, even though a product consists or contains GM ingredients, if there is no GM-DNA found in the final product, then the labeling requirement is not applied. Furthermore, Japan uses a 5\% threshold level for GM food labeling, meaning that food that consists or contains less than 5\% of GM ingredient is exempted from the GM labeling requirement. Moreover, the labeling requirement is only applied to seven "designated genetically modified agricultural products" and 32

527 USC § 1639. 
processed foods, which contain the "designated genetically modified agricultural products" (USDA 2016). Within the list, soybeans and soybean-based processed foods are the most prominent. Besides the mandatory labeling scheme, Japan also applies the voluntary $\mathrm{GM}(\mathrm{O})$-free labeling scheme and use the same 5\% threshold as the mandatory scheme.

4. Malaysia

Although soybean imports from the US to Malaysia have been increasing in recent years, these soybeans are not intended for human consumption. Soybeans for human consumption account for only $25 \%$ of the total imported soybeans (USDA 2015c). Malaysia also imports non-GM soybeans, but not from the US (USDA 2013). Moreover, there is no GM crop that has been approved for planting, and only a small amount of maize and soybean GM events have been authorized for import and commercialization, which results in fewer objects requiring labeling enforcement (USDA 2013). The Prime Minister of Malaysia, Mr. Badawi, pointed out that "while Malaysia is aware that biotechnology holds much promise, we are also concerned that biotechnological products should not pose any threat to the environment, or to human health and safety" (NRE-Malaysia 2008). This statement reflects Malaysia's current policy towards GM food, which relates to their labeling regulation.

In July 2014, Malaysia enforced their regulation on GM food labeling (MoH 2014). The regulation is based on the Biosafety Act of 2007 and Food Regulation of 1985, which was amended in 2010 to enforce GM labeling. According to the Ministry of Health of Malaysia, a GMO is defined as "an organism in which the genetic material has been changed through modern biotechnology in a way that it does not occur naturally by multiplication or natural recombination or both." GM food labeling is mandatory in Malaysia. Moreover, Malaysia uses a more process-based approach for GM food labeling. Thus, the scope of the labeling becomes quite wide, covering all foods that are composed of or contain GM ingredients and foods that are produced from a GMO but do not contain a GMO in the final product. Despite that, there are exemptions to the GM food labeling requirement:

a. Food that contains GM ingredients by less than $3 \%$, provided that this presence is adventitious;

b. Highly refined foods, such as refined oil, plant sterol, boiled sweet, sugar, corn syrup, honey, and dextrin (other than that with *altered characteristics);

c. Processing aids and food additives (e.g., dextrin), acidic foods (e.g., pickles and vinegar), and salty foods (e.g., soy sauce) when novel DNA and/or novel protein is not present in the final food;

d. Food from animals being fed with GM animal feed (e.g., meat, milk, eggs);

e. Foods produced from fermentation using GMM (genetically modified microorganisms) not present in the final products (e.g., vitamins, amino acids); 
f. Foods produced by a GM enzyme (e.g., cheese, bakery products produced with amylase).

In spite of these exemptions, there is no labeling exemption for foods that contain, consist of or are produced from a GMO whose genes are derived from an animal or substance that may cause hypersensitivity. There is also no labeling exemption for highly refined foods with altered characteristics, i.e. a significant composition or nutrition difference with its conventional counterpart, significant anti-nutritional factors or natural toxicants with its conventional counterpart, produced allergens, a different intended use than its conventional counterpart.

\section{China}

China is the largest importer of GM crops in the world, but it has not yet approved any GM food for cultivation (USDA 2015a). This is in line with the remark from China's President, Xi Jinping, assuring governmental support for biotechnology research, while at the same time calling for a cautious approach to commercialization (USDA 2015a). In terms of labeling, China applies the mandatory approach and uses a $0 \%$ threshold level. Next, the scope is based on the short list in the Ministry of Agriculture's catalog (Wong and Chan 2016). Similar to the EU, Malaysia, and Japan, the approval for commercial cultivation of GM crops is minimal. Despite that, the implementation of mandatory GM food labeling is not effective in China, which is reflected by its weak enforcement of the regulation (Zhu et al. 2016). This is due to the application of a $0 \%$ threshold level, which is not feasible because of the technical constraints, such as the capacity for laboratory analysis, the weak commitment of the food safety authorities, and the low compliance of the food businesses.

Table 11. Comparison matrix of GM food labeling regulations in the EU, the US, Japan, Malaysia, China, and Indonesia

\begin{tabular}{|l|l|l|l|l|}
\hline Country & $\begin{array}{c}\text { Nature of } \\
\text { Labeling }\end{array}$ & $\begin{array}{c}\text { Product/ } \\
\text { Process }\end{array}$ & \multicolumn{1}{|c|}{ Scope } & Threshold \\
\hline The EU & Mandatory & Process & $\begin{array}{l}\text { Covers all GM foods, except for foods } \\
\text { with GMO traces that are no higher } \\
\text { than 0.9\% of the individual ingredient } \\
\text { and where the operator can } \\
\text { demonstrate to the competent } \\
\text { authority that they have taken } \\
\text { appropriate steps to avoid the } \\
\text { presence of GM material. Besides that, } \\
\text { it covers meat, milk or eggs obtained } \\
\text { from animals fed with GM feed or } \\
\text { treated with GM medicinal products }\end{array}$ & $\begin{array}{l}0.9 \% \text { of } \\
\text { authorized } \\
\text { GM foods } \\
\text { and 0\% of } \\
\text { unauthorized } \\
\text { GM foods } \\
\text { and 0.1 of } \\
\text { unauthorized } \\
\text { GM feed. }\end{array}$ \\
\hline
\end{tabular}




\begin{tabular}{|c|c|c|c|c|}
\hline The US & $\begin{array}{l}\text { Voluntary } \\
\text { or } \\
\text { mandatory }\end{array}$ & Product & All GM foods based on content. & $\begin{array}{l}\text { (To be } \\
\text { determined } \\
\text { by USDA } \\
\text { before July } \\
2018 \text { ) }\end{array}$ \\
\hline Japan & $\begin{array}{l}\text { Mandatory } \\
\text { and } \\
\text { Voluntary }\end{array}$ & Product & Limited list of foods & $5 \%$ \\
\hline Malaysia & Voluntary & Product & $\begin{array}{l}\text { Covers all GM foods, except for foods } \\
\text { with GMO traces that are no higher } \\
\text { than } 3 \% \text { of the individual ingredient } \\
\text { and where the operator can } \\
\text { demonstrate to the competent } \\
\text { authority that they have taken } \\
\text { appropriate steps to avoid the } \\
\text { presence of GM material as well as } \\
\text { highly refined foods e.g., refined oil, } \\
\text { plant sterol, boiled sweet, sugar, corn } \\
\text { syrup, honey, and dextrin (other than } \\
\text { that with *altered characteristics). The } \\
\text { following are exempted when novel } \\
\text { DNA and/or novel protein is not } \\
\text { present in the final food: processing } \\
\text { aids and food additives (e.g., dextrin), } \\
\text { acidic foods (e.g., pickles and } \\
\text { vinegar), salty foods (e.g., soy sauce), } \\
\text { food products derived from animals } \\
\text { fed with GM animal feed (e.g., meat, } \\
\text { milk, eggs), foods produced from } \\
\text { fermentation using GMM (genetically } \\
\text { modified microorganisms) not present } \\
\text { in the final products (e.g., vitamins, } \\
\text { amino acids), and foods produced by } \\
\text { a GM enzyme (e.g., cheese, bakery } \\
\text { products produced with amylase). }\end{array}$ & $3 \%$ \\
\hline China & Mandatory & Process & Limited list of foods & $0 \%$ \\
\hline $\begin{array}{l}\text { Indonesi } \\
\text { a }\end{array}$ & Mandatory & Product & $\begin{array}{l}\text { Highly refined foods, including but } \\
\text { not limited to oils, sugars, fats, or } \\
\text { starches are exempted }\end{array}$ & $5 \%$ \\
\hline
\end{tabular}

\subsubsection{The Translation of an ALOP to a FSO for Indonesia}

As revealed in subchapter 4.2, an ALOP is not very useful for food safety authorities nor the food businesses to exercise food safety controls. Thus, the ALOP should be first 
translated into a more technical terminology that defines the maximum concentration of a hazard in a food at the point of consumption. This level is referred in the FSO/ALOP framework as the food safety objective (FSO). Despite the fact that the determination of the threshold level for the GM food labeling requirement is not based on science, as there is no conclusive scientific evidence that proves GM food is unsafe for human health. Therefore, the basis for the determination of FSO is the precautionary principle.

The objective for the determination of the threshold level is to assure that foods that may contain a minute trace of a GM food as a result of an adventitious or technically unavoidable presence along the food chain are exempted from the labeling requirement. In other words, a food product that contains, consists of, or is produced from a GMO is exempted from the labeling requirement if the presence of a GM food is below the tolerated level. Therefore, a threshold level is the only resource in the GM food labeling regulation that can be translated into a FSO.

Worldwide, the threshold level ranges from $0.9 \%$ to $5 \%$ (except for China that applies the level of $0 \%$ ). Therefore, if we referred to those threshold levels, then the FSO can range from $0 \%$ to $5 \%$. Next, to assess the applicability of those FSOs in the food control system, there is another metric that needs to be determined, which is the performance criteria (PC). The PC is the effect of control measures on being able to meet the FSO; one of the most important control measures to enforce the threshold level is the installment of a traceability system in the supply chain of GM food. Both food businesses and food safety authorities should be focused on implementing and monitoring the performance of the traceability system to provide the FSO or in this case the threshold level. A record should be made when there is at least one GM ingredient food produced or used in the supply chain. This report is mostly done by operators at the primary production and manufacturing stage in the supply chain. Apart from the 5\% threshold level applied in the current GM food labeling regulation in Indonesia, the corresponding traceability system is absent in the Indonesian legal system, and thus becomes the biggest loophole in the implementation of GM food labeling control in the supply chain in Indonesia, as described in Figure 2.

\subsection{DISCUSSION AND RECOMMENDATIONS}

The current mandatory GM food labeling regime in Indonesia, like in many developing countries, is not fully implemented. With respect to food control, the traceability system is absent. Thus, the post-market monitoring of GM food labeling is also absent in Indonesia. In other words, the law enforcement is absent since there is no food inspection in this manner (Bansal and Gruère 2010). Yet, the laboratory capacity is actually well prepared (NADFC 2017c). In addition, food businesses refrain from complying with GM food labeling, since they fear that it may stigmatize their products and possibly lead to customers distrusting them (Caplan 2015). Despite that, 
GM foods are often stigmatized as high-risk foods; therefore, it is important to inform consumers via the labeling requirement.

The precautionary approach, which is adopted in Indonesian law, points to the fact that Indonesian consumers should rather be informed about the potential risks of GM food. For consumers to be able to make informed decisions, GM food labeling can be used as a risk communication tool for food manufacturing. Therefore, there is a requirement to inform the consumers about the risk associated with GM food and later on for food safety authorities to carry out post-market surveillance to verify the level of compliance with regard to GM food labeling. Therefore, it is important to fully implement the mandatory GM food labeling regulation in Indonesia through these following recommendations:

First, the success of the implementation of GM food labeling depends on a wellfunctioning traceability system. Thus, we recommend that the government of Indonesia (NADFC) amend the current GM food labeling regulation and ensure that a traceability system is installed in the regulation. This addition will ensure that food businesses identify their suppliers and distributors to which the raw materials and final products through their food supply chain system can be traced (EU Commission 2017).

Second, as explained in the FSO/ALOP analysis, the data the consumption per capita of GM food products nor the data on the market share of $\mathrm{GM}(\mathrm{O})$ free products are not available. Thus, we cannot directly evaluate the current mandatory labeling scheme and whether to facilitate voluntary labeling in the national legislation. Despite that, we can use the comparative assessment to evaluate and determine which scheme will be appropriate for Indonesia. The mandatory labeling scheme refers to "positive labeling", which means to label GM food as such. Moreover, a mandatory labeling scheme requires an effective post-market control consisting of inspection and laboratory services. However, in practice, the non-applicability of GM labeling to the majority of GM foods in Indonesia (non-packaged tempeh and tofu), the low compliance of food businesses and the weak post-market control have impaired Indonesia's pro-mandatory GM food labeling policy. Despite that, the pro-mandatory GM food labeling policy has been adopted by more than 64 countries, including the US (Byrne et al. 2014). This consensus, especially between the EU and the US can endorse the harmonization of GM food labeling at the international level. Therefore, Indonesia should maintain its current mandatory labeling scheme for GM food. While Indonesia applies a mandatory labeling scheme on the one hand to preserve the disclosure, the "right to know" of the consumers should also prevail on the other hand. Hence, in the FSO/ALOP analysis there are some countries that apply a voluntary $\mathrm{GM}(\mathrm{O})$-free labeling ("negative labeling") scheme, which refers to a form of labeling where the operators have taken specific measures to strictly exclude the presence or use of GMOs in food products. The voluntary labeling scheme can be attractive for 
operators who would like to establish a market share in a niche for consumers who are actively looking for $\mathrm{GM}(\mathrm{O})$-free foods. Such consumers are also typically willing to pay the higher costs involved with a stricter threshold level (Byrne et al. 2014). In this respect, a label carrying the message "non-GM food" can hence serve as a quality property and secure the respective company a respective market share. Japan and the US have been practicing this form of labeling. In the EU, some Member States facilitate a voluntary labeling scheme in their national legislation. Additionally, in studies pertaining to the willingness to pay in other countries, voluntary labeling is often seen as being a more efficient approach (Carter and Gruère 2003). Based on these arguments, we recommend the government of Indonesia facilitate $G M(O)$-free voluntary labeling next to the existing mandatory labeling scheme.

Third, the threshold level should be set to a level that can be traced back and detected by the existing laboratory capacity, and the required level should also be set based on the capacity of food businesses. Beyond that, we can also use the existing data of consumption per capita of soybean products, especially tempeh (around $7 \mathrm{~kg}$ per capita per year) to evaluate the fit for purpose of the threshold level. Tempeh and other soybean products become essential in the evaluation of threshold level due to the fact that $67.8 \%$ of soybean is imported from GM food producing countries such as the US (MoA 2016). As explained in the section on FSO/ ALOP analysis, the stricter $0 \%$ threshold level with regard to the mandatory GM food labeling in China has resulted in a very low level of compliance due to a weak post-market surveillance and technical constraints on the capability of laboratories for event detection. Moreover, even though the $0.9 \%$ threshold level with regard to the mandatory GM food labeling in the EU seems to work well, GM-labeled foods in the EU market are almost not visible due to the low use of GM ingredients by food businesses in the EU since they wish to avoid any negative stigma from EU consumers. Moreover, there is another option of a 3\% threshold level, such as is applied in Malaysia. Despite the lower level compared to the one in China and the EU, this relatively moderate threshold level has the potential to replace the current 5\% threshold level in Indonesia. The reasons to have the 3\% threshold level are: most of the countries with GM food labelling regulation use threshold level lower than 5\%, except Japan and the existing capacity of laboratories in Indonesia is sufficient to detect the threshold, and the relatively low consumption per capita of GM food products in Indonesia (assumed from the consumption per capita of tempeh). Therefore, we recommend that the government of Indonesia to change the current 5\% threshold level to a lower 3\% threshold level.

Fourth, several EU countries have been using the threshold level of $0.1 \%$ for their $\mathrm{GM}(\mathrm{O})$-free voluntary labeling scheme, even though at the EU level the related regulation is still absent. In the latest report from the EU, there is an option to adopt the less restrictive option of a $0.9 \%$ threshold for $\mathrm{GM}(\mathrm{O})$-free voluntary labeling, which will allow more $\mathrm{GM}(\mathrm{O})$-free products to appear on the EU market. We recommend the 
government of Indonesia apply a $0.9 \%$ threshold level for its $\mathrm{GM}(\mathrm{O})$-free voluntary labeling scheme.

Fifth, with respect to coverage, Malaysia has defined clear criteria for GM foods that are exempted from the labeling requirement, beyond just highly refined foods. Malaysia in its criteria includes processing aids, food additives, acidic foods and salty foods, when the GM DNA is absent in the final product, animal products made from animals that were fed with GM feed, fermented foods that are produced using genetically modified microorganisms, when the GM DNA is absent in the final product, and foods produced by a GM enzyme. These exemptions do not apply to foods which contain, consist of, or are produced from a GMO whose genes are derived from an animal or plant that may cause hypersensitivity and also highly refined foods with significantly altered characteristics. This more sophisticated exemption will ensure the scope of the labeling to the level of a necessary basis and to ensure the legal certainty of the GM food labeling regulation. Therefore, we recommend that the government of Indonesia develop a more sophisticated exemption list in the amended regulation, based on the example of Malaysia.

Six, with regard to the content of the label, the current regulation requires labeling for each GM ingredient in the food product to appear on the label. Though, this provision puts the unnecessary burden on operators, particularly for the manufacturers since they must analyze every GM ingredient used in the product. Therefore, we recommend the government of Indonesia take Malaysia as an example and set a limit of only three main GM ingredients that have the biggest share in terms of the weight of the overall product to be on the label. This decision will cut the cost of compliance and enforcement, especially concerning the analysis and detection of a GM event.

\subsection{CONCLUSION}

The absence of a traceability system, a wide range of labeling scope, and the provision to put all GM ingredients on the label have become shortcomings in the current GM food labeling regulation in Indonesia. The result of these shortcomings has been the absence of post-market surveillance and labeled GM foods in the market. To remedy the situation and to be able to meet the desirable public health goals, a legal reform is needed to be taken by the government. The GM food labeling issue covers all the ideal conditions for the application of the FSO/ALOP framework in designing food laws and regulations. By using the FSO/ALOP framework that is based on WTO law and food safety science, the analysis has shown us that a top-down approach is more appropriate and should be applied as a part of the legal reform. A comparative law on the similar GM food labeling regulations of the EU, US, Japan, Malaysia, and China is used as the baseline for the legal reform of such regulation in Indonesia.

This study proposes the addition of a voluntary $\mathrm{GM}(\mathrm{O})$-free labeling scheme to the existing mandatory labeling scheme. This voluntary $\mathrm{GM}(\mathrm{O})$-free labeling scheme 
will be attractive for operators who would like to establish a market share in a niche for consumers who are actively looking for $\mathrm{GM}(\mathrm{O})$-free foods. A second proposition is to use the $3 \%$ threshold level combined with the traceability system, for the mandatory GM food labeling and $0.9 \%$ threshold level, for the voluntary GM(O)-free labeling scheme. The traceability system will ensure that the operators identify suppliers and the companies to which the products have been delivered and at the same time ensure the applicability of the threshold level as the food safety objective (FSO). Third, it is very important to have in the future more sophisticated exemptions of the labeling requirements in order to restrict the scope of the labeling and to ensure the legal certainty of the GM food labeling regulation. Finally, the last recommendation is to put only the 3 major GM ingredients on the label. This will cut the cost of compliance and enforcement, especially in terms of the analysis and detection of a GM event. 



\section{CHAPTER 5 \\ SPICING UP THE EXPORT MARKET ACCESS OF INDONESIA TO THE EU: THE CASE OF SHRIMP AND NUTMEG}

\section{Dasep WAHIDINa, b, Kai PURNHAGEN ${ }^{a}$}

aLaw and Governance Group, Wageningen University and Research, Hollandseweg 1, PO Box 8130, 6700 EW, Wageningen, The Netherlands; bNational Agency of Drug and Food Control of Indonesia (NADFC), Percetakan Negara, 23, 10560, Jakarta, Indonesia. 


\begin{abstract}
The EU has been implementing strict food laws and regulations that de facto constrain exports from Indonesia, particularly with regard to agricultural products. This study uses the comparative law method and the FSO/ALOP framework to analyze how to design better strategies for Indonesia when dealing with the more stringent food laws and regulations of the EU, particularly in the case of shrimp and nutmeg. This study proposes that the choice of strategy should depend on the nature of the hazard, the existing national food control system, and the availability of the relevant international standard.
\end{abstract}

Keywords: national food control system, export market access, shrimp, nutmegs. 


\subsection{INTRODUCTION}

Access to markets in developed countries has always been an important factor for the success of economies in developing countries. It stimulates dynamic export growth for developing countries and raises domestic revenues (Trebilcock 2015). In food trade, the lack of national food control systems in developing countries has been a major constraint to obtaining access (Athukorala and Jayasuriya 2003) to export markets of developed countries, which usually impose more stringent food laws and regulations (Ferro et al. 2015). While such laws and regulations are conventionally viewed as an obstacle for developing countries, they can also act as an opportunity for developing countries to innovate and improve their national food control systems. If the system adapts to the lack of data and resources present in developing countries, these strict laws and regulations can also act as catalysts for upgrading the level of food safety in developing countries and at the same time an increase in access to export markets (Henson and Jaffee 2006; Jongwanich 2009), the so-called market access effect (Purnhagen 2015b).

Both shrimp and nutmegs are the most imported food product by the EU from developing countries, and Indonesia is one of the most important suppliers of these commodities. In most areas, the EU fosters the most stringent food laws and regulations; these laws and regulations can be categorized as non-tariff barriers (NTBs), particularly for raw or lightly processed goods, such as frozen shrimp or dried nutmegs (Shepherd and Wilson 2013). An explicit indicator of the export market can be found in the number of import notifications, including border rejections (Henson and Jaffee 2006). In the case of exports of Indonesian agricultural products to the European Union (EU), shrimp and nutmegs have received recurrent notifications in a certain sequential period. There were in total 44 notifications related to prohibited substances (antimicrobials) found in shrimp in the period of 2001 until 2008, 23 of which were due to the use of chloramphenicol (EU-RASFF 2017). ${ }^{53}$ Whereas, there were in total 68 notifications related to aflatoxins (AFs) in nutmegs in the period of 2000 until 2017 (EU-RASFF 2017). ${ }^{54}$ The fact that the recurrent import notifications of chloramphenicol in shrimp occurred throughout the 7-year period and have been absent since 2009 up until now and the fact that recurrent notifications of aflatoxins in nutmegs have occurred throughout for at least the last 17 years and are still happening up until now need to be investigated and analyzed to find the causalities and a way to prevent recurrent notifications in the future. We investigate the risk management of these two different case studies to further propose better strategies for Indonesia to deal with more stringent food laws and regulations and at the same time to increase their access to the export markets in the EU.

\footnotetext{
53 When referring to shrimp, we include farmed and wild caught crustaceans and products thereof.

54 When referring to nutmegs, we include whole nutmegs and nutmegs in powder form.
} 
The remainder of this paper is structured as follows: In section II, we describe the research methodology. In section III, we briefly describe the trade of shrimp and nutmegs between the EU and Indonesia and the related import notifications from the EU for these two Indonesian exported commodities. In section IV, we apply the FSO/ALOP framework for the application in developing countries to analyze the case of chloramphenicol in shrimp and AFs in nutmegs. In section $\mathrm{V}$, we discuss the analysis and propose better strategies for the government of Indonesia (GOI) to deal with the more stringent food laws and regulations in the EU. Finally, in section VI, we summarize our findings in the conclusion.

\subsection{RESEARCH METHODOLOGY}

In this study, we use the textual and contextual data of relevant food laws and regulations in Indonesia and the EU. In particular, we use the regulations on the maximum level of contaminants in foods as our primary data. We use a comparative law method to analyze those regulations. Whereas, for secondary data, we use journals, books, internet databases, and government reports. We obtain import notification data from the EU-RASFF portal. Moreover, we use the food safety objective/appropriate level of protection (FSO/ALOP) framework of our previous work to analyze risk management applied in those aforementioned case studies and to further propose better strategies in dealing with more stringent food laws and regulations (Wahidin and Purnhagen 2017).

\subsection{THE TRADE OF SHRIMP AND NUTMEG BETWEEN INDONESIA AND THE EU AND THE RELATED IMPORT NOTIFICATIONS}

Indonesia is the second largest fish producer in the world, with more than six million tons of marine captures and 13 million tons of aquaculture production annually (FAO Globefish 2016; EUMOFA 2015). Moreover, Indonesia is the second largest producer of crustaceans, with the production of more than 600 thousand tons per year (FAO Globefish 2016). Shrimp has been Indonesia's main fishery export commodity, for which vannamei shrimp dominates the nation's shrimp productions and exports (GBG 2014; MMAF 2015). Whereas, the EU has been the world's biggest importer of fish, seafood, and aquaculture products (DG SANCO 2016a). In 2009, Indonesia accounted for $6 \%$ of the frozen shrimp supplied by foreign suppliers to the EU market (Lord et al. 2010) Therefore, Indonesia has the potential to become a major exporter of shrimp to the EU. Indonesia is also well known as a major exporter of nutmegs in the world, with a market share of approximately 75\% (CBI 2016). Indonesia's main trading partners are Vietnam, the US, Japan, and the EU (particularly Germany, the Netherlands, Italy, and France). As for Vietnam and the Netherlands, most of the Indonesian nutmegs are processed into ground nutmeg (powder) and re-exported to other countries. 
Exported shrimp and nutmeg from Indonesia have a long history of import notifications from the EU due to noncompliance with the regulations related to the maximum level of contaminants in foods (European Commission 2017). Import notifications that occurred in the period of 2001 until 2008 concerning the noncompliant exported shrimp shipments from Indonesia were mostly due to the use of banned antimicrobials (e.g., chloramphenicol) (Figure 5). In contrast, import notifications related to the non-compliant exported nutmeg are mostly due to the contamination of AFs. The import notifications have been occurring since 1999, with 23 notifications in 2016 alone (Figure 6) (European Commission 2017).

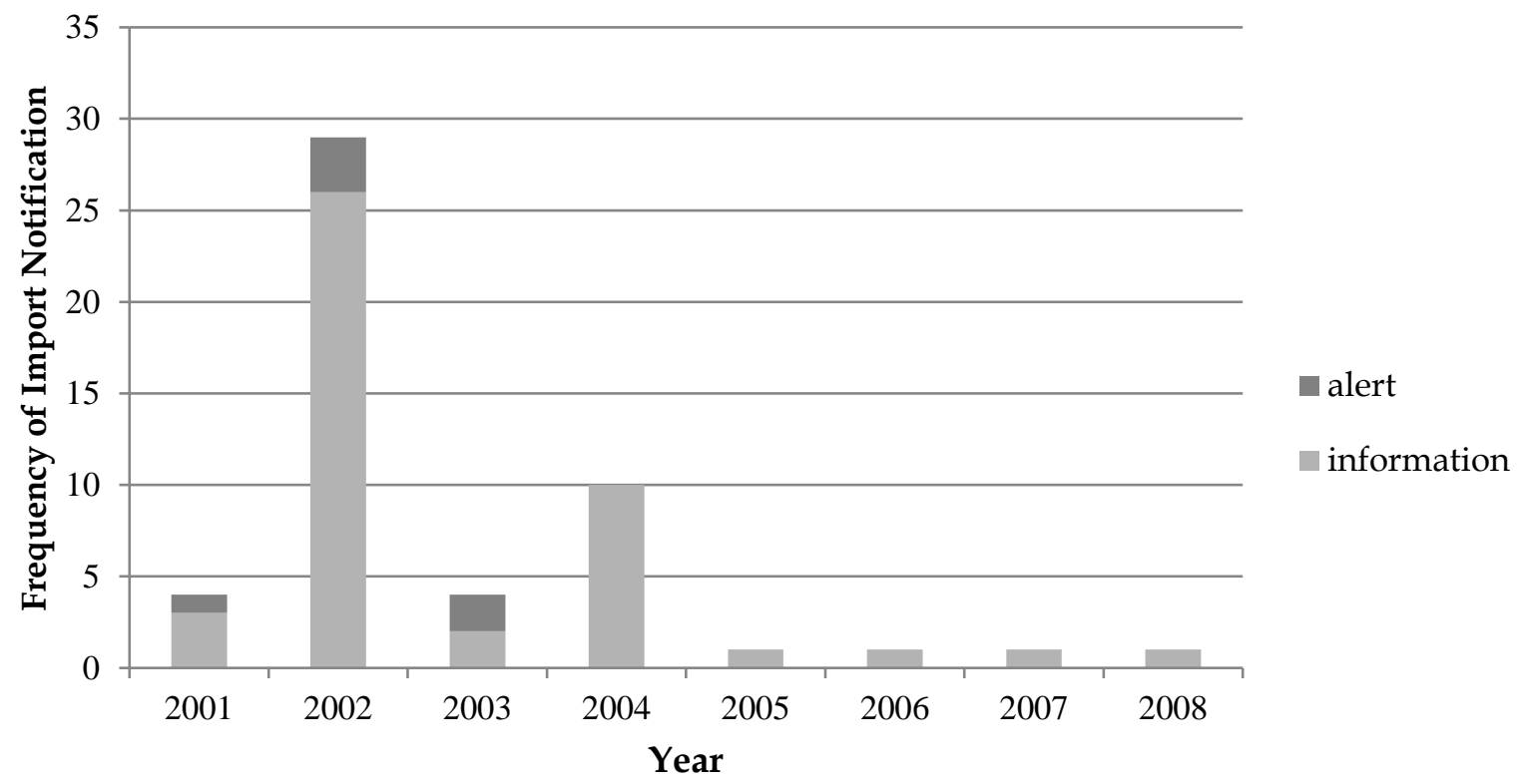

Figure 5. Frequency of notifications by the EU concerning banned antimicrobials in shrimp imports from Indonesia.

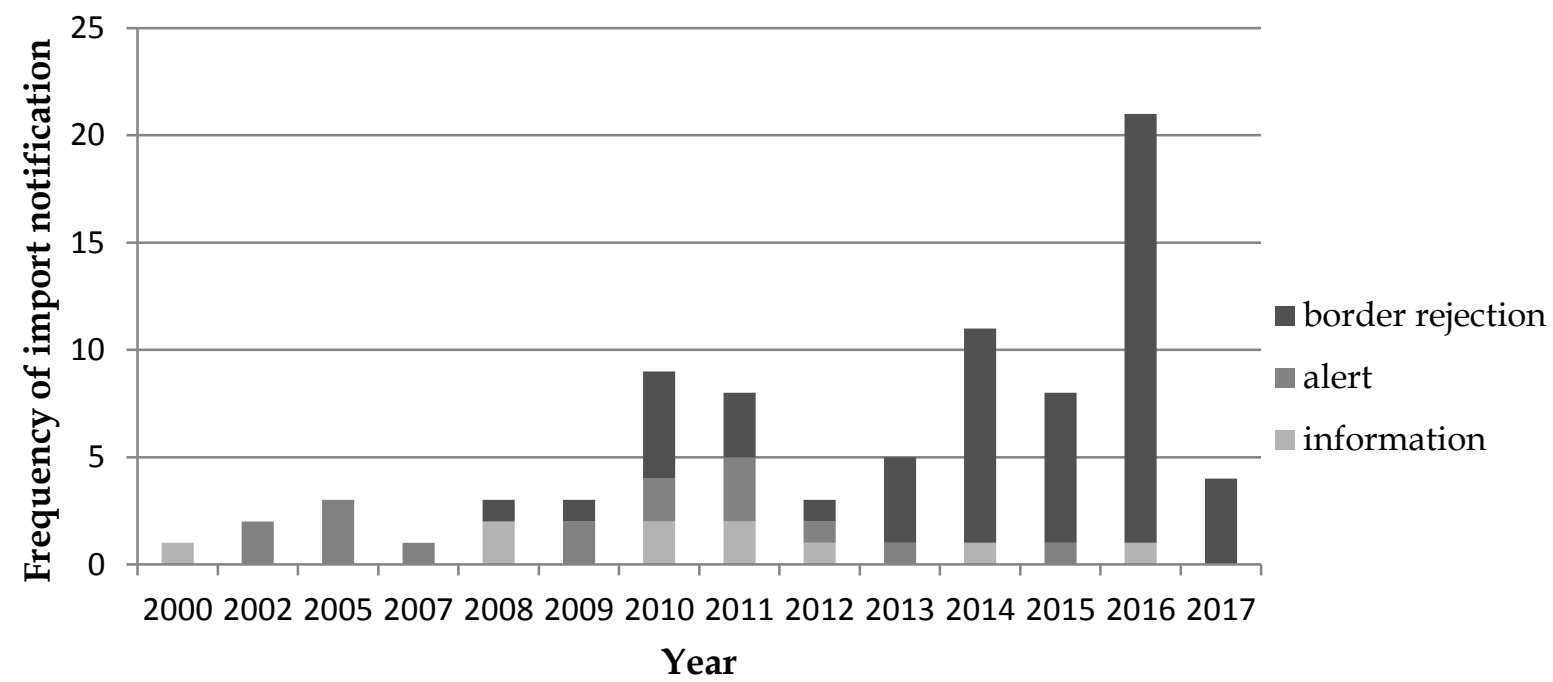

Figure 6. Frequency of import notifications by the EU concerning aflatoxins (AFs) in nutmeg imports from Indonesia. 


\subsection{FSO/ALOP ANALYSIS}

In order to analyze food control measures both by Indonesia and the EU and to propose better strategies for Indonesia in dealing with the strict food laws and regulations in the EU, particularly in relation to shrimp and nutmeg imports, this study uses the FSO/ALOP framework for the application in developing countries. The framework follows the principle of farm to fork, where the level of contaminants should be kept lower than the FSO at all stages of the food supply chain to contribute to the ALOP (Figure 7) (Wahidin and Purnhagen 2017). The ALOP refers to "the level of protection deemed appropriate by the Member establi: ${ }^{*}$ Primary Producer $\quad$ ir phytosanitary measure to protect human, animal or plant life Primary Producer territory" (WTO 1995). The FSO refers to the maximum level of a contaminant at the point of consumption and can be applied directly to previor Manufacturer and retailer $\quad y$ chain (primary producers, manufacturers, and retailers) ( level Purnhagen 2017). Food safety management systems, e.g., Good Agricu“ " $\quad$ i n $\quad$.. (GAP), Good Handling Practices (GHP), Good Manufacturing Pri Hazard and Critical Control Point (HACCP), and Good Distribution Practices (GDP), applied in the food supply chain can minimize or eliminate the level of contamination throughout the food supply chain. However, if the FSO is too low, like the cases of genotoxic and carcinogenic hazards, then performance objectives (POs) must be established for each specific stage of the food supply chain (Wahidin and Purnhagen 2017). For example, if the initial level of contamination (Ho) has already been high on the primary production stage, there is a high possibility that the level of contamination can increase at this stage $\left(\sum \mathrm{I}\right)$ and at the same time a minimum control measure that can be implemented to reduce the level of contamination $\left(\sum R\right)$. Thus, the actual level of contamination $(\mathrm{H})$ will also be high beyond the stage of primary production. The actual contamination level at the primary production stage will become the initial level of contamination at the manufacturer and retail stages. In practice, a food manufacturer becomes the key player in establishing POs for its suppliers (primary producers) and distributors following the traceability system.

$$
\begin{aligned}
& \mathrm{Ho}+\sum \mathrm{I}-\sum \mathrm{R} \leq \mathrm{H} \leq \mathrm{PO} 1 \\
& \downarrow \\
& \mathrm{Ho}+\sum \mathrm{I}-\sum \mathrm{R} \leq \mathrm{H} \leq \underset{\downarrow}{\mathrm{PO} 2} \\
& \mathrm{Ho}+\sum \mathrm{I}-\sum \mathrm{R} \leq \mathrm{FSO} \\
& \text { Where: } \mathrm{H}=\text { Actual level of contamination } \\
& \text { Ho }=\text { Initial level of contamination } \\
& \sum \mathrm{I}=\text { Total increase level of contamination } \\
& \sum \mathrm{R}=\text { Total reduction level of contamination } \\
& \mathrm{PO}=\text { Performance objective } \\
& \mathrm{FSO}=\text { Food safety objective }
\end{aligned}
$$

Figure 7. Food safety objective (FSO) and its relationship to performance objectives (PO) at different stages of the supply chain. 
In the context of international trade, an FSO is determined by importing countries and generally set as a regulatory requirement (Figure 8). Hence, exporting countries are required to apply appropriate food control systems to meet the FSO of the importing countries. The POs act as targets of FSMSs at each specific stage of the food supply chain that contributes to the FSO and ALOP. Both a FSO and PO function as critical levels, and both are equivalent, meaning that the food is safe if the level of the hazard remains below the levels defined by them and unsafe if the hazard is beyond those levels.

To administer food safety, a food safety matrix other than a FSO or a PO needs to be established, which should be a performance criteria (PC). This PC should encompass two elements: a process criteria ( $\operatorname{PrC})$ and a product criteria $(\operatorname{PrdC})$. Both the PrC and PrdC determine how the PC is achieved. The PrC is controlled parameters regarding the processes of food production, whereas the PrdC is intrinsic parameters of the food that need to be met to guarantee food safety. For example, in order to achieve an FSO of $10 \mu \mathrm{g} / \mathrm{kg}$ of Aflatoxin B1 (AFB1) in nutmeg and a PO of $5 \mu \mathrm{g} / \mathrm{kg}$ of AFB1, a specific control measure $(\operatorname{PrC})$ at the production stage, such as drying at a temperature no higher than $60^{\circ} \mathrm{C}$ for 14 days, is required to keep the moisture content of the nutmeg below 10\% (PrdC).

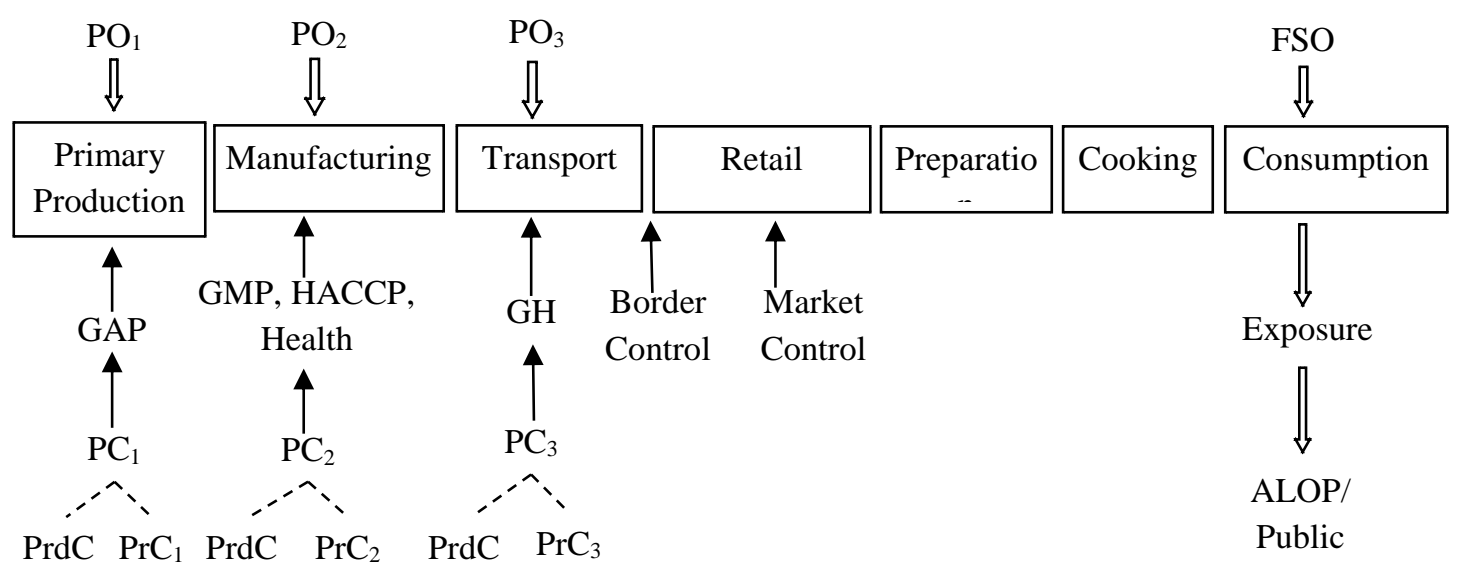

Figure 8. Model of the FSO/ALOP in the international food supply chain.

Developing countries need to design a quantitative ALOP to define a food safety matrix to be used by actors in the food supply chain in the development and implementation of FSMSs (Figure 8). The FSO links the ALOP to the FSMSs of food supply chain actors. However, to determine the ALOP and later on the FSO (FSO/ALOP), the government needs to establish an appropriate risk profile by conducting a qualitative risk assessment that consists of a hazard assessment, a hazard characterization, an exposure assessment, and a risk characterization. Subsequently, if it is found that the risk estimate is high, the government can assign an independent scientific body to conduct a more sophisticated scientific assessment (quantitative 
assessment). The government (food safety authorities) can use the risk estimate, which when combined with the value judgment (socioeconomic assessment) can determine the FSO/ALOP.

As mentioned previously, there are two ways to determine an FSO/ALOP: a topdown and bottom-up approach. In the context of regulation where relevant international standards or similar regulations from other countries are available, it is recommended that a country adopt those standards or regulations in the determination of its FSO/ALOP (top-down approach). Whereas, if relevant international standards and similar regulations from other countries are not available, then countries must determine their FSO/ALOP based on a risk assessment (bottomup approach).

To evaluate FSMSs, whether those have achieved the FSO/ALOP or not, we need to assess whether the PCs achieve the POs (Figure 3). If the PCs do not meet the POs, then the actors in the food supply chain are required to adjust their FSMSs through the mechanism of corrective action and preventive action (CAPA). Whereas from the government's side (food safety authorities), if the FSO/ALOP is not realized, then they need to adjust the FSO/ALOP, verify the current FSMSs of food manufacturing, and conduct post-market surveillance.

\subsubsection{The FSO/ALOP of the EU Related to the Imports of Indonesian Shrimp and Nutmeg}

The EU maintains a high level of protection as specified in Article 1 of the General Food Law (GFL)55, which "provides the basis for the assurance of a high level of protection of human health and consumers' interest in relation to food, taking into account, in particular, the diversity in the supply of food including traditional products, whilst ensuring the effective functioning of the internal market." According to Article 6 of the GFL, the EU requires the use of risk analysis-based measures as tools to achieve the ALOP. However, according to Article 7 of the GFL, in circumstances where there is a lack of scientific evidence, the precautionary principle should be used as a complement to the risk analysis (Purnhagen 2015a). In other words, where there is a lack of scientific evidence, food safety authorities can apply the precautionary principle as the pertinent option for risk management. The "zero-tolerance" approach that is applied in the case of banned antimicrobials being found in shrimp imported from South Asian countries is one of the textbook examples of the implementation of the precautionary principle by the EU.

The overarching policy of the EU regarding imported foods is to reduce noncompliant foods at designated points of entry through a comprehensive border control and audits in exporting countries (European Commission 2016b, 2016a). Due to a high

\footnotetext{
55 Regulation (EC) No 178/2002 of The European Parliament and of The Council of 28 January 2002 laying down the general principles and requirements of food law, establishing the European Food Safety Authority and laying down procedures in matters of food safety, (OJ L 31/1, 1.2.2002).
} 
number of import notifications related to shrimp and nutmeg imports from Indonesia, the EU has steadily increased the level of official import controls for these products that result in a more stringent FSO/ALOP. The EU Food and Veterinary Office (FVO) carried out several audits in Indonesia regarding residues and contaminants in live animals and animal products as well as the control of AF contamination in nutmeg shipments intended for export to the EU (DG SANCO 2012a, 2012b, 2016b). The EU has been implementing a very strict FSO in the form of the minimum required performance level (MRPL) of $0.3 \mu \mathrm{g} / \mathrm{kg}$ of chloramphenicol in shrimp and a maximum level (ML) of $5 \mu \mathrm{g} / \mathrm{kg}$ of aflatoxin $\mathrm{B}_{1}\left(\mathrm{AFB}_{1}\right)$ and $10 \mu \mathrm{g} / \mathrm{kg}$ of total aflatoxins (total $\mathrm{AFs}$ ) in spices, including nutmeg. Exporters are obliged to attach a health certificate (a statement that the product complies with the EU's standard) from the local food safety authorities to each consignment of both commodities. At the EU borders, the local food safety authorities conduct both a check of certificates and physical checks to ensure compliance.

\subsubsection{Chloramphenicol in Shrimp}

1. Risk profile

Antimicrobials, such as chloramphenicol, have been conventionally used by shrimp farmers to treat and prevent disease outbreaks. Chloramphenicol has a wide spectrum and thus can effectively combat gram positive bacteria, gram negative bacteria, and also viruses. Despite that, chloramphenicol has both genotoxic and carcinogenic properties. The International Agency for Research on Cancer (IARC) has classified chloramphenicol in Group 2A (likely carcinogenic to humans) (IARC 2012). Moreover, the WHO/FAO Joint Expert Committee on Food Additives (JECFA) has stated that there is no acceptable daily intake (ADI) and therefore no maximum residue limit (MRL) for chloramphenicol in food-producing animals. ${ }^{56}$ A Codex standard (veterinary drugs residues in foods) for chloramphenicol exists based on the JEFCA opinion. No MRL is allocated and the risk management recommendation (RMR) stipulates competent authorities to prevent residues of chloramphenicol by avoiding the use of chloramphenicol in food-producing animals (CAC 2015). In order to minimize the risk of chloramphenicol in shrimp, the EU uses the "zero-tolerance" approach, which is based on the linear non-threshold (LNT) model that trivializes the food safety regulation since one molecule may result in an irreversible health damage (Hanekamp and Bast 2015). Though, the risk from the level of exposure to chloramphenicol through the consumption of shrimp is negligible (RIVM 2001).

\footnotetext{
56 Food-producing animals are defined as animals used in the production of food. The term "foodproducing animals" includes all terrestrial and aquatic animals (that is, includes aquaculture) used to produce food. For the purposes of these guidelines, the term "food-producing animals" is considered an equivalent term to "food animals" (WHO 2017a).
} 


\section{2. $\mathrm{FSO} / \mathrm{ALOP}$}

The EU applies the principle of "as low as reasonably achievable" (ALARA) in determining its FSO/ALOP with respect to chloramphenicol in food-producing animals. This is due to the genotoxic and carcinogenic properties of the chloramphenicol. Thus, the public exposure to chloramphenicol shall be controlled to a very minimum level or even to the zero level. Chloramphenicol has been banned from use in food-producing animals in the EU since 1994, following the recommendation from the Committee for Medicinal Products for Veterinary Use (CVMP) (EFSA, 2014). The EU uses whichever level can be detected by regulatory laboratories of Member States (Hanekamp et al. 2003), as specified in Article 5 of Regulation 2377/90.57 Chloramphenicol is listed in Annex IV of the same regulation as a "substance hazardous at whatever limit".

Chloramphenicol is not only classified as an anthropogenic chemical contaminant, but it is also classified as a natural contaminant since it is produced by soil bacteria, may occur in plants, and also can be found in food-producing animals as an unintentional contaminant (Chain 2014). This means that the "zero-tolerance" approach or classification as a "substance hazardous at whatever limit" is not feasible. Though, the most pertinent reason for not applying the "zero-tolerance" approach is the need to have an FSO for routine border inspection. Despite the need, the determination of an FSO for chloramphenicol in shrimp is difficult since the EU must ensure that chloramphenicol is not indirectly tolerated either in the EU or in exporting countries. Consequently, the EU shifted from the "zero-tolerance" approach to the MRPL concept, where the value is not related to risk assessment, but more to the ability of a laboratory to test the occurrence of a hazard. The newly appointed MRPL, as stipulated in the Commission Decision 2005/34/EC, is therefore not related to food safety and human health, but rather related to analytical and technological capabilities (Hanekamp and Bast 2015). This MRPL acts as the FSO so that a Member State can take the necessary actions if the result of the analysis is equal or above the FSO. The EU established an FSO for banned antimicrobials by harmonizing the MRPL across member states. ${ }^{58}$

In addition to the general requirement of the EU towards exporting countries to adhere to the rules and principles stipulated in the General Food Law, there are four additional legal requirements regarding the importing of shrimp into the EU that are related to the control of residues of veterinary medicines. First, the exporting countries

57 Council Regulation (EEC) No 2377/90 of June 26, 1990 describes a community procedure for the establishment of maximum residue limits of veterinary medicinal products in foodstuffs of animal origin (OJ L 224, 18.8.1990, p. 1-8).

58 2005/34/EC: Commission Decision of January 11, 2005 describes harmonized standards for the testing for certain residues in products of animal origin imported from third countries, (OJ L 16, 20.1.2005, p. 61-63). 
are required to be on the list of third countries that may export food of animal origin to the EU. Inclusion on this list is obtained by submitting an annual national residue monitoring plan to the European Commission. The plan must show that the third country applies measures that have an equivalent effect as the ones implemented in the Member States, as specified in Article 29 of Directive 96/23/EC. 59 Thus, to be equivalent, exporting countries are required to implement GMP, HACCP, internal and second party audits of suppliers, traceability of products, external audits by the competent authority, catch certificates, and test certificates (Golub and Varma 2014). After the plan is approved by the Commission, the country will be listed in Commission Decision 2011/163/EU.60 Second, the exporting country is required to install a traceability system in its national food laws and regulations. The system can provide a proper information related to harvesting and production of all raw and some processed products that intended for the exports into the EU. Third, according to Regulation (EU) No 852/2004, ${ }^{61}$ the exporting country is required to apply HACCPbased risk management systems. Thus, all raw and processed products must meet all basic hygiene requirements and HACCP principles. Fourth, the exported product must be in compliance with the tolerance level set for contaminants. The exporting country must, therefore, test the consignment before exporting to the EU in order to avoid border rejections. This step is indeed crucial because border rejections are mainly caused by the detection of residues of banned antimicrobials in shrimp (European Commission 2017). Contaminants stem mostly from the use of veterinary drugs during production (European Commission 2017). The results of the testing must be attached to a health certificate as specified in Regulation (EU) No 854/2004,62 Regulation (EC) No 2074/2005,63 and Regulation (EC) No 1250/2008.64 The allowed

59 Council Directive 96/23/EC of April 29, 1996 on measures to monitor certain substances and residues thereof in live animals and animal products and repealing Directives 85/358/EEC and 86/469/EEC and Decisions 89/187/EEC and 91/664/EEC, (OJ L 125, 23.5.1996, p. 10-32).

60 Commission Decision 2011/163/EU of March 16, 2011 on the approval of plans submitted by third countries in accordance with Article 29 of Council Directive 96/23/EC (notified under document C (2011) 1630; OJL 70, 17.3.2011, p. 40-46).

61 Regulation (EC) No 852/2004 of the European Parliament and of the Council of April 29, 2004 on the hygiene of foodstuffs(OJ L 139, 30.4.2004, p. 3-21).

62 Regulation (EC) No 854/2004 of the European Parliament and of the Council of April 29, 2004 describes specific rules for the organization of official controls on products of animal origin intended for human consumption (OJ L 139, 30.4.2004, p. 206-320).

63 Commission Regulation (EC) No 2074/ 2005 of December 5, 2005 describes the implementation of measures for certain products under Regulation (EC) No 853/2004 of the European Parliament and of the Council and for the organization of official controls under Regulation (EC) No 854/2004 of the European Parliament and of the Council and Regulation (EC) No 882/2004 of the European Parliament and of the Council, derogating from Regulation (EC) No 852/2004 of the European Parliament and of the Council and amending Regulations (EC) No 853/2004 and (EC) No 854/2004 (OJ L 338, 22.12.2005, p. 27-59).

64 Commission Regulation (EC) No 1250/2008 of December 12, 2008 amending Regulation (EC) No $2074 / 2005$ with regards to certification requirements for the import of fishery products, live bivalve mollusks, 
level of residues or MRL is stipulated in Table 1 of Regulation (EU) No 37/2010.65 It is notable, however, that there is no MRL allocated for chloramphenicol, as specified in Table 2 of the same regulation. Technically, a "zero-tolerance" approach as the ALOP is not feasible for use in the inspection control and laboratory testing. Thus, the EU translates the ALOP into an FSO of $0.3 \mu \mathrm{g} / \mathrm{kg}$, which the EU calls the MRPL. It is different from the notion of the maximum regulatory limit (MRL) since there is no ADI intended for chloramphenicol in animals intended for consumption. Another reason why the EU uses $0.3 \mu \mathrm{g} / \mathrm{kg}$ as the MRPL is that the European Food Safety Agency (EFSA) concluded that there is a small possibility of exposure to chloramphenicol contaminated food at or below the $0.3 \mu \mathrm{g} / \mathrm{kg}$ level that would result in a health issue, such as aplastic anemia or reproductive/hepatotoxic effects. In this sense, an MRPL must be allocated, as defined in Article 4 of Commission Decision 2002/657/ EC66 and the amending Commission Decision No 2003/181/EC.67 The MRPL for chloramphenicol in aquaculture products is $0.3 \mu \mathrm{g} / \mathrm{kg}$ (Annex II, Commission Decision No 2003/181/EC).

In Indonesia up until now, there is no available data related to the risk of chloramphenicol in shrimp through the consumption pathway similar to the data available in the EU. Nevertheless, the EU's zero-tolerance approach is in line with the JECFA's policy to not establish an ADI and MRL for the use of chloramphenicol in food-producing animals. In other words, the government of Indonesia has limited options in the establishment of a risk profile and the design of its own FSO/ ALOP. Thus, in the case of chloramphenicol in shrimp, it is reasonable to use the same FSO/ALOP as the one applied in the EU.

The initial contamination (Ho) of chloramphenicol in shrimp most likely occurs on the primary production stage through the intentional use of chloramphenicol by shrimp farmers to treat or prevent disease outbreaks (Cabello et al. 2013; Li et al. 2016). Alternatively, the initial contamination may also occur from the environment, particularly in integrated poultry and fish farming (Neela et al. 2015). Hence, there is always a probability of detecting banned antimicrobials in shrimp $(\mathrm{H})$ that might exceed the MRPL. There is only a very low probability of an increase in contamination level or re-contamination $\left(\sum \mathrm{I}\right)$ after the primary production stage, and there are also no further control measures to reduce the level of contamination $\left(\sum R\right)$ at later stages in

Echinoderms, tunicates and marine gastropods intended for human consumption (OJ L 337, 16.12.2008, p.31-40).

65 Commission Regulation (EU) No 37/2010 of December 22, 2009 on pharmacologically active substances and their classification regarding maximum residue limits in foodstuffs of animal origin (OJ L 015 20.1.2010, p.1).

66 Commission Decision 2002/657/EC of August 12, 2002 implementing Council Directive 96/23/EC concerning the performance of analytical methods and the interpretation of results, (OJ L 221, 17.8.2002, p. 8-36).

67 Commission Decision 2003/181/EC of March 13, 2003 amending Decision 2002/657/EC with regards to the setting of minimum required performance limits (MRPLs) for certain residues in food of animal origin, (OJL 71, 15.3.2003, p. 17-18). 
the supply chain. Therefore, the PO should be set equal to the FSO. This means that the PC can be set simply: a very low concentration or the absence of chloramphenicol in shrimp. In this context, the PrC and the PrdC maintains that the chloramphenicol concentration in shrimp is kept as low as possible or even absent at the stage of primary production.

\section{Indonesian risk management for shrimp}

Indonesia has actually banned the use of chloramphenicol in foods since 1988 due to the establishment of the Minister of Health Regulation No 722/Menkes/Per/IX/1988. Besides this regulation, there is the Indonesian national standard (SNI) No 01-2705.1-2006 that stipulates the ban of chloramphenicol in frozen shrimp products. The effectiveness of this regulation and standard is seen in the absence of the EU's import notifications regarding the shrimp imported from Indonesia since 2009 up until now.

The government of Indonesia has been taking further legal measures to comply with the requirements of the EU and to prevent import notifications in the future. The government has adopted comprehensive systems of safety and quality control and has enhanced the added value of seafood and seafood products, based on HACCP principles. This system is outlined in Law No 45/2009 concerning Fishery Amending Law No 31/2004 (herein after called Fishery Law) ${ }^{68}$, Government Regulation No $57 / 2015$ concerning the quality control and safety of fishery products system and leverage of fishery product's added value, ${ }^{69}$ and Ministry of Marine Affairs and Fisheries (MMAF) Regulation No PER.19/MEN/2010 concerning the quality and safety control system of fishery products. ${ }^{70}$ The control of residues of veterinary drugs, chemicals, and contaminants in aquaculture is regulated in MMAF Regulation No 39/PERMEN-KP/2015 concerning veterinary drugs, chemical substances, and contaminants in fish-consumption aquaculture. ${ }^{71}$ This regulation also establishes the

68 Government of Indonesia, Law No. 45/2009 concerning Fishery amending Law No. 31/2004, http:/ / www.ilo.org/dyn/natlex/docs/ELECTRONIC/89346/102626/F1953216388/IDN89346.pdf, accessed January 25, 2017.

69 Translated by D. Wahidin, Peraturan Pemerintah No. 57 Tahun 2015 tentang Sistem Jaminan Mutu dan Keamanan Hasil Perikanan Serta Penilaian Nilai Tambah Produk Hasil Perikanan,

http://peraturan.go.id/pp/nomor-57-tahun-2015.html, accessed January 25, 2017.

70 Translated by D. Wahidin, Peraturan Menteri Kelautan dan Perikanan Republik Indonesia No. Per.19/Men/2010 tentang Pengendalian Sistem Jaminan Mutu dan Keamanan Hasil Perikanan. http://www.iphp-

online.kkp.go.id/portal/file/1.\%20PER\%2019\%20MEN\%202010\%20sistem\%20jaminan\%20mutu, accessed January 25, 2017.

71 Translated by D. Wahidin, Peraturan Menteri Kelautan dan Perikanan Republik Indonesia No. 39/Permen-KP/2015 tentang Pengendalian Residu Obat Ikan, Bahan Kimia, dan Kontaminan Pada Kegiatan Pembudidayaan Ikan Konsumsi, available at http://meacenter.kkp.go.id/wpcontent/uploads/2016/02/PENGENDALIAN-RESIDU-OBATIKAN-BAHAN-KIMIA-DAN-KONTAMINAN.pdf, accessed January 25, 2017. 
MRPL for chloramphenicol and other prohibited substances in fish and shrimp; the MRPL is identical to the one that was adopted in the EU, which is $0.3 \mu \mathrm{g} / \mathrm{kg}$.

From the perspective of the FSO/ALOP framework, the government of Indonesia has therefore completely harmonized its FSO/ALOP with the one in the EU that goes with the top-down approach. This measure is taken due to the availability of the relevant international standard. Furthermore, there is one important factor that needs to be highlighted in this case, which is the relatively simple and more controllable food supply chain of shrimp that makes it possible for the food control system in Indonesia to be able to provide more effective law enforcement, despite the resources limitation.

Despite the simple food supply chain system of shrimp in Indonesia, more than $80 \%$ of Indonesia's shrimp enterprises are still using traditional and extensive aquaculture method. Hence, the application of GAP is still limited or even barely applied. However, the Indonesian shrimp sector is actually relatively mature and professional, especially regarding the medium- to large-scale enterprises. The shrimp processing industries usually act as exporters and become the key players in dealing with the EU's food safety laws and regulations (CBI, 2009).

With the average of $60 \%$ of shrimp production per year being allocated for export, shrimp commodities are very vulnerable to the requirements and food laws and regulations of importing countries. Hence, shrimp enterprises have no option but to comply with those requirements and food laws and regulations that are set by importing countries, including the "zero-tolerance" policy of chloramphenicol in shrimp set by the EU. To comply with the EU's food laws and regulations, which are more stringent than the ones in the existing conventional export markets (the US and Japan), Indonesia should apply the GAP and HACCP certification scheme in order to provide a better brand image than other shrimp exporting countries. This scheme not only should be seen as an opportunity to more deeply penetrate the EU market, which has a strong demand for shrimp, but also opens up niche markets beyond the mainstream ones.

\subsubsection{Aflatoxins in Nutmeg}

\section{Risk Profile}

AFs are produced by fungi of the genus Aspergillus, which grows in regions with a high temperature and humidity. AFs are therefore natural contaminants in subtropical and tropical countries. There are four types of AFs that naturally occur in some foodstuffs: aflatoxin B1 (AFB1), aflatoxin B2 (AFB2), aflatoxin G1 (AFG1), and aflatoxin G2 (AFG2). The AFB1 is the most potent genotoxic and carcinogenic AF and is classified as Group 1 (carcinogenic to humans) (IARC 2012). Indonesia is a tropical country, which puts Indonesia at a very high risk of AF contamination, a risk that applies to nutmeg. Besides that, there is a lack of food safety infrastructures and resources of nutmeg farmers to control the level of AFs. These two factors implicate 
the high actual level of AFs in nutmegs in the local market, particularly due to a higher water content in semi-dried nutmegs and a high number of damaged nutmeg kernels (Dharmaputra et al. 2016).

On average, the EU's nutmeg consumption is about 30 grams per capita per year. Whereas, Indonesia's nutmeg consumption is about 20 grams per capita per year. Nutmegs are usually consumed in a powder (grounded) form as a condiment. Despite the relatively small amount of consumption (low exposure level), the risk estimate for nutmeg is still considered high due to the potent genotoxic and carcinogenic properties of AFs.

\section{2. $\mathrm{FSO} / \mathrm{ALOP}$}

There is no available international standard of AFs in spices; therefore, individual countries can set their own maximum levels (FSOs). The Scientific Committee for Food of the European Commission (European Commission 1996) pointed out that "for that type of carcinogen, there is no threshold dose below which no tumor formation would occur. In other words, only a "zero level of exposure" will result in "no risk." Based on this observation, the EU uses the ALARA principle to determine the FSO for AFs in food. The EU sets the FSO for AFs for the groups of spices of Capsicum spp. (dried fruits thereof, whole or ground, including chilies, chili powder, cayenne, and paprika), Piper spp. (fruits thereof, including white and black pepper), Myristica fragrans (nutmeg), Zingiber officinale (ginger), and Curcuma longa (turmeric), as is specified in Commission Regulation (EC) No 1881/2006 of December 19, 2006, setting maximum limits for certain contaminants in foodstuffs. This regulation amended Commission Regulation (EC) No 466/2001. ${ }^{72}$ The Regulation specifies the FSO of mycotoxins in spices, which was absent in the previous regulation. The FSO of aflatoxin $\mathrm{B}_{1}\left(\mathrm{AFB}_{1}\right)$ is $5 \mu \mathrm{g} / \mathrm{kg}$ and $10 \mu \mathrm{g} / \mathrm{kg}$ for total aflatoxins (total AFs). This FSO applies to all spices; there is no specific FSO of AFs in nutmeg.

For the export of nutmeg to the EU, the general requirements are the same as for the export of shrimp. However, there is no positive list of EU-approved countries for nutmeg exports. Instead, there is a regulation that specifies the criteria for an increasing level of control regarding specific agricultural products from designated third countries. For nutmeg, the European Commission has established the Implementing Regulation (EU) 2016/ 24 of January 8, 2016, which amends Regulations (EC) No 669/2009 and (EU) No 884/2014,73 and imposes special conditions governing the import of groundnuts from Brazil, Capsicum annuum and nutmeg from India, and nutmeg from Indonesia. In this new regulation, the EU requires that "all consignments

72 Commission Regulation (EC) No 466/2001 of March 8, 2001 sets the maximum levels for certain contaminants in foodstuffs (OJ L 77, 16.3.2001, p. 1-13).

73 Commission Implementing Regulation (EU) 2016/24 of January 8, 2016 imposes special conditions governing the import of groundnuts from Brazil, Capsicum annuum and nutmeg from India, and nutmeg from Indonesia and amends Regulations (EC) No 669/2009 and (EU) No 884/2014 (OJ L 8, 13.1.2016, p. 1-5). 
[...] of nutmeg from Indonesia [...] be accompanied by a health certificate (HC) stating that the product has been sampled and analyzed for the presence of aflatoxins (AFs) and has been found compliant with the Union legislation. The results of the analytical tests or the certificate of analysis (CA) also should be attached to the health certificate." Upon arrival in the EU, consignments are still subject to document checks $(100 \%$ of consignments) as well as identity and physical checks (20\% of consignments) (EU, 2014; EU, 2016).

The initial contamination level (Ho) of AFs in nutmeg imports already existed prior to harvest. The increase in the level of contamination and the possibility of recontamination $\left(\sum \mathrm{I}\right)$ can occur at the post-harvest stage, particularly when the drying time is delayed during the storage, handling, and transport stage, more often when the water content exceeds the critical levels of mold growth (Cornel University 2015; Giray et al. 2007). Therefore, it is crucial to implement FSMSs on all stages of the food supply chain to reduce or eliminate the growth of mold and to reduce the AF contamination level $\left(\sum \mathrm{R}\right)$.

The PO from the previous stage becomes the Ho of the next stage in the food supply chain (Figure 7). For nutmeg, the GAP and GMP are commingled at the primary production stage. Hence, the FSMS at the primary production stage becomes the most critical element, compared to FSMSs at other stages of the food supply chain. In other words, the key to ensuring the compliance of goods with the FSO is to minimize the initial contamination level (Ho) on the primary production stage. PCs at the primary production stage include proper harvest time, effective physical sortation, avoiding contact with soil during the drying process, more appropriate drying process, more appropriate storage condition, better hygiene, and more appropriate packaging. The close proximity between the GAP and GMP in the primary production of nutmeg can be beneficial if the farmer can implement effective food safety management systems to prevent the accumulation of AFs in nutmeg, which then results in a very low initial level of contamination for the next stages of the food supply chain. However, it is very difficult to define a PO at the primary production stage. This challenge is due to the fact that most of the primary production actors are mainly small farmers with limited resources. This difficulty is in line with the one concerning applying HACCP at the farm level since no critical control points can be established (Cerf et al. 2011). The validation process of compliance with the PO is not feasible at the primary production level.

\section{Indonesian Risk Management for Aflatoxins in Nutmeg}

Those intensive regulations of AFs in spices have always been the triggering factors of import notifications with regards to nutmeg from Indonesia (Figure 6), notably in 2010, 2015, and 2016. Hence, Indonesia should put more food safety efforts when dealing with this situation, especially when the current food control system is insufficient. In contrast to chloramphenicol in shrimp, the formation of AFs in nutmeg 
can occur throughout the entire food supply chain (farm, transportation, storage, and production). Following the system outlined in Figure 2, actors in the nutmeg food supply chain must apply an appropriate FSMS to prevent noncompliance due to the contamination of AFs. Possible FSMSs are a good agricultural practice (GAP) at the farm level, a good manufacturing practice (GMP) and hazard analysis and critical control point (HACCP) principles at the manufacturing/processing level, and a good distribution practice (GDP) at the storage and transportation stage. Beyond that, the government of Indonesia shall require the exporters to provide a health certificate based on laboratory testing prior to a shipment's export to the EU. It is also critical for Indonesia to establish an FSO equal to the EU's FSO $\left(5 \mu \mathrm{g} / \mathrm{kg}\right.$ for $\mathrm{AFB}_{1}$ and $10 \mu \mathrm{g} / \mathrm{kg}$ for total aflatoxins), as the first and most important strategy to grant market access to the EU. However, most nutmeg farmers in Indonesia currently have not yet met the GAP and GMP standard. The initial contamination (Ho) has already been high at the stage of primary production (Roeroe et al. 2015). Currently, as stipulated in the Head of NADFC Regulation No HK.00.06.1.52.4011, the FSO of spices (powder) is $10 \mu \mathrm{g} / \mathrm{kg}$ for $\mathrm{AFB}_{1}$ and $20 \mu \mathrm{g} / \mathrm{kg}$ for total aflatoxins. ${ }^{74}$ Whereas in the SNI 7385-2009 (Indonesian National Standard), the FSO for AFB1 in spices is $15 \mu \mathrm{g} / \mathrm{kg}$ and for total aflatoxins in spices is $30 \mu \mathrm{g} / \mathrm{kg}$. Different from the EU, there are two different FSOs, each for whole and powder spices. The FSO for powder spices is more stringent than for whole spices since the possibility to be contaminated is higher when the spice is in a powder form than when it is whole (Pesavento et al. 2016). In this case, the government of Indonesia shall provide a full risk assessment to justify the application of a less stringent FSO/ALOP than the ones in the EU. In other words, the government applies the bottom-up approach because currently, the relevant international standard is not yet available. Despite that, Indonesia and other nutmeg importers should use the Codex forum to establish an international standard on the maximum limits of aflatoxins in spices that is less stringent than the one applied in the EU.

Following the establishment of the Implementing Regulation (EU) 2016/24 of January 8, 2016, Indonesian nutmeg received the highest number of import notifications. In response, the government of Indonesia through the Ministry of Agriculture has established a sufficient legal framework, such as the Minister of Agriculture Regulation No 04/ 2015 on food safety control of agrifood produce of plant origin at the exit and entry points; the Minister of Agriculture Regulation No 53/2012 on guidelines for post-harvest handling of nutmeg; the Minister of Agriculture Regulation No 320/2015 on guidelines for production, certification, distribution and control of nutmeg seeds for replanting; the Indonesian National Standard (SNI) 0006:2015 on nutmeg, which encompasses quality control, sampling, analysis methods and labeling; and finally the Minister of Agriculture Regulation No 20/2010, which 74 Attachment of the Head of NADFC Regulation No. HK.00.06.1.52.4011 on maximum level of
microbial and chemical contaminants in foods. 
establishes the requirements for the implementation of good hygiene practice, good manufacturing practice (GMP), and good agricultural practice (GAP) and for procedures based on the hazard analysis critical control points (HACCP) principles and the traceability of foodstuffs, which is still done on a voluntary basis. Beyond the requirement for collectors and exporters to be registered with the competent authorities under the Minister of Agriculture, there is also a plan from the Minister of Agriculture to merge Regulation No 20/2010 and Regulation No 51/2008 on fresh produce registration into a single law for the official control and sampling of all agricultural commodities. However, until now, the merge is not yet realized. This is a cause for concern at the farmer's level, where the harvest time is not proper and the handling is less hygienic as well as at the collector/exporter level, particularly in the process of sorting, in which all nutmegs from different farmers are mixed together and the storing and packaging is not proper. Hence, quality control, best practices (GAP and GMP), and traceability systems, as is required by the Minister of Agriculture Regulation No 53/2012 and Minister of Agriculture Regulation No 20/2010, are difficult or even impossible to apply. We suspect this condition resulted in recurring import notifications in 2017 (4 border rejections).

\subsection{DISCUSSION AND RECOMMENDATIONS}

Harmonized standards have greatly facilitated trade across borders and have often been a de facto prerequisite of such trade (Jørgensen and Schröder 2014). In many instances, however, harmonization of product requirements may not be desirable for other reasons, such as differences in cultural and socioeconomic factors (Sykes 2000). For example, issues related to food availability in the domestic market might influence the choice for harmonization. In other words, there is no general reasoning for or against the harmonization of standards, as this depends largely on the context. In the context of food safety, however, harmonization of standards is desirable in order to provide a high level of protection of public health, to safeguard a consistency of food safety control systems worldwide, and to avoid negative trade effects.

Developed countries require imported products to comply with their strict food laws and regulations when crossing their borders to meet the objective of reducing food safety risks. This is particularly challenging for developing countries since a lack of technological advancements, production facilities, and infrastructure has been constraining the capacity of developing countries to comply with the requirements of developed countries (Murina and Nicita 2014; Athukorala and Jayasuriya 2003).

Ideally, from the perspective of regulators, businesses, and the facilitation of trade, an international standard exists for each agricultural product, which can be used by all countries. In reality, however, there are foods that are not covered by international standards. Even when international standards do exist, some developed countries can apply more stringent food safety laws and regulations due to a risk assessment. In this situation, developing countries need to design better strategies to 
administer their limited capacity in a way that enhances the export performance of their agricultural products and at the same time achieves a comparable level of protection as the level achieved in developed countries.

In the case of chloramphenicol in shrimp, the nature of the hazard is mainly anthropogenic, and the initial contamination is of most relevance to the hazard level. The international standard is available, and Indonesia has an effective national food control system. In this situation, Indonesia has chosen to harmonize its FSO with the one applied in the EU. This is an example of a standards being a catalyst (top-down approach) in the establishment of the FSO/ALOP. The approach has been successful, which is clearly shown in Figure 1, where the frequency of import notifications (information) from the EU dropped significantly from 2005 onwards, with zero notifications from 2009 onwards. Food businesses have been complying with HACCP principles because it is obliged by the law. Besides that, by complying with HACCP principles, food businesses can penetrate more export markets beyond the existing ones. The adoption of the comprehensive system for the control of safety for seafood in Indonesia (e.g., application of HACCP principles in fishery industry) was not, however, solely due to import notifications from the EU. The system was also adopted in response to the accumulation of import notifications from other important Indonesian shrimp export destinations, such as the US and Japan, which commenced in 2005 and 2006, respectively.

In the case of AFs in nutmeg, the hazard is a natural contaminant, and the contamination can occur at all stages of the supply chain. Furthermore, the current national food control system for AFs in Indonesia is relatively weak. Besides that, no international standard exists. In addition, there is a wide gap between Indonesia's and the EU's FSO. With respect to the supply chain actors, most nutmeg farmers in Indonesia are small farmers, who may not be capable to apply GAP properly. Furthermore, the manufacturing process (drying, processing, and packaging) also occurs at this stage. Thus, GMP must also be applied to manage food safety at the primary production stage, especially when considering AFs. This places a heavy burden on the farmer to keep the initial contamination (Ho) of AFs at a low level. The application of GAP, GHP, GDP, etc. has not yet managed to eliminate the risk of AFs (Karlovsky et al. 2016). Based on the above explanation, the loophole is quite obvious, which is the absence of applying the FSO at the food supply chain and to decide critical control points where most food safety efforts should be focused on. Most of the nutmeg farmers are small-scale farmers with limited resources to apply GAP and GHP. Hence, the initial contamination has already been high at the farmer's level. The fact that the concentration of AFs can increase following fungal growth at later stages of the food supply chain and there is a minimum or even absence of control measures at the later stages beyond the primary production stage worsens the situation. Moreover, no traceability system is applied within the food supply chain. All of these 
loopholes have resulted in a high probability of non-compliant nutmeg with respect to the EU's requirements since the level of contamination of AFs in nutmeg cannot meet the EU's FSO or even Indonesia's FSO as stipulated by the Head of the NADFC and in the SNI 7385-2009.

To meet the strict FSO of the EU within this harsh situation and with limited resources, food safety efforts should be allocated mainly at the primary production stages (nutmeg farmers) through meeting the GAP and GHP by focusing the FSMSs on the parameters of moisture content and number of intact kernels in order to avoid the optimum conditions for the development of Aspergillus flavus and its subsequent production of AFs. Such efforts would be hygienic handling, proper drying processes (maintaining the temperature under $45^{\circ} \mathrm{C}$ ), proper packaging, proper storage conditions (maintaining the temperature under $25^{\circ} \mathrm{C}$ and the relative humidity under $62 \%)$, maintaining the kernel moisture content under $10 \%$, and physical sortation to select kernels that are free from damage and insect infestation. To support these technical measures, incentives from the government are essential, like GAP and GHP training for the nutmeg farmers, GDP and GMP training for the collectors/ exporters, and free or subsidized GAP, GHP, GDP, GMP, and HACCP certification schemes. Besides that, in order to make the traceability system applicable, the Minister of Agriculture must realize its plan to merge the regulations on the official control and sampling of all agricultural commodities as well as its plan to establish a mandatory requirement for the registration of collectors/exporters with the competent authorities.

No international standard exists for the ML (FSO) for AFs in spices. Hence, each country establishes its own FSO for AFs in spices, including in nutmeg. The disparity of the FSO between local and export markets makes it increasingly difficult for nutmeg farmers to achieve compliance and to gain market access to developed countries. The recent EU requirement that nutmeg consignments must be accompanied by a health certificate, a requirement which was implemented in 2016, has become the most current control measure from the EU that creates an additional burden for the farmers. The regulation has resulted in a significant increase of import notifications in connection with Indonesian nutmeg at the EU border (see Figure 6, in the year of 2016).

Despite the import notifications, the high demand for Indonesian nutmeg from EU countries and the low supply from other nutmeg exporting countries, such as Granada, should be seen as a great opportunity for Indonesia to apply better food control systems and to develop to better meet the EU consumers' demand. Despite that, the increasing frequency of import notifications has jeopardized the perception of the quality and eventually has led to a decrease in the export value of Indonesian nutmeg. In considering whether to fully harmonize the FSO with the EU, Indonesia cannot just rely on that harmonization, but also has to consider the issue of nutmeg availability in the Indonesian local market and the capability of the actors in the food 
supply chain to implement the FSO. For example, by weighing the risk management options and by taking into account the possibility of the absence of nutmeg in the local market if Indonesia applies the same FSO as the EU.

In contrast to the top-down approach that was successfully applied in the case of chloramphenicol in shrimp, we recommend Indonesia choose the bottom-up approach, which requires a full risk assessment. In addition to the above recommendation, we recommend for Indonesia to take further actions to realize the international standard of maximum limits of AFs in spices that accommodates its socioeconomic factors. However, the establishment of an international standard is a lengthy process. In the meantime, Indonesia must develop effective food control systems to comply with the recent requirement of the EU to accompany every nutmeg consignment with a health certificate. To achieve this, the role of the National Agency for Drug and Food Control (NADFC) should be strengthened through the framework of the National Quality Assurance (NQA) in order to facilitate the testing of nutmegs and to provide a health certificate for export markets (Ministry of Trade 2015). Beyond the considerations of international trade, Indonesia should regard AFs as a priority of the national food safety scheme. We recommend that Indonesia establish a national committee to have the means for implementing effective national food control systems that will reduce the risk of AFs in spices and other agricultural commodities and enhance the quality of these commodities both for the local and export market.

\subsection{CONCLUSION}

In this study, we used the FSO/ALOP framework developed for the application in developing countries to propose better strategies for Indonesia to meet the strict food laws and regulations in the EU. We conclude that the choice of strategy should depend on the nature of the hazard, the existing national food control system, and the existence of the relevant international standard. The FSO/ALOP analysis showed that the topdown approach is more appropriate for coping with the case of chloramphenicol in shrimp. This is due to the nature of chloramphenicol as an anthropogenic contaminant, a relatively well-established food control system, and the existing international standard that prohibits the use of chloramphenicol in food-producing animals. This has proven to be a successful strategy for Indonesia to have more market access to export shrimp not only to the EU but also to other potential export market destinations. In contrast, the bottom-up approach is more appropriate for the case of AFs in nutmeg. This is due to the growth of AFs throughout the stages in the supply chain, a relatively poor national food control system, and the absence of the relevant international standard of AFs in spices. We recommend that Indonesia apply the current FSO of AFs in spices and provide a full risk assessment to justify it. Furthermore, we recommend that Indonesia become actively involved in the establishment of an international standard of the maximum limits of AFs in spices, which accommodates its national interests and constraints. As this process is lengthy, in the meantime the government 
of Indonesia should develop programs to train nutmeg farmers on the application of GAP and GHP and collectors/exporters on the application of GMP and GDP to minimize the initial contamination and the probability of an increase in the contamination level of AFs in nutmeg as well as programs to enhance the National Quality Assurance (NQA) to test the level of AFs in nutmeg. 


CHAPTER 6

GENERAL CONCLUSIONS AND REFLECTION 


\subsection{INTRODUCTION}

The number of non-compliant foods detected in Indonesia increases each year (FAO 2017). This indicates that shortcomings exist in the national food control system in Indonesia. Drawing on existing regulatory literature, it is likely that most of these shortcomings stem from the generally perceived shortcomings of state-centered regulation (Black 2002). In addition, the negative effects associated with the emergence of transnational food safety problems and the strategic role of international trade in the economic development of Indonesia have called upon Indonesian policymakers to strengthen the national food control system through the establishment of better food laws and regulations.

In this thesis, I have developed a policy tool to assess and design more effective laws and regulations with a view towards establishing a stronger national food control system that is based on the requirements of WTO law and food safety science and is particularly tailored to the special socioeconomic prerequisites in developing countries. This tool is termed "FSO/ALOP framework for the application in developing countries". The main research question of this thesis is: How can Indonesia strengthen its national food control system by designing more effective food laws and regulations through the lens of WTO law and food safety science? To address this main research question, four sub-research questions are provided as follows:

1. How to design an effective management tool for developing more effective food laws and regulations in developing countries?

2. Science vs. politics: Which one is the preferred reasoning for determining an ALOP in food trade from a developing country's perspective?

3. In practices, how would the application of the FSO/ALOP framework in developing countries improve Food laws and Regulations in Indonesia?

4. How would the application of the FSO/ ALOP framework in developing countries facilitate export trade from Indonesia to the EU?

In section II, I provide answers to each of these sub-research questions and to the main research question. In section III, I explain the main contributions of this thesis to the literature on international economic law, particularly by introducing food laws and regulations designed with the FSO/ALOP-based tool. Next, in section IV, I reflect upon the main findings of this thesis and the limitation of the research and propose directions for future research. This thesis ends with providing some policy recommendations for the policymakers in Indonesia.

\subsection{SYNTHESIS OF THE RESEARCH}

\subsubsection{Answering the Research Questions}

Research Question 1: How to design an effective management tool for developing more effective food laws and regulations in developing countries? 
I developed an FSO/ALOP framework for the application in developing countries to be used as a tool to design more effective food laws and regulations in Indonesia. This tool draws on the requirements set by WTO-SPS law and food safety science and is tailored to the socioeconomic prerequisites of developing countries. The tool consists of three steps:

1. Setting a risk profile through a qualitative risk assessment and determining an FSO/ALOP through a quantitative risk assessment

The first step consists of two phases. First, a risk profile needs to be set. In this respect, an effective establishment of an FSO/ALOP requires careful consideration since food is likely to have a significant impact on public health (ICMSF 2006). Governments (food safety authorities) shall establish a risk profile based on a qualitative risk assessment that consists of a hazard assessment, a hazard characterization, an exposure assessment and a risk characterization. The product of this risk assessment is a qualitative risk estimate, which determines whether the risk is low, medium, or high.

Based on that risk profile, if it is found that the risk is high and needs to be minimized or eliminated, then food safety authorities can go to the second phase, which is the determination of the FSO/ALOP. This phase is determined by using a quantitative risk assessment while considering socioeconomic factors. However, special attention needs to be given to the fact that food safety infrastructure and resources in developing countries are very limited in terms of conducting such quantitative risk assessments. Hence, developing countries do need to resort to alternative risk assessment approaches apart from the conventional approach used by developed countries. In this thesis, I have developed alternative methods for conducting a quantitative risk assessment, which can be categorized as the top-down and bottom-up approach. The top-down approach refers to the use of epidemiological data to determine the FSO/ALOP. By contrast, the bottom-up approach refers to the use of supply chain data to determine the FSO/ALOP. With regard to accuracy, the top-down approach has more advantages compared to the bottom-up approach. However, both are legally acceptable methods of risk assessment with respect to the SPS Agreement. In developing countries where the epidemiological data are very limited, the top-down approach is difficult to apply. Instead, the bottom-up approach, which uses the supply chain data, can be used as an alternative to establish the FSO/ALOP. Using these approaches will allow the developing countries to design science-based laws and regulations, while taking into account data gathered from the socioeconomic needs of the country or at least using the most similar data available.

2. Food business determines their own performance objectives (POs), and food control institutions limit themselves to the task of overlooking the performance of food businesses in achieving their POs. 
The second step consists of the enforcement of compliance control via food laws and regulations. Food businesses, which will be enabled to determine their own POs, have the responsibility of maintaining the compliance of their products. To ensure that these POs are set at a scientifically sound level, these POs need to conform to the FSO. Establishment of POs will be framed by guidelines from the government in order to enable food businesses to fulfill their responsibilities. Public food control, on the other hand, shall oversee the compliance of businesses based on the POs.

3. Appropriate monitoring and review - A successful implementation of the FSO/ALOP framework requires an effective monitoring and review.

The third step consists of designing a risk management plan (RMP) model for the successful implementation of the FSO/ALOP concept. The RMP shall be drawn and governed by food control authorities, as they are in the position to oversee whether businesses achieve the FSO/ALOP. The provision of such an RMP makes it easier for businesses to comply with existing food laws and regulations, reduces the cost of inspection and compliance for food authorities as well as aids in the avoidance of redundant monitoring and review.

Research question 2: Science vs. politics: Which one is the preferred reasoning for determining an ALOP in food trade from a developing country's perspective?

The determination of the FSO/ALOP is indeed a political process. The determination of the FSO/ALOP is part of the risk management of food safety authorities, which involves weighing political factors, such as citizens' trust, bureaucracy, trade control and consumer protection, and science factors, such as a risk assessment and information about the technical expertise of food businesses. Despite that, to provide an accurate and objective FSO/ALOP, the decision-making process must be based on science factors that are represented in the form of a risk assessment. To this end, there is no study about the preferences of developed and developing countries with respect to determining the FSO/ALOP, much less that information in a quantitative form derived from comparable situations. In this thesis, I have illustrated the implementation of several political and scientific ALOP determinations in a comparable situation (radioactive contaminants in foods following the Fukushima nuclear accident) by two developed entities (the EU and Japan) and compared them to an developing entity (Indonesia) by using the FSO/ ALOP framework for developing countries.

Following the Fukushima nuclear accident, Japan determines its FSO/ALOP for radioactive contaminants in foods based on a quantitative risk assessment (MHLW 2012a). However, despite the fact that the outcome of the risk assessment showed a low risk of radioactive contaminants in foods, the Japanese food safety authorities increased the level of protection for political reasons, mainly to maintain consumer trust in the domestic market as well as to maintain consumer trust in the international 
market. The EU followed suit without carrying out their own risk assessment. ${ }^{75}$ According to the Implementing Regulation No 351/2011, the reason for this decision was to safeguard the consistency with the FSO/ALOP applied in Japan. ${ }^{76}$ However, Indonesia has taken a different approach by applying its own FSO/ALOP that is less stringent compared to the FSO/ ALOP applied by Japan and the EU. ${ }^{77}$ The Indonesian $\mathrm{FSO} / \mathrm{ALOP}$ in the new regulation (following the Fukushima nuclear accident) is even less stringent than the ones in the previous regulation (following the Chernobyl nuclear accident). ${ }^{78}$ However, its value is still higher than the one proposed by Codex. Indonesia did not conduct a risk assessment; however, ironically the Indonesian FSO/ALOP is mostly in line with the outcome of the risk assessment conducted by Japan and adopted by the EU.

In response to the Fukushima nuclear accident, Japan, the EU, and Indonesia have intentionally adopted a political approach to the establishment of their FSO/ALOP for radioactive contaminants in foods. While Japan and EU both used risk assessment as a shield to hide their political decision for a higher FSO/ALOP, Indonesia chose a higher level of protection based on purely political determinations. This may arguably be categorized as an infringement of the SPS agreement, which requires no impositions of unjustified trade barriers if risk profiles and conditions are comparable.

I have shown that if the FSO/ALOP framework for developing countries, as proposed in this thesis, had been applied, the outcome would have been more in line with the requirements of WTO law, food safety science, and socioeconomic prerequisites. The proposed FSO/ALOP would have entailed a high level of consumer protection based on scientific necessity and hindered an unnecessary trade barrier between these three countries. By applying a quantitative approach based on the principle of international radiological protection of ICRP and Codex, I unfolded the reason behind the political decision of the determination of the FSO/ALOP done by Japan, the EU, and Indonesia and weighed it against the scientific solution to do so.

Research question 3: In practice, how would the application of the FSO/ALOP framework for the application in developing countries improve food laws and regulations in Indonesia?

\footnotetext{
75 See Commission Implementing Regulation (EU) No 322/2014 of March 28, 2014, which imposes special conditions governing the import of feed and food originating in or consigned from Japan following the accident at the Fukushima nuclear power station.

76 See Commission Implementing Regulation (EU) No 351/2011 of April 11, 2011 amending Regulation (EU) No 297/2011, which imposes special conditions governing the import of feed and food originating in or consigned from Japan following the accident at the Fukushima nuclear power station.

77 See Minister of Health Regulation No 1031/MENKES/PER/V/2011 on the maximum level of radioactive contaminant in food. Translated by $\mathrm{D}$. Wahidin.

78 See Minister of Health Regulation No 00474/B/II/87 on the Requirement to Attach Health Certificate and Certificate of Analysis of Radiation free for Imported Food. Translated by D. Wahidin.
} 
Despite the existence of a mandatory GM food labeling regulation, GM food labels are largely absent from the Indonesian market. ${ }^{79}$ One reason for this shortfall is the lack of surveillance mechanisms. ${ }^{80}$ The partially implemented GM food labeling regulation in Indonesia is related to the unnecessarily high level of the FSO/ALOP in a situation where surveillance mechanisms, i.e. the inspection and laboratory services, are very limited to be able to enforce the regulation. To remedy this shortfall and to allow the meeting of the desirable public health goals, a legal reform of the current GM food labeling regulation needs to be taken by the government of Indonesia. Therefore, in this thesis, I have applied the FSO/ALOP framework for developing countries to the legal reform of GM food labeling in Indonesia to illustrate how this tool works in developing countries to reform laws and regulations in a situation where the surveillance mechanisms are poor.

By applying the FSO/ALOP tool, I was able to show that the top-down approach identified in chapter 2 is more appropriate for legal reforms in developing countries. The top-down approach entails the use of epidemiological data, whereas the bottomup approach entails the use of supply chain data. However, in terms of the special cases of GM foods where sufficient data for those two approaches are not available, both approaches are needed for realignment. Comparative law is used in the top-down approach, while taking into account similar GM food labeling regulations in the EU, US, Japan, Malaysia, and China as the baseline for legal reform in Indonesia.

Interpreting these findings, I propose a reform of the current GM food labeling regulation to be done by the government of Indonesia. The first proposal is to establish a voluntary $\mathrm{GM}(\mathrm{O})$-free labeling scheme along with the existing mandatory labeling scheme. This voluntary $\mathrm{GM}(\mathrm{O})$-free labeling scheme will be attractive for food businesses that would like to establish a market share in a niche for consumers who are actively looking for $\mathrm{GM}(\mathrm{O})$-free foods. Alongside that, the responsibility of assessing the validity of the claim falls to food businesses, which leads to a reduction in the cost of enforcement for the food safety authority. The second proposal is to change the current 5\% threshold level to the level of 3\% as the determining limit for whether the GM food has to be labeled or not. This new threshold level must be combined with a traceability system in order to ensure the applicability of the surveillance mechanisms of the food safety authority. Applying a lower threshold would be an additional burden on both the food safety authority and food businesses, especially when taking into account the currently limited food safety infrastructure and resources in Indonesia. The traceability system will ensure that operators identify their supplier and the companies to which the products have been delivered; moreover, it will ensure the applicability of the threshold level as the food safety

\footnotetext{
79 See the Head of the NADFC Decree No HK.03.1.23.03.12.1564/2012 on the GM food labelling control. Translated by D. Wahidin.

80 See the Head of the NADFC Decree No HK.03.1.23.03.12.1564/2012 on the GM food labelling control. Translated by D. Wahidin.
} 
objective (FSO). More sophisticated exemptions from the labeling requirement also need to be established in order to restrict the scope of the labeling and to ensure the legal certainty of the GM food labeling regulation. Finally, to improve the understanding of consumers, I propose to limit the GM ingredients on the label to three items. This regulation will positively affect the costs associate with compliance and enforcement, especially pertaining to the analysis and detection of a GM event.

Research question 4: How would the application of the FSO/ALOP framework for developing countries facilitate export trade from Indonesia to the EU?

In this study, I used the FSO/ALOP framework for the application in developing countries to investigate strict food laws and regulations adopted by developed countries and the potential strategies that can be adopted by developing countries to meet these laws and regulations and use them to increase their level of food safety. In this thesis, I have analyzed two food safety cases in the international trade between Indonesia and the EU: chloramphenicol in shrimp and AFs in nutmeg. I conclude that the choice of strategy should depend on the nature of the hazard, the existence of a relevant international standard, and the existing food safety control systems.

The case studies showed that the top-down approach with respect to the findings of chapter 3 is more appropriate as a strategy for dealing with the food safety regulation concerning chloramphenicol in shrimp. This is due to the nature of chloramphenicol as an anthropogenic contaminant, the presence of a relatively wellestablished food control system, and the existing international standard that prohibits the use of chloramphenicol in food-producing animals. In contrast, the bottom-up approach is more appropriate for dealing with the food safety regulation concerning AFs in nutmeg. This is due to the growth pattern of AFs throughout all stages of the supply chain, the presence of a relatively poor food safety control system, and the absence of the relevant international standard for AFs in spices.

\subsubsection{Answering the Main Question}

\section{How can Indonesia strengthen its national food control system by designing more effective food laws and regulations through the lens of WTO law and food safety science?}

Based on the findings in this thesis, I argue that the FSO/ALOP framework for the application in developing countries can assist Indonesia in improving its national food control system. Summing up the main findings of chapter 2, I have shown that based on the FSO/ALOP framework for developing countries, Indonesia should only establish an FSO/ALOP if it is required, for example, if the hazard/food combination significantly affects the public health or if the food is intended for vulnerable consumers, such as infants, pregnant women, or elderly people. Therefore, to strengthen the national food control system in a situation where the food safety infrastructure and resources are limited, Indonesia needs to establish a risk ranking 
based on a risk profile based on a qualitative risk assessment in the determination of the FSO/ALOP. This strategy will ensure effective resource management for the law enforcement, such that they are only focused on the most important food safety problems based on the risk ranking.

Summing the findings in chapter 3: For developing countries such as Indonesia, conducting a full risk assessment as the basis for the establishment of food laws and regulations has proven to be difficult. As a remedy, Indonesia may resort to the relevant international standard in order to strengthen its national food control system. If no standard is available, Indonesia may resort to similar laws or regulations in other countries. In this respect, a comparative analysis can form an alternative method for the determination of the FSO/ ALOP.

Summing the findings in chapter 4: Indonesia has established a complete set of food laws and regulations that have similar functions compared to the ones established in developed countries. However, as requirements are too stringent and/or postmarket control is absent, compliance based on those rules and regulations is ineffective. Therefore, the most rational option for the government of Indonesia to strengthen its national food control system is to reform the existing food laws and regulations based on the existing capacity of the post-market control (inspection and laboratory activities).

Summing the findings in chapter 5: I showed that the application of the FSO/ALOP framework for developing countries within Indonesian food control systems can determine their effectiveness in terms of facilitating export trade with developed countries. A stringent application of the three criteria of the FSO/ALOP framework for developing countries has the potential to enable Indonesian food businesses to comply with the higher standards of foreign developed export markets in a situation where the resources are limited. I illustrated with the example of export trade in nutmeg and shrimp how the FSO/ALOP framework for developing countries can be used to assess the successes and failures of export trade with the EU and how a stringent application of the FSO/ALOP framework can improve such market access. For shrimp, I could show that Indonesian exports have been successful because they largely adopted EU standards. In the case of nutmeg, however, access to export markets was not successful because EU standards could not be adopted. The application of the FSO/ALOP framework showed that this discrepancy is due to differences in the nature of each hazard, the nature of the food supply chain, and the availability of a relevant international standard. After having been able to precisely identify the shortfalls via the adoption of the FSO/ALOP framework developing countries, I recommend that the government of Indonesia apply three criteria of the FSO/ALOP framework for developing countries in order to create better strategies in dealing with the more stringent food laws and regulations of developed countries and to increase the access to markets in these developed countries. Specifically, to 
strengthen its national food control system, I propose that the government of Indonesia implement an appropriate risk profiling on a case by case basis as the first phase to enable accurate and effective food control options to meet the importing countries' FSO/ALOP. In that respect, I recommended that the government of Indonesia establish its own FSO/ALOP regarding the AFs in spices, including nutmeg, through the provision of a sound risk assessment. In addition to those recommendations, I recommend that the government of Indonesia get involved in the Codex forum in order to lobby for an international standard of regulatory limits on AFs in spices, including nutmeg, which are less stringent than the ones in the EU.

\subsection{THEORETICAL CONTRIBUTIONS}

The first contribution is the enrichment of the solution from the decentered regulation theory (Black 2002). I argue that the solution, decentered regulation, should be applied with care in the case of Indonesia. The FSO/ALOP framework for developing countries can instead be used to align food safety control systems and the socioeconomic prerequisites of Indonesia with decentered regulation. The first aspect of decentered regulation is the complexity that refers to the causal complexity and to the complexity of interactions between actors in society. Under the FSO/ALOP framework for developing countries, there are two phases of complexity: the complexity of risk assessors and risk managers as well as the complexity of risk managers and food businesses. The first phase of the complexity is involving an intensive interaction between a food safety authority as the risk manager and an independent scientific body as the risk assessor and each of their competence risk management and risk assessment. The interaction is referred to as risk communication. In practice, it is often impossible to distinguish between these competencies, risk assessments (allegedly objective) and risk managements (allegedly subjective) in the decision-making regarding risk regulation (Poortvliet et al. 2016). A hybrid between risk assessment and risk management (risk hybrid) can provide an environment where risk communication affects the realities of risk regulation (Poortvliet et al. 2016).

The concept of a risk hybrid aligns with the FSO/ALOP framework for developing countries. In the step of risk profiling, the risk manager makes a request to the risk assessor to establish a risk profile through a qualitative risk assessment of the concerned food safety problem. The risk assessor can inform the risk manager to either act further or do nothing. If the risk manager chooses to act further, then another request is sent to the risk assessor to develop an FSO/ALOP through a quantitative risk assessment. The risk manager then weighs the proposed FSO/ALOP taken from the risk assessor with other factors, such as socioeconomic and political factors in order to establish it as the legal code (regulatory limit).

In the second phase, the food safety authority (risk manager) verifies the implementation of the FSO/ALOP in the food supply chain. Food businesses can inform the government on the implementation of the FSO/ALOP through their 
evaluation, which is based on internal audits combined with the RMP (risk management plan) model. The food safety authority can also use the information from the food businesses to evaluate the FSO/ALOP. These two phases of complexity in the FSO/ALOP framework have shown that the risk communication can change the realities of the risk regulation.

The second aspect of decentered regulation is the fragmentation and construction of knowledge, which refers to the notion that no single actor possesses all the knowledge required to solve complex, diverse, and dynamic problems and that no single actor has the sufficient overview to use all the infrastructures and resources required to provide effective regulation (Black 2002). Under the FSO/ALOP framework, to solve the problems, all food safety stakeholders, i.e., food safety authorities, food businesses, and consumers, have to work hand in hand through sharing knowledge and managing available food safety infrastructure and resources. The ALOP shall be seen as the society's acceptable level of risk as the result of the knowledge and efforts of food safety stakeholders to minimize or eliminate the risk with respect to the existing food safety infrastructure and resources. By contrast, the FSO shall be seen as the operational objective of the efforts to ensure food safety by achieving the ALOP. The FSO is the maximum concentration or level of a hazard at the point of consumption (the end of the food supply chain). Any significant failure on the previous stages of the food supply chain could result in a food safety hazard. In other words, food businesses, especially at the production stage, shall ensure that the level of a hazard starting from the primary production until distribution stays below the level of the FSO. Food safety authorities shall monitor and verify the performance of food businesses to maintain the level of a food safety hazard below the FSO level through on-site inspections at the production stage and a post-market surveillance system. In addition, food safety authorities and food businesses shall educate the consumers by sharing knowledge and information on how to handle food according to its intended use to avoid food safety hazards. Nevertheless, food safety is all about the probability. Food businesses must improve their probability of producing safe foods and conduct a necessary modification in their risk management efforts if the probability is lower than the expected objective. Whereas, the consumers must improve their probability to consume safe foods and conduct a necessary change in their ways of purchasing, handling and processing foods if they find that their current food purchasing, handling, and processing can attract food safety hazards. Food safety authorities shall determine an accurate FSO and create a conducive business environment so that food industries can meet the FSO and increase the probability of safety at the point of consumption (the consumer level).

The third aspect is the fragmentation of the exercise of power and control, which refers to the recognition of the absence of the government's monopoly on the exercise of power and control. Instead, it is fragmented between social actors and not between 
actors and government (Black 2002). This aspect is strongly related to the fourth aspect of decentered regulation, which is the recognition of the autonomy of social actors, which refers to the freedom of actors to develop or act in their own way without any intervention (Black 2002). Under the FSO/ALOP framework, food safety authorities are obliged to determine an FSO/ALOP if they are convinced that the food/hazard combination can significantly affect the public health. Based on the decided FSO, food businesses have the right, which is given by law, to establish their own POs that are equivalent to the FSO. Moreover, food businesses are given the autonomy to implement their own control measures to meet their POs, which informs the FSO/ALOP. If it is found that a food business is not able to meet its POs, food safety authorities can interfere in the way that the food business implements its control measures via the corrective and preventive action (CAPA) mechanism.

The fifth aspect is the existence and complexity of interactions and interdependencies between social actors and the government in the process of regulation. This aspect refers to the fact that society and the government both have problems and solutions and are interdependent. The fifth aspect leads to the sixth aspect, that is, the collapse of the public/private distinction. This aspect refers to the absence of a formal legal sanction that forms the regulation. It is the product of the interaction between social actors and the government without the exercise of power and control from the government. Under the FSO/ALOP framework, this aspect can be partially applied. The one who has the primary responsibility for dealing with food safety hazards is the food businesses. Appropriate food safety management systems (FSMSs) must be applied by food businesses to ensure the safety of their products. Whereas, food safety authorities are responsible for the verification of the safety of the products by evaluating the applied FSMSs and carrying out on-site inspections and post-market controls to ensure the compliance of food businesses. This two-way process is the form of interdependencies between food businesses and food safety authorities in the implementation of the FSO/ALOP framework. The interdependencies take a different form in the determination of FSO/ALOP. Food businesses are not directly involved in the FSO/ALOP decision-making process, but they can inform food safety authorities about their performance in achieving the FSO/ALOP. Legal sanctions are still relevant in the FSO/ALOP framework for maintaining the compliance of food businesses.

The seventh aspect of decentered regulation is the set of normative propositions as to the regulatory strategies that should be adopted. This aspect refers to the hybrid concept, where the government and non-governmental bodies are combined and a number of diverse strategies are used simultaneously or sequentially and indirectly (Black 2002). Under the FSO/ALOP framework and as explained in the complexity aspect, it is required to conduct an appropriate risk communication based on the risk hybrid concept, where the risk assessor and risk manager are intermingled in the 
decision-making and implementation of the FSO/ALOP. The FSO is the tool used by food safety authorities to communicate to food businesses, and it acts as the target of food businesses' FSMSs to further inform the ALOP. Moreover, food safety authorities are required to apply a number of diverse strategies simultaneously or sequentially to ensure that food businesses can meet the FSO/ALOP. The decision-making of these strategies will be effective if there is an appropriate risk profile that comprises a hazard identification, a hazard characterization, an exposure assessment, and a risk characterization.

The second contribution is the development of the FSO/ALOP framework as an effective management tool in developing food laws and regulations in Indonesia. This becomes important following the increasing awareness of the government of Indonesia towards food safety issues. The NADFC is currently formulating a new food safety regulation to replace the Government Regulation No 28/2004 on food safety, quality, and nutrition. ${ }^{81}$ Therefore, the FSO/ALOP framework can be used in the decision-making process of the new government regulation on food safety to ensure that the new regulation can be effective in protecting the health of Indonesian citizens.

\subsection{REFLECTION}

\subsubsection{Limitations of the Research}

There are at least two limitations of this research that require further elaboration. First, this thesis only focuses on public regulations. I put the primary focus of this thesis on the public regulations since the aim of this thesis is to strengthen the national food control system that covers only mandatory regulatory activity. Private standards, liability, and insurance as important regulative tools in food safety governance have not been taken into account in this research. However, the role of private standards is currently becoming an important part of food safety governance in both developed and developing countries. There are also concerns about the emergence of these private standards and their implications for developing countries, particularly in the food supply chains that are governed by these standards. Based on that observation, in principle, there is a need to make a close relationship between public regulations and private standards. Thus, the governments of developing countries should also take into account private standards in the representation of market demands in developed countries when determining their FSO/ALOP.

The second limitation is the lack of primary data on the actual practices of the FSMS in the food industries. The availability of this data will boost the validity of the FSO/ALOP framework for the application in developing countries and thereby help to address the capacity of food industries to meet the FSOs that provide the ALOP. By identifying the capacity of the food industries, the determination and evaluation of the

81 See Peraturan Pemerintah No 28 Tahun 2004 tentang Keamanan, Mutu, dan Gizi Pangan. Translated by D. Wahidin, available at http:/ / peraturan.go.id/pp/nomor-28-tahun-200411e44c4ee74173f09491313231373239.html. 
FSO/ALOP will be more feasible and accurate. Additionally, the information on the technological advancement of the food industries will become available, which then can be used by the government in the determination of the FSO/ALOP framework for developing countries. Unfortunately, the data of the actual practices of the FSMS by the food industries in Indonesia are currently not available. The government of Indonesia (NADFC) currently implements the risk management plan (RMP) program, which can be used as a tool to harvest the data on the actual practices of the FSMS in the food industries. However, the scope of the RMP is still limited to certain high-risk food industries. Despite that, in the near future, this RMP program can be a potential tool in the determination phase and in the evaluation phase of the FSO/ALOP.

\subsubsection{Directions for Future Research}

The FSO/ALOP framework for the application in developing countries can provide the way for Indonesia to have an effective national food control system through the reform of food laws and regulations. However, there are other areas that need further elaboration beyond food laws and regulations (Figure 9), such as food control management inspection services; laboratory services (food monitoring and epidemiological data); and information, education, communication, and training. The elaboration of the FSO/ALOP framework for developing countries in those areas can integrate all resources and food safety institutions to reach the same goal, which is to protect the people and to gain access to export markets.

Besides that, there is another aspect of the FSO/ALOP framework for the application in developing countries that need to be investigated, which is the economics of the FSO/ALOP. To this end, from the economic perspective, we define the ALOP as a static equilibrium where the margin of the benefit over cost of food safety measures is maximized. The benefit is always increasing when the level of food safety is increasing. However, the yield of the benefit decreases along with an increase in the cost of food safety measures. Food businesses naturally desire an optimum profit, where the marginal cost equals with the marginal benefit. Under the FSO/ALOP framework for the application in developing countries, additional costs are associated with the application of food safety management systems (GMP, GHP, and HACCP) in their operation. These costs will increase along with the increase of FSO/ALOP stringency, and the additional costs will drive the price of the product up. In the short run, from the perspective of international trade, if the importing country establishes new food laws and regulations with a more stringent FSO, the supply from the exporting country will decline. However, in the long run, the impact is uncertain. We expect that the economics of the FSO/ALOP framework for developing countries will shed light on the impact of more stringent food safety laws and regulations of developed countries in the long run and provide strategies for developing countries to handle these laws and regulations and to see them as the catalyst for better national food control systems and better export opportunities. 


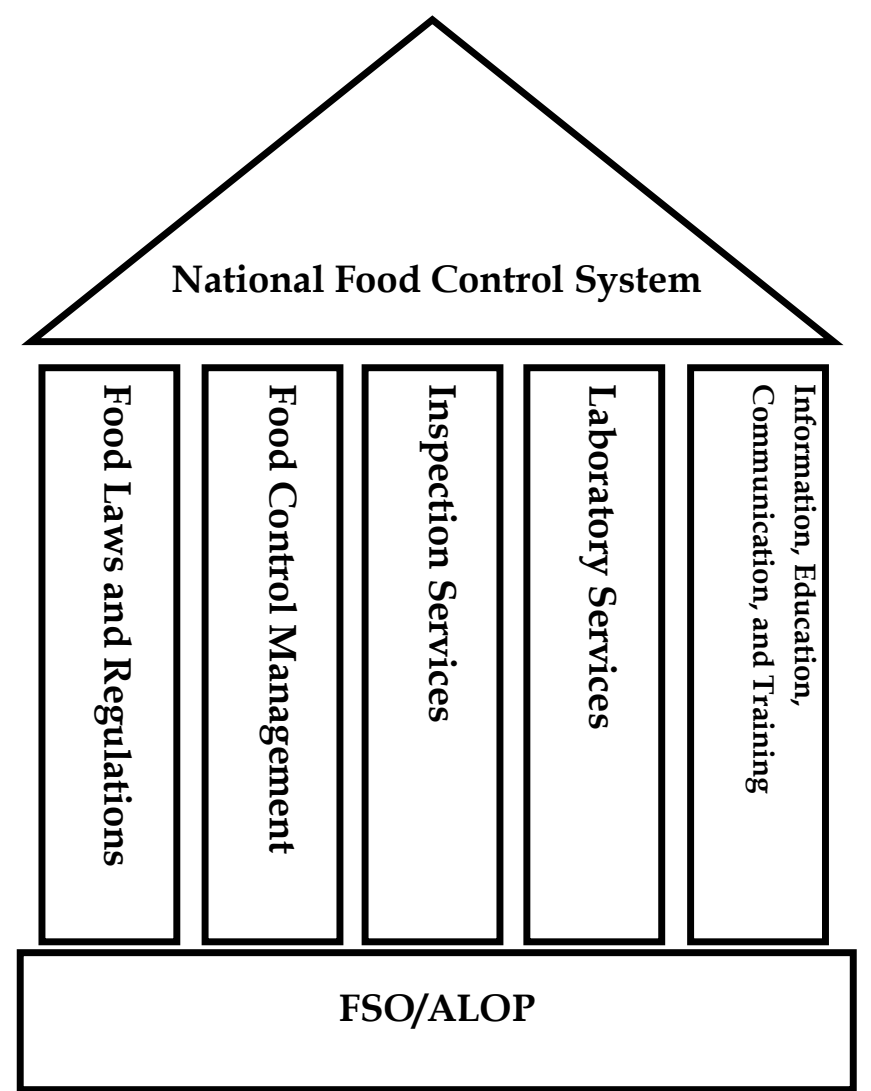

Figure 9. FSO/ALOP-based national food control system, adapted from FAO/WHO.

\subsection{POLICY RECOMMENDATIONS}

In this section, I set two additional policy recommendations to complement the aforementioned recommendations in the answers to the main research questions. First, as previously explained in this thesis, there is a need to establish an independent scientific committee in Indonesia to do a risk assessment, to assess the priority for the national food control system, to assess the capacity of the existing FSMS of the food industries, and in the end to determine scientific recommendations for the establishment of the FSO/ALOP. A representative from food safety authorities (MoA, MoMAF, MoH, NADFC, MoI, and MoT), academics, food industry associations, and consumer protection organizations should be involved in the scientific committee. This composition of stakeholders will make the integration of food safety governance, food safety science, technical expertise, socioeconomic, and consumer interest in the determination of an appropriate FSO/ALOP possible. Despite that, in the end, the FSO/ALOP-decision making is a political process. However, by ensuring the availability of a proper scientific recommendation, the political process will be more on the objective side due to its consideration of scientific and socioeconomic factors.

Second, the government of Indonesia (NADFC) has been officially installing the RMP program since 2017 through the establishment of the Head of NADFC Regulation No 2/2017 on the implementation of the food safety risk management program in food 
industries. ${ }^{82}$ To this end, this program has only been required for certain food industries that produce infant formulas and commercial sterile foods. The aim of this program is for food industries to consistently apply a FSMS. Through this program, there is a shift from government-based food control to self-regulatory control, where food industries take the full responsibility for ensuring the safety of their products. The scope of food control will be based on a risk profile of the food industry related to any history of infringements, non-compliance products, consumer reports, and withdrawal reports. To be more meaningful in the efforts of strengthening the national food control system, the RMP program should also be applied to the importers and home industries. Related to the self-regulatory control in the RMP, as explained in this thesis, the FSO/ALOP framework for developing countries provides more flexibility to food industries. Specifically, they can set their own control measures and technology in their FSMS as long as they can meet the FSO/ALOP. The RMP is actually aligned with the FSO/ALOP framework for developing countries. Therefore, I recommend that the government of Indonesia improve this RMP program to become a tool to harvest data on the actual practices of the FSMS in food industries in order to eventually strengthen its national food control system and thereby become an essential part of the FSO/ALOP framework for the application in developing countries.

82 The Head of NADFC Regulation No 2/2017 on the implementation of the food safety risk management program in food industries, translated by D. Wahidin; and see the NADFC 2018 risk management program. National Agency of Drug and Food Control (NADFC) 2017 [cited 15 January 2018]. Available from http://pmr.pom.go.id/index.php. 


\section{BIBLIOGRAPHY}

Akhtar, S., M. R. Sarker, and A. Hossain. 2014. Microbiological food safety: a dilemma of developing societies. Critical Reviews in Microbiology 40 (4): 348359. http:/ / dx.doi.org/10.3109/1040841X.2012.742036.

Angulo, F. J., P. Collignon, J. H. Powers, T. M. Chiller, A. Aidara-Kane, and F. M. Aarestrup. 2009. World Health Organization ranking of antimicrobials according to their importance in human medicine: a critical step for developing risk management strategies for the use of antimicrobials in food production animals. Clinical infectious diseases 49 (1): 132-141.

ASEAN. 2017. ASEAN Common Principles for Food Control Systems. ASEAN.

Athukorala, P. C., and S. Jayasuriya. 2003. Food safety issues, trade, and WTO rules: a developing country perspective. The World Economy 26 (9): 1395-1416.

Atik, J. 2011. On the Efficiency of Health Measures and the 'Appropriate Level of Protection'.

Balonov, M. I., L. R. Anspaugh, A. Bouville, and I. A. Likhtarev. 2007. The contribution of internal exposures to the radiological consequences of the Chernobyl accident. Radiation Protection Dosimetry 127 (1-4): 491-496. http://dx.doi.org/10.1093/rpd/ncm301.

Bansal, S., and G. Gruère. 2010. Labeling genetically modified food in India: economic consequences in four marketing channels. International Food Policy Research Institute (IFPRI). Available at http://indiaenvironmentportal.org.in/files/ifpridp00946.pdf (accessed 05.05.2017).

BATAN. 2017. Survey of people's acceptance on Nuclear power plant Jakarta: Indonesian National Nuclear Energy Agency (BATAN). Available at http:/ / drive.batan.go.id/gunber/?page=9 (accessed 12.06.2017).

Bawa, A. S., and K. R. Anilakumar. 2013. Genetically modified foods: safety, risks and public concerns - a review. Journal of Food Science and Technology 50 (6): 1035-1046. http://dx.doi.org/10.1007/s13197-012-0899-1.

Black, J. 2001. Decentring Regulation: Understanding the role of regulation and selfregulation in a post-regulatory world. Current legal problems 54 (1): 103.

- - - 2002. Critical reflections on regulation. Austl. J. Leg. Phil. 27: 1.

BPS-Statistics Indonesia. 2016. Statistical yearbook of Indonesia. edited by BPSStatistics Indonesia. Jakarta: BPS-Statistics Indonesia.

Byrne, P., D. Pendell, and G. Graff. Labeling of Genetically Modified Foods. Colorado State University 2014 [cited 13 November 2017. Available from https:// extension.colostate.edu/docs/pubs/foodnut/09371.pdf.

CAA. Distribution Manual for Genetically and Non-genetically Modified Hawaiian Papayas Consumer Affairs Agency, Government of Japan 2011 [cited 13 November 2017. Available from http://www.caa.go.jp/en/pdf/syokuhin736.pdf. 
Cabello, F. C., H. P. Godfrey, A. Tomova, L. Ivanova, H. Dölz, A. Millanao, and A. H. Buschmann. 2013. Antimicrobial use in aquaculture re-examined: its relevance to antimicrobial resistance and to animal and human health. Environmental Microbiology 15 (7): 1917-1942. http:/ / dx.doi.org/10.1111/1462-2920.12134.

CAC. 2010. Codex Stan 193-1995 laying down contaminants and toxins in foods and feeds. Amended 2010.

- - - . 2015. Maximum Residue Limits (MRLs) and Risk Management Recommendations (RMRs) for residues of veterinary drugs in foods Codex Alimentarius Commission.

- - - 2016a. Codex Alimentarius Commission Procedural Manual. Twenty-fifth edition. FAO/WHO.

- - - 2017. Is Codex promoting genetically-modified food (GM foods) and irradiated food? What about organic or halal foods? Codex Alimentarius Commission 2016b [cited 13 November 2017]. Available from http:/ / www.fao.org/fao-whocodexalimentarius/faqs/specific-codex-work/en/.

Callon, M. 2009. Acting in an uncertain world: MIT press.

Cantrell, B. 2015. Food, the State and Development: A Political Economy of Agriculture and Trade in Indonesia.

Caplan, A. GMO Foods Should be Labeled, But Not for Safety: Bioethicist. http://www.nbcnews.com/health/health-news/why-gmo-foods-should-be-labeledn423451 (accessed 27.01.2017) 2015.

Carter, C. A., and G. P. Gruère. 2003. Mandatory labeling of genetically modified foods: does it really provide consumer choice? AgBioForum 6(1\&2) 68-70. Available at http://www.agbioforum.org/v6n12/v6n12a13-carter.htm (accessed 01.06.2017).

CBI. 2018. CBI Product Factsheet: Nutmeg in Europe. CBI-EU 2016 [cited 3 January 2018]. Available from

https://www.cbi.eu/sites/default/files/market_information/researches/pro duct_factsheet___nutmeg_in_europe_2016.pdf.

CDC. Risk Management Practice Guide. CDC 2006 [cited 11 December 2017. Available from

https://www2a.cdc.gov/cdcup/library/practices_guides/CDC_UP_Risk_M anagement_Practices_Guide.pdf.

- - - 2017. ALARA - As Low As Reasonably Achievable. CDC 2015 [cited 14 December 2017]. Available from https://www.cdc.gov/nceh/radiation/alara.html.

Cerf, O., E. Donnat, and F. H. W. Group. 2011. Application of hazard analysisCritical control point (HACCP) principles to primary production: What is feasible and desirable? Food Control 22 (12): 1839-1843. 
Chain, E. P. o. C. i. t. F. 2014. Scientific Opinion on Chloramphenicol in food and feed. EFSA Journal 12 (11): 3907-n/a. http://dx.doi.org/10.2903/j.efsa.2014.3907.

Christodouleas, J. P., R. D. Forrest, C. G. Ainsley, Z. Tochner, S. M. Hahn, and E. Glatstein. 2011. Short-term and long-term health risks of nuclear-power-plant accidents. New England journal of medicine 364 (24): 2334-2341.

Clarke, R., and J. Valentin. 2009. ICRP publication 109. Application of the Commission's Recommendations for the protection of people in emergency exposure situations. Annals of the ICRP 39 (1): 1-110.

Cole, M. 2004. Food safety objectives: Concept and current status. Mitteilungen aus Lebensmitteluntersuchung und Hygiene 95 (1): 13-20.

Cornel University. 2016. Aflatoxins: Occurrence and Health Risks 2015 [cited 7 December 2016]. Available from http://poisonousplants.ansci.cornell.edu/toxicagents/aflatoxin/aflatoxin.ht $\underline{\mathrm{ml}}$.

De Swarte, C., and R. Donker. 2005. Towards an FSO/ALOP based food safety policy. Food Control 16 (9): 825-830.

Dey, M. M., M. A. Rab, K. M. Jahan, A. Nisapa, A. Kumar, and M. Ahmed. 2005. FOOD SAFETY STANDARDS AND REGULATORY MEASURES: IMPLICATIONS FOR SELECTED FISH EXPORTING ASIAN COUNTRIES. Aquaculture Economics \& Management 9 (1-2): 217-236. http://dx.doi.org/10.1080/13657300590967450.

DG SANCO. 2010. Evaluation of the EU legislative framework in the field of GM food and feed Brussel: European Commission: Directorate General for Health and Consumers

- - - 2012a. Final report of an audit carried out in Indonesia from 13 to $22 \mathrm{March}$ 2012 in order to assess the controls of aflatoxin contamination in nutmegs intended for export to the European Union

- - - 2012b. Final report of an audit carried out in Indonesia from 25 January to 03 February 2012 in order to evaluate the monitoring of residues and contaminants in live animals and animal products, including controls on veterinary medicinal products.

- - - . EU Import Conditions for Seafood and Other Fishery Products. Accessed on 19 October 2016. Available from http://ec.europa.eu/food/safety/docs/ia_trade_importcond-fish_en.pdf 2016a.

- - - . 2016b. Final Report of An Audit Carried out in Indonesia from 07 March 2016 to 17 March 2016 in Order to Assess the Controls of Aflatoxin Contamination in Nutmeg Intended for Export to the European Union. European Commission/DG SANCO. 
Dharmaputra, O. S., S. Ambarwati, I. Retnowati, and N. Nurfadila. 2016. Fungal Infection and Aflatoxin Contamination in Stored Nutmeg (Myristica fragrans) Kernels at Various Stages of Delivery Chain in North Sulawesi Province. BIOTROPIA-The Southeast Asian Journal of Tropical Biology 22 (2): 129-139.

Dietze, G., J. Harrison, and H. Menzel. 2009. Effective dose: a flawed concept that could and should be replaced. Comments on a paper by DJ Brenner (Br J Radiol 2008; 81: 521-3). The British journal of Radiology 82 (976): 348-351.

Eberle, E. J. 2009. The Method and Role of Comparative Law. Wash. U. Global Stud. L. Rev. 8: 451.

ENS. 2017. Stochastic Radiation Effect. European Nuclear Society 2017 [cited 14 December 2017]. Available from https://www.euronuclear.org/info/encyclopedia/s/stochastic-radiationeffect.htm.

EU-RASFF. 2017. RASSF portal. EU-RASFF 2017 [cited 30 May 2017]. Available from https:// webgate.ec.europa.eu/rasffwindow/portal/? event=searchResultList.

EU. 2012. Consolidated version of the Treaty Establishing the European Atomic Energy Community In 2012/C 327/01, edited by EURATOM.

EU Commission. 2006. Report from the Commission to the Council and the European

Parliament on the implementation of Regulation (EC) No 1829/2003 of the European Parliament and of the Council on genetically modified food and feed Brussel: EU Commission.

- - - . Traceability and labeling. EU commission 2017 [cited 13 November 2017. Available from https://ec.europa.eu/food/plant/gmo/traceability_labelling_en.

EU Parliament. Imports of GM food and feed Right of Member States to opt out. EU Parliament, 2015 [cited 13 November 2017. Available from http:// www.europarl.europa.eu/RegData/etudes/BRIE/2015/569030/EPRS BRI(2015)569030_EN.pdf.

EUMOFA. 2015. The EU Fish Market 2015.

European Commission. 2016. Reports of the scientific committee for food. Luxembourg: Office for Official Publication of the European Communities 1996 [cited 30 November 2016]. Available from https://ec.europa.eu/food/sites/food/files/safety/docs/cs_contaminants_c atalogue_alfatoxins_scf_reports_35_en.pdf.

- - - Food and feed of non-animal origin. Retrieved on 27 November 2016, from http://ec.europa.eu/food/safety/official_controls/legislation/imports/non-animal_en 2016a.

- - - Veterinary border control. Retrieved on 27 November 2016, from https://ec.europa.eu/food/animals/vet-border-control_en $2016 \mathrm{~b}$. 
- - - RASSF Portal 2017 [cited 05 April 2017. Available from

https:// webgate.ec.europa.eu/rasffwindow/portal/?event=searchResultList.

European Ombudsman. The decision of the European Ombudsman closing his owninitiative inquiry OI/5/2011/BEH concerning the European Commission. Accessed on November 2015. Available from

http://www.ombudsman.europa.eu/en/cases/decision.faces/en/10827/html.bookmark 2011.

FAO. 1999. The Codex General Principles of Food Hygiene. In Scope, use, and definition: FAO.

- - - . 2018. Stronger Food Control for Safer Food in Indonesia. FAO 2017 [cited 09 January 2018]. Available from http://www.fao.org/indonesia/news/detailevents/en/c/878315/.

FAO Globefish. FAO Globefish Reports - Shrimp February 2016. Accessed on 16 Oct 2016. Available from http://www.thefishsite.com/reports/?id=5972. 2016.

FAO/WHO. 1995. Codex General Standard for Contaminants and Toxins In Food and Feed FAO/WHO.

- - - . 1997. Hazard Analysis and Critical Control Point (HACCP) System and Guidelines for Its Application. In Annex to CAC/RCP 1-1969, Rev. 3 (1997): $\mathrm{FAO} / \mathrm{WHO}$.

- - . 2003. Assuring food safety and quality: guidelines for strengthening national food control systems: FAO/WHO.

- - - 2006. Principles for Traceability/Product Tracing as a Tool Within a Food Inspection and Certification System. FAO/WHO.

- - - 2007. Strengthening national food control systems: A quick guide to assess capacity building needs. Rome: FAO of the UN.

Fardiaz, D., R. Bhat, and S. Sareen. 2011. Guidelines for risk categorization of food and food establishments applicable to ASEAN countries. RAP Publication (FAO) eng no. 2011/22.

Fernandez-Cornejo, J., and S. Wechsler. Recent trends in GE adoption. Available at http://www. ers. USDA. gov/data-products/adoption-of-genetically engineered-cropsin-the-us/recent-trends-in-ge-adoption. aspx (accessed 30.05.2017). US Department of Economic Research Services 2014.

Ferro, E., T. Otsuki, and J. S. Wilson. 2015. The effect of product standards on agricultural exports. Food Policy 50: 68-79.

Fukuda, K. 2017. Food Safety in a Globalized World. WHO 2015 [cited 17 December 2017]. Available from http:/ / www.who.int/bulletin/volumes/93/4/15154831/en/.

GBG. Indonesia's Aquaculture E Fisheries Sector. Accessed on 19 October 2016. Available from 
http://www.gbgindonesia.com/en/agriculture/article/2014/indonesia_s_aquaculture_a nd_fisheries_sector.php 2014.

Gibney, E. Fukushima data show rise and fall in food radioactivity. Nature 2015. Available from http:/ / www.nature.com/news/fukushima-data-show-rise-and-fall-infood-radioactivity-1.17016 (accessed 17.02.2017).

Gilmour, S., S. Miyagawa, F. Kasuga, and K. Shibuya. 2016. Current Measures on Radioactive Contamination in Japan: A Policy Situation Analysis. PLoS ONE 11 (3): e0152040. http:/ /dx.doi.org/10.1371/journal.pone.0152040.

Giray, B., G. Girgin, A. B. Engin, S. Aydın, and G. Sahin. 2007. Aflatoxin levels in wheat samples consumed in some regions of Turkey. Food Control 18 (1): 23-29. http://dx.doi.org/http://dx.doi.org/10.1016/j.foodcont.2005.08.002.

Gkogka, E., M. W. Reij, L. G. M. Gorris, and M. H. Zwietering. 2013. The application of the Appropriate Level of Protection (ALOP) and Food Safety Objective (FSO) concepts in food safety management, using Listeria monocytogenes in deli meats as a case study. Food Control 29 (2): 382-393.

http://dx.doi.org/https://doi.org/10.1016/j.foodcont.2012.04.020.

Golub, S., and A. Varma. 2014. Fishing Exports and Economic Development of Least Developed Countries: Bangladesh, Cambodia, Comoros, Sierra Leone and Uganda Paper Prepared for UNCTAD. UNCTAD. Swarthmore College.

Gorris, L. G. 2005. Food safety objective: An integral part of food chain management. Food Control 16 (9): 801-809.

The government of Malaysia. 2004. Foodborne Disease Monitoring and Surveillance Systems. edited by FAO. Seremban, Malaysia: FAO.

Grossman, M. 2016. The United States Bioengineered Food Disclosure Standard: Labels for Genetically Engineered Food. European Food and Feed Law Review 11 (6): 502-507.

Gruère, G. P., C. A. Carter, and Y. H. Farzin. 2009. Explaining international differences in genetically modified food labeling policies. Review of International Economics 17 (3): 393-408.

Gruère, G. P., and S. Rao. 2007. A review of international labeling policies of genetically modified food to evaluate India's proposed rule. AgBioForum 10(1): 51-64. Available at http://agbioforum.org/v10n1/v10n1a06-gruere.htm (accessed 07.02.2017).

Hanekamp, J. C., and A. Bast. 2015. Antibiotics exposure and health risks: Chloramphenicol. Environmental Toxicology and Pharmacology 39 (1): 213-220. http://dx.doi.org/http://dx.doi.org/10.1016/j.etap.2014.11.016.

Hanekamp, J. C., G. Frapporti, and K. Olieman. 2003. Chloramphenicol, food safety and precautionary thinking in Europe. Environmental Liability 11 (6): 209-219.

Harada, K. H., T. Niisoe, M. Imanaka, T. Takahashi, K. Amako, Y. Fujii, M. Kanameishi, et al. 2014. Radiation dose rates now and in the future for 
residents neighboring restricted areas of the Fukushima Daiichi Nuclear

Power Plant. Proceedings of the National Academy of Sciences 111 (10): E914-E923.

Hariyadi, P. 2018. Food Safety Challenges and Opportunities for Developing Countries:

Case of Indonesia. SEAFAST Centre 2011 [cited 15 January 2018]. Available from http://seafast.ipb.ac.id/publication/presentation/Food-SafetyChallenges.pdf.

Harrison, H., M. Birks, R. Franklin, and J. Mills. 2017. Case Study Research: Foundations and Methodological Orientations. Paper read at Forum Qualitative Sozialforschung/Forum: Qualitative Social Research.

Henson, S., and S. Jaffee. 2006. Food safety standards and trade: Enhancing competitiveness and avoiding exclusion of developing countries. The European Journal of Development Research 18 (4): 593-621.

Henson, S., and R. Loader. 2001. Barriers to Agricultural Exports from Developing Countries: The Role of Sanitary and Phytosanitary Requirements. World Development 29 (1): 85-102. http:/ / dx.doi.org/https:/ / doi.org/10.1016/S0305750X(00)00085-1.

Hoffmann, S. 2010. Ensuring Food Safety around the Globe: The many roles of risk analysis from risk ranking to Microbial risk assessment. Risk Analysis 30 (5): 711-714.

Howse, R. 2007. The WTO System: Law, Politics E Legitimacy: Cameron May.

Hutchinson, T. 2014. Vale Bunny Watson: Law Librarians, Law Libraries, and Legal Research in the Post-Internet Era. Law Libr. J. 106: 579.

IARC. 2016. IARC monographs on the evaluation of carcinogenic risks to humans. IARC 2012 [cited 30 November 2016]. Available from http://monographs.iarc.fr/ENG/Classification/latest_classif.php.

ICMSF. 2006. A simplified guide to understanding and using food safety objectives and performance objectives. International Commission on Microbiological Specifications for foods (ICMSF).

ICRP. 1995. Age-dependent Doses to the Members of the Public from Intake of Radionuclides - Part 5 Compilation of Ingestion and Inhalation Coefficients. ICRP Publication 72. Annals of the ICRP 26 (1).

- - - 1999. Protection of the Public in Situations of Prolonged Radiation Exposure. ICRP Publication 82. Annals of the ICRP 29 (1-2).

- - - ICRP Publication 103: The 2007 Recommendations of the International Commission on Radiological Protection 2007. Available from http://www.icrp.org/docs/ICRP_Publication_103Annals_of_the_ICRP_37(2-4)-Free_extract.pdf (accessed on 16.02.2017). Japan. 2003. Food Safety Basic Law. Japan. 
Ji, A.-L., Y.-L. I. Wong, T.-J. Cai, and J. Liu. 2014. Infant formula safety concerns and consequences in China. World Journal of Pediatrics 10 (1): 7-9.

http://dx.doi.org/10.1007/s12519-014-0447-3.

Jongwanich, J. 2009. The impact of food safety standards on processed food exports from developing countries. Food Policy 34 (5): 447-457.

http://dx.doi.org/http://dx.doi.org/10.1016/j.foodpol.2009.05.004.

Jørgensen, J. G., and P. J. Schröder. 2014. Harmonization versus Mutual Recognition: Some pitfalls for the coordination of product standards under imperfect competition. Discussion Papers on Business and Economics, University of Southern Denmark 23.

Juwana, H. 2004. Law and Development under Globalization: The Introduction and Implementation of Competition Law in Indonesia. 国際開発研究フォーラム 27: 1-16.

Kaptan, G., A. R. Fischer, and L. J. Frewer. 2017. Extrapolating understanding of food risk perceptions to emerging food safety cases. Journal of Risk Research: 1-23.

Karlovsky, P., M. Suman, F. Berthiller, J. De Meester, G. Eisenbrand, I. Perrin, I. P. Oswald, et al. 2016. Impact of food processing and detoxification treatments on mycotoxin contamination. Mycotoxin research 32 (4): 179-205.

Kimura, A. H. 2013. Standards as a hybrid forum: comparison of the post-Fukushima radiation standards by a consumer cooperative, the private sector, and the Japanese government. International Journal of Sociology of Agriculture and Food 20 (1): 11-29.

Lake, R. J., P. J. Cressey, D. M. Campbell, and E. Oakley. 2010. Risk ranking for foodborne microbial hazards in New Zealand: the burden of disease estimates. Risk Analysis 30 (5): 743-752.

Lau, J. Same Science, Different Policies: Regulating Genetically Modified Foods in the U.S. and Europe. Harvard University 2015 [cited 13 November 2017. Available from http://sitn.hms.harvard.edu/flash/2015/same-science-different-policies/.

Li, K., L. Liu, J. H. Clausen, M. Lu, and A. Dalsgaard. 2016. Management measures to control diseases reported by tilapia (Oreochromis spp.) and white-leg shrimp (Litopenaeus vannamei) farmers in Guangdong, China. Aquaculture 457: 91-99. Library of Congress. Restrictions on Genetically Modified Organisms: Japan. The Law Library of Congress, 09 June 20152015 [cited 13 November 2017. Available from https://www.loc.gov/law/help/restrictions-on-gmos/japan.php.

Lord, M., R. Oktaviani, and E. Ruehe. 2017. Indonesia's Trade Access to The European Union: Opportunities and Challenges. Transtec \& Equinoccio 2010 [cited 4 January 2017]. Available from http:/ / eeas.europa.eu/archives/delegations/indonesia/documents/press_co rner/tradeaccess_annex_en.pdf. 
MacKenzie, A. A. 2000. The process of developing labeling standards for GM foods in the Codex Alimentarius.

MAFF. The solution to stop the contaminated water and the safety of fishery products at TEPCO's Fukushima Daiichi nuclear power station 2017. Available from http://www.jfa.maff.go.jp/e/inspection/170223_English.pdf (accessed 05.03.2017).

Matsuzaki, S.-i. S., N. H. Kumagai, and T. I. Hayashi. 2016. Need for Systematic Statistical Tools for Decision-Making in Radioactively Contaminated Areas. ACS Publications.

Media Indonesia. Baru 24 persen UMKM terapkan cara produksi pangan sesuai standar. Media Indonesia 2016 [cited 21 November 2017. Available from http://mediaindonesia.com/news/read/79245/baru-24-persen-umkmterapkan-cara-produksi-pangan-sesuai-standar/2016-11-23.

Merz, S., G. Steinhauser, and N. Hamada. 2013. Anthropogenic radionuclides in Japanese food: Environmental and legal implications. Environmental Science and Technology 47 (3): 1248-1256. http://dx.doi.org/10.1021/es3037498.

MHLW. 2017. New Standard Limits for Radionuclides in Food. Minister of Health, Labor, and Welfare (MHLW) 2012a [cited 15 January 2017]. Available from http://www.mhlw.go.jp/english/topics/2011eq/dl/new_standard.pdf.

- - - . New Standard Limits for Radionuclides in Foods. Accessed on 11 October 2016. Available from http://www.mhlw.go.jp/english/topics/2011eq/dl/new_standard.pdf. 2012b.

- - - 2017a. Information on the Great East Japan earthquake: food. Available at http://www.mhlw.go.jp/english/topics/2011eq/index_food.html (accessed on 09.06.2017).

- - - 2017. What's New 2017? MHLW 2017b [cited 16 December 2017]. Available from http:// www.mhlw.go.jp/english/new-info/.

Michaels, R. 2006. The functional method of comparative law.

Ming Du, M. 2010. Autonomy in setting the appropriate level of protection under the WTO law: rhetoric or reality? Journal of International Economic Law 13 (4): $1077-$ 1102.

- - - 2011. The rise of national regulatory autonomy in the GATT/WTO regime. Journal of International Economic Law 14 (3): 639-675.

Ministry of Agriculture (MoA). Outlook of Soybean comodity. Pusat Data dan Informasi Pertanian, Kementrian Pertanian, 2016 [cited 05 May 2017. Available from http:/ / epublikasi.setjen.pertanian.go.id/epublikasi/outlook/2016/Tanpang/ OUTLOOK\%20KEDELAI\%202016/files/assets/common/downloads/OUTL OOK\%20KEDELAI\%202016.pdf.

Ministry of Primary Industry. Food risk profiles. Ministry of Primary Industry, 2017 [cited 14 December 2017. Available from http://www.mpi.govt.nz/food- 
safety/food-safety-and-suitability-research/food-risk-assessment/food-riskprofiles/.

Ministry of Trade. 2017. The European Union TSP II DG of Standardization \& Consumer Protection: To Reach Global Quality Standards. Ministry of Trade of Indonesia 2015 [cited 2 January 2017]. Available from http:/ / www.kemendag.go.id/files/pdf/2015/10/06/tsp-ii-uni-eropa-dirjenspk-demi-raih-standar-mutu-dunia-en0-1444114519.pdf.

MMAF. 2018. Udang Vaname dan Udang Windu Masih Andalan Ekspor Indonesia (Vannamei and tiger shrimp are top export commodities of Indonesia) Ministry of Marine Affairs and Fisheries (MMAF) 2015 [cited 2 January 2018]. Available from http://www.djpb.kkp.go.id/arsip/c/246/Udang-Vaname-dan-UdangWindu-Masih-Andalan-Ekspor-Indonesia/?category_id=13.

MoH. 2014. Guidelines on Labelling of Foods and Food Ingredients Obtained Through Modern Biotechnology. edited by Ministry of Health of Malaysia. Malaysia.

Murina, M., and A. Nicita. 2014. Trading with Conditions: The Effect of Sanitary and Phytosanitary Measures on Lower Income Countries' Agricultural Exports: UN.

NADFC. Genetically modified products. Available at http://standarpangan.pom.go.id/index.php/produk-standardisasi/produk/lainlain/produk-rekayasa-genetik (accessed 09.05.2017). 2017a [cited 18 May 2017. Available from http://standarpangan.pom.go.id/index.php/produkstandardisasi/produk/lain-lain/produk-rekayasa-genetik.

- - - . Risk Management Plan. NADFC 2017b [cited 14 December 2017. Available from http://pmr.pom.go.id/index.php.

- - - . Training Course on Collaborative Study on Validation of Detection and Quantification of GMO Event Specific Methods. NADFC 2017c [cited 13 November 2017. Available from http://www.pom.go.id/mobile/index.php/view/berita/13753/TrainingCourse-on-Collaborative-Study-on-Validation-of-Detection-andQuantification-of-GMO-Event-Spesific-Methods.html.

NEA-OECD. Explanation of terms. OECD 2008 [cited 14 December 2017. Available from https:/ / www.oecd-nea.org/rp/chernobyl/explanation_of_terms.htm.

Neela, F. A., M. N. A. Banu, M. A. Rahman, M. H. Rahman, and M. F. Alam. 2015. The occurrence of Antibiotic-Resistant Bacteria in Pond Water Associated with Integrated Poultry-Fish Farming in Bangladesh. Sains Malaysiana 44 (3): 371377.

Neeliah, S. A., and D. Goburdhun. 2007. National Food Control Systems: A Review. Food Reviews International 23 (1): 35-51. http://dx.doi.org/10.1080/87559120600998148.

NRE-Malaysia. The Biosafety Act of Malaysia: Dispelling the Myths. Available at http://www.nre.gov.my/ms- 
my/PustakaMedia/Penerbitan/Dispelling\%20the\% 20Myths.pdf (accessed 07.05.2017). Ministry of Natural Resources and Environment (NRE) Malaysia 2008.

Pesavento, G., M. Ostuni, C. Calonico, S. Rossi, R. Capei, and A. L. Nostro. 2016. Mycotic and aflatoxin contamination in Myristica fragrans seeds (nutmeg) and Capsicum annum (chili), packaged in Italy and commercialized worldwide. Journal of preventive medicine and hygiene 57 (2): E102.

Poortvliet, P. M., M. Duineveld, and K. Purnhagen. 2016. Risk Communication:

Performativity in Action: How Risk Communication Interacts with Risk Regulation. European Journal of Risk Regulation 7 (1): 213-217.

Pound, R. 1910. Law in books and law in action. Am. L. Rev. 44: 12.

Povinec, P. P., K. Hirose, and M. Aoyama. 2013. Fukushima accident: radioactivity impact on the environment: Newnes.

Purnhagen, K. 2013. The Politics of Systematization in EU Product Safety Regulation: Market: Springer Netherlands.

Purnhagen, K., and J. Wesseler. 2016a. "The "Honey" Judgment of Bablok and Others Versus Freistaat Bayern in the Court of Justice of the European Union: Implications for Co-existence." In The coexistence of genetically modified, organic and conventional foods, 149-165. Springer.

- - - . 2016b. "The Principle (s) of Co-existence in the Market for GMOs in Europe: Social, Economic and Legal Avenues." In The Coexistence of Genetically Modified, Organic and Conventional Foods, 71-85. Springer.

Purnhagen, K. P. 2015a. The EU's Precautionary Principle in Food Law is an Information Tool!

- - - 2015b. Mapping Private Regulation-Classification, Market Access and Market Closure Policy, and Law's Response. Journal of World Trade 49 (2).

Purnhagen, K. P., and P. H. Feindt. 2015. Better Regulatory Impact Assessment: Making Behavioural Insights Work for the Commission's New Better Regulation Strategy. European Journal of Risk Regulation 6 (3): 361-368.

Reid, E. 2012. Risk assessment, science, and deliberation: managing regulatory diversity under the SPS agreement? European Journal of Risk Regulation 3 (4): 535-544.

Reiher, C. 2016. Food safety and consumer trust in post-Fukushima Japan. Paper read at Japan Forum.

- - - 2017. Food safety and consumer trust in post-Fukushima Japan. Paper read at Japan Forum.

Reimann, M., and R. Zimmermann. 2007. The Oxford Handbook of Comparative Law.

New York: Oxford University Press.

RIVM. 2001. Advies met betrekking tot chloramphenicol in garnalen. 
Roeroe, H. J., J. Marmis, N. S. Tongkeles, and L. Lengkey. 2015. The Quality of Nutmeg Seeds and Mace From North Sulawesi. Jurnal LPPM Bidang Sains dan Teknologi 2 (1): 111-121.

Sandefur, R. L. 2015. When is Law in Action? Ohio State Law Journal 77: 59.

Schrama, W. 2011. How to Carry out Interdisciplinary Legal Research-Some Experiences with an Interdisciplinary Research Method. Utrecht L. Rev. 7: 147.

Shepherd, B., and N. L. Wilson. 2013. Product standards and developing country agricultural exports: The case of the European Union. Food Policy 42: 1-10.

Shimura, T., I. Yamaguchi, H. Terada, E. R. Svendsen, and N. Kunugita. 2015. Public health activities for mitigation of radiation exposures and risk communication challenges after the Fukushima nuclear accident. Journal of radiation research 56 (3): 422-429.

Shimura, T., I. Yamaguchi, H. Terada, T. Yunokawa, E. R. Svendsen, and N. Kunugita. 2015. The efficiency of Excess Monitoring for Beef after the Fukushima Accident. Food Safety 3 (3): 84-91.

http://dx.doi.org/10.14252/foodsafetyfscj.2015018.

Sinopoli, D., and K. P. Purnhagen. 2016. When Life Gives You Lemons: The Battle of Science on the Correct Interpretation of Data on Citrus Black Spot Disease between the European Union and South Africa according to the SPS Agreement. Trade L. \& Dev. 8: 29.

Skovgaard, N. 2003. Microorganisms in Foods 7: Microbiological Testing in Food Safety Management: By International Commission for the Microbiological Specifications of Foods (ICMSF). Kluwer Academic/Plenum Publishers, New York, xiii+ 367 pages, hardbound, ISBN 0-306-47262-7,€ 144.50/US \$125.00/GP£ 88.50. http:// www.wkap.nl. Elsevier.

Smits, J. M. 2006. Comparative law and its influence on national legal systems.

Steinhauser, G., A. Brandl, and T. E. Johnson. 2014. Comparison of the Chernobyl and Fukushima nuclear accidents: A review of the environmental impacts. Science of the Total Environment 470-471: 800-817. http:/ / dx.doi.org/10.1016/j.scitotenv.2013.10.029.

Stilwell, M. Protecting GMO Labeling from a WTO Challenge. Available at https://www.iatp.org/files/Protecting_GMO_Labeling_from_a_WTO_Challenge.htm (accessed on 30.05.2017). 1999.

Sykes, A. O. 2000. Regulatory Competition or Regulatory Harmonization? A Silly Question? Journal of International Economic Law 3 (2): 257-264.

Szajkowska, A. 2010. The impact of the definition of the precautionary principle in EU food law. Common Market Law Review 47 (1): 173-196.

Takahashi, T. 2009. Laws and Regulations on Food Safety and Food Quality in Japan. the paper published at the website named "Food quality and food safety", the website link is http://www. ab.auone-net. jp/ ttt/index.html. 
Transparency International. 2018. Corruption Perception Index 20162016 [cited 15 January 2018]. Available from

https://www.transparency.org/news/feature/corruption_perceptions_index 2016 .

Trebilcock, M. J. 2015. Advanced introduction to international trade law: Edward Elgar Publishing.

Tubiana, M., L. E. Feinendegen, C. Yang, and J. M. Kaminski. 2009. The Linear NoThreshold Relationship Is Inconsistent with Radiation Biologic and Experimental Data 1. Radiology 251 (1): 13-22.

Unnevehr, L. 2015. Food safety in developing countries: Moving beyond exports. Global Food Security 4: 24-29. http://dx.doi.org/http://dx.doi.org/10.1016/j.gfs.2014.12.001.

USDA. 2013. Malaysia Agricultural Biotechnology Annual Report. USA: GAINUSDA.

- - - 2015a. China Agricultural Biotechnology Annual Report. USA: GAIN-USDA.

- - - GAIN Report: Indonesia Agricultural Biotechnology Annual. GAIN Report Number: 1526.

http://gain.fas.usda.gov/Recent\%20GAIN\%20Publications/Agricultural\% 20Biotechn ology\%20Annual_Jakarta_Indonesia_7-14-2015.pdf (accessed 03.01.2017). 2015b.

- - - 2015c. Malaysia Oilseeds and Products Annual Report. USA: GAIN-USDA.

- - - Soybeans $\mathcal{E}$ Oil Crops. USDA, 06 October 2017 2015d [cited 13 November 2017. Available from https://www.ers.usda.gov/topics/crops/soybeans-oilcrops/related-data-statistics/.

- - - 2016. Japan Agricultural Biotechnology Annual Report. edited by GAINUSDA. The USA.

Van de Venter, T. 2000. Emerging foodborne diseases: a global responsibility. Food Nutrition and Agriculture (26): 4-13.

Van der Meulen, B. 2010. The global arena of food law: emerging contours of a metaframework. Erasmus L. Rev. 3: 217.

van Schothorst, M., M. H. Zwietering, T. Ross, R. L. Buchanan, and M. B. Cole. 2009. Relating microbiological criteria to food safety objectives and performance objectives. Food Control 20 (11): 967-979. http://dx.doi.org/https://doi.org/10.1016/j.foodcont.2008.11.005.

Vos, E. 2000. EU food safety regulation in the aftermath of the BSE crisis. Journal of Consumer Policy 23 (3): 227-255.

Wahidin, D., and K. P. Purnhagen. 2017. Determining a Science-based Food Safety Objective/Appropriate Level of Protection for Application in Developing Countries. European Journal of Risk Regulation 8 (2): 403-413. http://dx.doi.org/10.1017/err.2017.18.

Weygandt, J. J., P. D. Kimmel, and D. E. Kieso. 2009. Managerial Accounting: Tools for business decision making: John Wiley \& Sons. 
WHO. 2013. Health risk assessment from the nuclear accident after the 2011 Great East Japan Earthquake and Tsunami based on a preliminary dose estimation. WHO Press. Available at http://apps.who.int/iris/bitstream/10665/78218/1/9789241505130_eng.pdf (accessed 11.06.2017).

- - - Frequently asked questions on genetically modified foods 2014 [cited 27 June 2017. Available from http://www.who.int/foodsafety/areas_work/foodtechnology/faq-genetically-modified-food/en/.

- - - 2017a. WHO Guidelines on Use of Medically Important Antimicrobials in FoodProducing Animals. Geneva: WHO.

- - - WHO's first ever global estimates of foodborne diseases find children under 5 accounts for almost one-third of deaths. WHO 2017b [cited 11 December 2017. Available from http://www.who.int/mediacentre/news/releases/2015/foodborne-diseaseestimates/en/.

Wong, A. Y.-T., and A. W.-K. Chan. 2016. Genetically modified foods in China and the United States: A primer of regulation and intellectual property protection. Food Science and Human Wellness 5 (3): 124-140. http://dx.doi.org/https://doi.org/10.1016/j.fshw.2016.03.002.

World Bank. Indonesia Trade at a Glance: Most Recent Values, available at http://wits.worldbank.org/CountrySnapshot/en/IDN (accessed 12.01.2017) 2014.

WTO. 1995. Agreement on the Application of Sanitary and Phytosanitary Measures. In 1867 UNTS 493, edited by WTO: WTO.

- - - 1998a. Australia - Measures Affecting Importation of Salmon- AB-1998-5. In Report of the Appellate Body: WTO.

- - - 1998b. EC Measures Concerning Meat and Meat Products (Hormones). In Appellate Body Report. Geneva: WTO.

- - - 2006. European Communities - Measures Affecting the Approval and Marketing of Biotech Products. In Reports of the Panel. Geneva: WTO.

- - - . 2017. Trade and development. WTO 2010 [cited 17 December 2017]. Available from

https://www.wto.org/english/thewto_e/coher_e/mdg_e/development_e.ht $\underline{\mathrm{m}}$.

- - - 2015. India - Measures Concerning the Importation of Certain Agricultural Products - AB-2015-2. In Report of Appellate Body, edited by Appellate Body: WTO.

- - - . WTO Analytical Index: Sanitary and Phytosanitary Measures. WTO 2017 [cited 13 December 2017. Available from https://www.wto.org/english/res_e/booksp_e/analytic_index_e/sps_02_e. htm\#fnt-272. 
Xiao, P. 2011. China's milk scandals and its food risk assessment institutional framework. European Journal of Risk Regulation 2 (3): 397-406.

Yamaura, K., and T. Xia. 2010. Competition in Japanese Genetically Modified

Soybean Import Market. In Agricultural \& Applied Economics Association 2010, AAEA,CAES, \& WAEA Joint Annual Meeting. Denver, Colorado: Ageconsearch. Yin, R. K. 1994. Case study research. : 172-173.

Zhu, X., M. T. Roberts, and K. Wu. 2016. Genetically modified food labeling in China: in pursuit of a rational path. Food $\mathcal{E}$ Drug LJ 71: 30. 


\section{SUMMARY}

There are shortcomings in the current national food control system in Indonesia. This thesis assesses how to improve it with a focus on food laws and regulations. This thesis takes these two cornerstones (science-driven regulation and management between local and global) as a basis to propose a legal reform, drawing on WTO law and food safety science tailored to the local social prerequisites to improve the level of food safety in Indonesia.

In chapter 2, I developed a framework that could assist developing countries that lack the food safety infrastructure and resources to establish more effective food laws and regulations through the lens of WTO law and food safety science and meets the needs of their population. This FSO/ALOP framework for the application in developing countries encompasses these aspects:

1. To set a risk profile through a qualitative risk assessment and an FSO/ALOP through a quantitative risk assessment

Due to limited food safety infrastructure and resources, the first step in the FSO/ALOP framework for the application in developing countries is to determine a proper risk profile through a qualitative risk assessment. This step will ensure an effective food control management of the most important food safety hazards that significantly affect the public health. The next step is to determine an FSO/ALOP through a quantitative risk assessment. This method will be a better option for developing countries since it will prevent the use of a generically stated-ALOP that covers a wide range of hazard/food combinations. In other words, an FSO/ALOP shall be determined only for a specific hazard/food combination. Even though there is no obligation to complete a quantitative risk assessment for determining an FSO/ALOP, the level will be more accurate and more easily applied by food safety authorities and food businesses.

\section{To increase the public-private partnership}

An FSO/ALOP is the key for the government (food safety authorities) to communicate its public health goals to food businesses and to give them more flexibility in designing their own FSMSs within their food supply chain system. Under the FSO/ALOP framework for the application in developing countries, food safety authorities are in charge of the determination of the FSO/ALOP, whereas food businesses have the right to determine their own POs, which are equivalent to the FSO. Food businesses shall be mainly responsible for the design of FSMSs to meet their POs, and later on, they are expected to meet the FSO/ALOP. Food safety authorities shall be responsible for creating a system in the form of guidelines, in which food businesses can meet the FSO/ALOP.

3. Appropriate monitoring and review 
A successful implementation of the FSO/ALOP framework requires an appropriate monitoring and review. The risk management plan (RMP) is one option for developing countries to ensure food manufacturers' compliance with the existing laws and regulations. This monitoring and review scheme will reduce the inspection cost of food safety authorities and compliance cost of food businesses. Depending on the risk classification of the food businesses, food safety authorities can adjust their onsite inspection and rely more on the internal audit reports taken from the food businesses.

In chapter 3, I have illustrated the implementation of several political and scientific ALOP determinations in a comparable situation (radioactive contaminants in foods following the Fukushima nuclear accident) by two developed entities (the EU and Japan) and compared them to the developing entity (Indonesia) by using the FSO/ALOP framework for the application in developing countries. Following the Fukushima nuclear accident, Japan determines its FSO/ALOP for radioactive contaminants in foods based on a quantitative risk assessment (MHLW 2012a). However, despite the fact that the outcome of the risk assessment showed a low risk of radioactive contaminants in foods, the Japanese food safety authorities increased the level of protection for political reasons, mainly to maintain consumer trust in the domestic market as well as to maintain consumer trust in the international market. The EU followed suit without operating their own risk assessment. ${ }^{83}$ According to the Implementing Regulation No 351/2011, the reason for this decision was to safeguard consistency with the FSO/ALOP applied in Japan. ${ }^{84}$ However, Indonesia has taken a different approach, applying its own FSO/ALOP that is less stringent compared to the FSO/ALOP applied by Japan and the EU.85 The Indonesian FSO/ALOP in the new regulation (following the Fukushima nuclear accident) is even less stringent than the one in the previous regulation (following the Chernobyl nuclear accident). ${ }^{86}$ However, they are still higher than the ones proposed by Codex. Indonesia did not conduct a risk assessment; however, ironically the Indonesian FSO/ALOP is mostly in line with the outcome of the risk assessment conducted by Japan and adopted by the EU.

In response to the Fukushima nuclear accident, Japan, the EU, and Indonesia have intentionally adopted a political approach to the establishment of their FSO/ALOP for radioactive contaminants in foods. While Japan and the EU both used

\footnotetext{
83 See Commission Implementing Regulation (EU) No 322/ 2014 of March 28, 2014, which imposes special conditions governing the import of feed and food originating in or consigned from Japan following the accident at the Fukushima nuclear power station.

84 See Commission Implementing Regulation (EU) No 351/2011 of April 11, 2011 amending

Regulation (EU) No 297/2011, which imposes special conditions governing the import of feed and food originating in or consigned from Japan following the accident at the Fukushima nuclear power station.

85 See Minister of Health Regulation No 1031/MENKES/PER/V/2011 on the maximum level of radioactive contaminant in food. Translated by $\mathrm{D}$. Wahidin.

86 See Minister of Health Regulation No 00474/B/II/87 on the requirement to attach health certificate and certificate of analysis of radiation free for imported food. Translated by D. Wahidin.
} 
a risk assessment as a shield to hide their political decision for a higher FSO/ALOP, Indonesia chose a higher level of protection based on purely political determinations. This choice may arguably be categorized as an infringement of the SPS agreement, which requires no impositions of unjustified trade barriers if risk profiles and conditions are comparable.

I have shown that if the FSO/ALOP framework for developing countries, as proposed in this thesis, had been applied, the outcome would have been more in line with the requirements of WTO law, food safety science, and socioeconomic prerequisites. The proposed FSO/ALOP would have entailed a high level of consumer protection based on scientific necessity, while hindering an unnecessary trade barrier between these three countries. By applying a quantitative approach based on the principle of international radiological protection of the ICRP and Codex, I unfolded the reason behind the political decision of the determination of the FSO/ALOP done by Japan, the EU, and Indonesia and weighed it against the scientific solution to do so.

In chapter 4, I have applied the FSO/ ALOP framework for developing countries to the legal reform of GM food labeling in Indonesia to illustrate how this tool works in developing countries to reform laws and regulations in a situation where the surveillance mechanisms are poor. By applying the FSO/ALOP framework, I was able to show that the top-down approach identified in chapter 2 is more appropriate for a legal reform in developing countries. The top-down approach entails the use of epidemiological data, whereas the bottom-up approach entails the use of supply chain data. However, in terms of the special case of GM foods where sufficient data for those two approaches are not available, both approaches are needed for realignment. Comparative law is used in the top-down approach, taking into account similar GM food labeling regulations in the EU, the US, Japan, Malaysia, and China as the baseline for legal reform in Indonesia.

Interpreting these findings, I propose a reform of the current GM food labeling regulation by the government of Indonesia. The first proposal is to establish a voluntary $\mathrm{GM}(\mathrm{O})$-free labeling scheme along with the existing mandatory labeling scheme. This voluntary $\mathrm{GM}(\mathrm{O})$-free labeling scheme will be attractive for food businesses who would like to establish a market share in a niche for consumers who are actively looking for $\mathrm{GM}(\mathrm{O})$-free foods. Besides that, assessing the validity of the claim is the food businesses' responsibility, which will reduce the cost of enforcement of the food safety authority. The second proposal is to lower down the current $5 \%$ threshold level in to $3 \%$ threshold level as the determining limit (FSO) for whether the GM food has to be labeled or not. This threshold level must be combined with a traceability system as the control measures to meet the PC in order to ensure the applicability of surveillance mechanisms of the food safety authority. The traceability system will ensure that operators identify their supplier and the companies to which the products have been delivered and at the same time will ensure the applicability of 
the threshold level as the food safety objective (FSO). Furthermore, more sophisticated exemptions from the labeling requirement need to be established in order to restrict the scope of the labeling and to ensure the legal certainty of the GM food labeling regulation. Finally, to improve the understanding of consumers, I propose to limit the GM ingredients on the label to three items. This regulation will positively affect the cost of compliance and enforcement, especially with regard to the analysis and detection of a GM event.

In chapter 5, I used the FSO/ALOP framework for the application in developing countries to investigate the strict food laws and regulations adopted by developed countries and the potential strategies that can be adopted by developing countries to meet these laws and regulations in order to increase the level of food safety in developing countries. In this thesis, I have analyzed two food safety hazard cases in the international trade between Indonesia and the EU: chloramphenicol in shrimp and AFs in nutmeg.

I concluded that the choice of strategy should depend on the nature of the hazard, the existence of a relevant international standard, and the existing food safety control systems. The case studies showed that the top-down approach with respect to the findings of chapter 3 is more appropriate as a strategy to deal with the food safety regulation of chloramphenicol in shrimp. This suitability is due to the nature of chloramphenicol as an anthropogenic contaminant, the existing international standard, and a relatively well-established national food control system. In contrast, the bottom-up approach is more appropriate in dealing with the food safety regulation of AFs in nutmeg. This is due to the more complex nature of AFs, the absence of the relevant international standard of AFs in spices, and a relatively poor national food control system. 


\section{ABOUT THE AUTHOR}

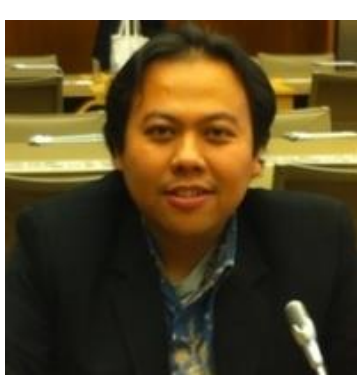

Dasep Wahidin was born on July 25, 1983 in Bandung, Indonesia. He studied pharmacy for his Bachelor of Science at Bandung Institute of Technology (ITB) and graduated in 2006. Later on He was certified as a pharmacist at the same university in 2007. In 2011, he started to study food safety at Wageningen University and Research and graduated in August 2013. In December 2013, he received a scholarship from the National Agency of Drug and Food Control (NADFC/BPOM) to fund his thesis research. He is currently, working as a researcher at the Law and Governance Group at Wageningen University and as a food inspector at NADFC/BPOM. 


\section{LIST OF PUBLICATIONS}

\section{International Peer-Reviewed Journals}

Wahidin, D., \& Purnhagen, K. P. (2017). Determining a Science-based Food Safety Objective/Appropriate Level of Protection for Application in Developing Countries. European Journal of Risk Regulation (EJRR), 8(2), 403-413.

\section{Under Review}

Wahidin, D., Purnhagen, P. (2017). Spicing Up the Level of Food Safety and Market Access in Developing Countries. Heliyon.

Wahidin, D., \& Purnhagen, K. P. (2017). How to Design Genetically Modified Food Labeling Regulation in Indonesia - An FSO/ ALOP Analysis. Food and Drug Law Journal.

Wahidin, D., Purnhagen, K.P. (2017). The Appropriate Level of Protection (ALOP) and Food Safety Regulation: The Case of Fukushima Nuclear Accident. Wageningen Journal of Life Science (NJAS).

\section{Proceeding}

Wahidin, D., Purnhagen, KP. (2016). Between Two Goliaths: the Enforcement of Genetically Modified Food Labelling Regulation in Indonesia. Asian Society of Agricultural Economic (ASAE), p. 1276-1292.

\section{Book Chapter}

Punt, A., and Wahidin, D. 2014. "Contaminants and Restricted Substances." In EU Food Law Handbook, 295-307. Wageningen Academic Publishers. 


\section{PhD candidate's authorship statement, Wageningen University}

PhD candidate's name : Dasep Wahidin

First promotor : : Professor Katrien Termeer

Title of $\mathrm{PhD}$ thesis : Strengthening the food safety control scheme in Indonesia through WTO law and food safety science

Date of public defence : : 8 May 2018

Chapter 1 General Introduction. The general structure was suggested by my promotor and co-promotor. I connected research questions with scientific literature, and checked the consistency and coherency with the overall structure of the thesis. I wrote the first draft and revised it three times, after comments of my promotor and co-promotor.

Chapter 2 Determining an FSO/ALOP for Application in Developing Countries . I developed the research question in collaboration with my co-promotor and aligned it with the latest scientific literatures and relevant social contexts. I developed the research methodology in collaboration with my co-promotor. I collected the data and analysed it. We jointly wrote the first part (introduction and methods) of the paper, and I wrote the other parts of the draft. The draft and revised it four times, after comments of my co-promotor. I submitted the paper to the international per-review scientific journal, after the approval of my co-promotor.

Chapter 3 Political Versus Science In the Establishment of Appropriate Level of Protection (ALOP): The Case of Fukushima Nuclear Accident. I developed the research question, discussed it with my co-promotor and aligned it with the latest scientific literatures and relevant social contexts. I developed the research methodology in collaboration with my co-promotor. I collected the data and analysed it. I wrote the draft and revised it four times, after comments of and text suggestions of my co-promotor. I submitted the paper to the international per-review scientific journal after the approval of my copromotor.

Chapter 4 How to Design A Genetically Modified Food Labeling Regulation In Indonesia by Using WTO Law and Food Safety Science. I developed the research question, discussed it with my co-promotor and aligned it with the latest scientific literatures and relevant social contexts. I developed the research methodology. I collected the data and analysed it. I wrote the draft and revised it four times, after comments and text suggestions of my co-promotor. I submitted the paper to the international peer-review scientific journal after the approval of my co-promotor.

Chapter 5 Spicing Up the Export Market Access of Indonesia To the EU: The Case of Shrimp and Nutmeg. I developed the research question, discussed it with my co-promotor and aligned it with the latest scientific literatures and relevant social contexts. I developed 
the research methodology. I collected the data and analysed it. I wrote the draft and revised it four times, after comments and text suggestion of my co-promotor. I submitted the paper to the international per-review scientific journal after the approval of my co-promotor.

Chapter 6 General Conclusion and Reflection. I wrote the first draft of the text after just one discussion with my promotor and co-promotor on the subjects and arguments to be included. I revised the text three times, after comments of my promotor and copromotor.

Wageningen, 24 January 2018

Signature PhD candidate

Signature promotor for agreement 
Dasep Wahidin

Wageningen School of Social Sciences (WASS)

Completed Training and Supervision Plan

\begin{tabular}{|c|c|c|c|}
\hline Name of the learning activity & Department/Institute & Year & ECTS* \\
\hline \multicolumn{4}{|l|}{ A) Project related competences } \\
\hline Food Safety & $\begin{array}{l}\text { SEAMEO-University of } \\
\text { Indonesia }\end{array}$ & 2016 & 2 \\
\hline Food and Nutrition Intervention & $\begin{array}{l}\text { SEAMEO-University of } \\
\text { Indonesia }\end{array}$ & 2016 & 2 \\
\hline Critical perspective on social theory & WASS & 2017 & 4 \\
\hline \multicolumn{4}{|l|}{ B) General research related competences } \\
\hline Introduction course & WASS & 2014 & 1 \\
\hline Research methodology & WASS & 2014 & 4 \\
\hline Writing proposal & WASS & 2014 & 6 \\
\hline $\begin{array}{l}\text { Techniques for writing and presenting } \\
\text { scientific paper }\end{array}$ & WGS & 2015 & 1.2 \\
\hline $\begin{array}{l}\text { The essential of scientific writing and } \\
\text { presenting }\end{array}$ & WGS & 2015 & 1.2 \\
\hline $\begin{array}{l}\text { Information literacy including endnote } \\
\text { introduction }\end{array}$ & WGS & 2014 & 0.6 \\
\hline Food Law Workshop & NADFC Indonesia & 2015 & 2 \\
\hline $\begin{array}{l}\text { 'Manifesto of An Appropriate Level of } \\
\text { Protection (ALOP) in the Food Safety } \\
\text { Realm: More Demand on Science and } \\
\text { National Interest' }\end{array}$ & $\begin{array}{l}\text { WISE conferences, } \\
\text { Wageningen }\end{array}$ & 2016 & 1 \\
\hline $\begin{array}{l}\text { 'Determining an FSO/ALOP for the } \\
\text { Application in Developing Countries' }\end{array}$ & $\begin{array}{l}\text { WISE conferences, } \\
\text { Wageningen }\end{array}$ & 2017 & 1 \\
\hline $\begin{array}{l}\text { 'Between the Two Goliaths: The } \\
\text { Enforcement of Genetically Modified Food } \\
\text { Labelling Regulation in Indonesia' }\end{array}$ & $\begin{array}{l}\text { ASAE conference Bangkok, } \\
\text { Presentation and Committee } \\
\text { Chair }\end{array}$ & 2017 & 2 \\
\hline Reviewing scientific paper & WGS & 2015 & 0.1 \\
\hline Scientific publishing & WGS & 2015 & 0.3 \\
\hline \multicolumn{4}{|c|}{ C) Career related competences/personal development } \\
\hline Social Dutch I & WGS & 2014 & 2.4 \\
\hline Project and time management & WGS & 2015 & 1.5 \\
\hline Teaching & LAW & 2014-2015 & 4 \\
\hline Total & & & 36.3 \\
\hline
\end{tabular}

${ }^{*}$ One credit according to ECTS is on average equivalent to 28 hours of study load 


\section{FUNDING ORGANIZATION}

The research described in this thesis was financially supported by The National Agency of Drug and Food Control (NADFC/BPOM) Indonesia.

Cover design by Asep Bayu Ekawijaya \& Dasep Wahidin.

Printed by Digiforce-Proefschiriftmaken.nl, Vianen, The Netherlands 
